Key Words: Performance Assessment Saltstone Degradation

Saltstone Microstructure

Retention: Permanent

\title{
SALTSTONE MATRIX CHARACTERIZATION AND STADIUM SIMULATION RESULTS
}

SIMCO TECHNOLOGIES, INC. TASK 6 REPORT

\author{
SIMCO TECHNOLOGIES, INC. \\ SUBCONTRACT SIMCORD08009 ORDER AC48992N
}

\author{
Christine A. Langton
}

July 30, 2009

Savannah River National Laboratory Savannah River Nuclear Solutions, LLC Aiken, SC 29808

Prepared for the U.S. Department of Energy Under Contract No. DE- AC09-08SR22470

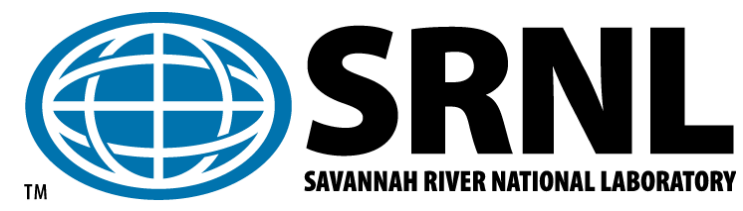




\section{DISCLAIMER}

This work was prepared under an agreement with and funded by the U.S. Government. Neither the U.S. Government or its employees, nor any of its contractors, subcontractors or their employees, makes any express or implied: 1. warranty or assumes any legal liability for the accuracy, completeness, or for the use or results of such use of any information, product, or process disclosed; or 2. representation that such use or results of such use would not infringe privately owned rights; or 3. endorsement or recommendation of any specifically identified commercial product, process, or service. Any views and opinions of authors expressed in this work do not necessarily state or reflect those of the United States Government, or its contractors, or subcontractors.

This document was prepared in conjunction with work accomplished under Contract No. DE-AC09-08SR22470 with the U.S. Department of Energy.

Printed in the United States of America

Prepared For U.S. Department of Energy 
Key Words: Performance Assessment Saltstone Degradation Saltstone Leaching Saltstone Microstructure

Retention: Permanent

\title{
SALTSTONE MATRIX CHARACTERIZATION AND STADIUM SIMULATION RESULTS
}

SIMCO TECHNOLOGIES, INC. TASK 6 REPORT

\author{
SIMCO TECHNOLOGIES, INC. \\ SUBCONTRACT SIMCORD08009 ORDER AC48992N (U)
}

\author{
Christine A. Langton
}

July 30, 2009

Savannah River National Laboratory Savannah River Nuclear Solutions, LLC Aiken, SC 29808

Prepared for the U.S. Department of Energy Under Contract No. DE- AC09-08SR22470

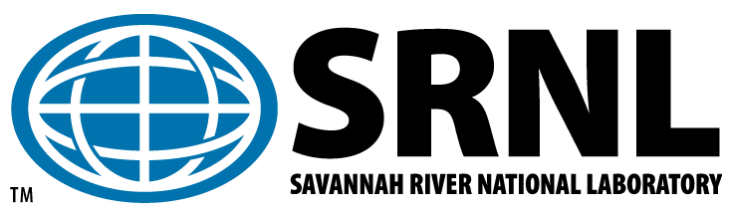




\section{REVIEWS AND APPROVALS}

Authors:

C. A. Langton, SRNL / E\&CPT Date

\section{Technical Reviewer:}

G. P. Flach, SRNL / Geo-Modeling

Date

SRNL Management Approvals:

H. H. Burns, Project Manager, SRNL / E\&CPT $\quad$ Date

A. B. Barnes, Manager, SRNL / E\&CPT

Date

S. L. Marra, Manager, SRNL / E\&CPT

Date

\section{Customer Approvals:}

T. C. Robinson Jr., SRR / WASTE DETERMINATIONS

Date 


\section{TABLE OF CONTENTS}

Page ii

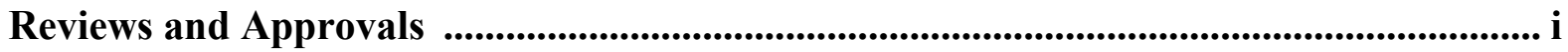

Table of Contents $\quad$................................................................................................................ ii

List of Acronyms $\quad$..................................................................................................................... iv

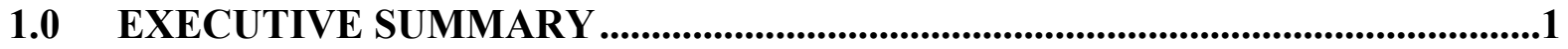

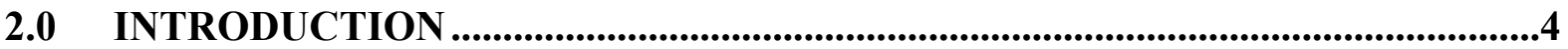

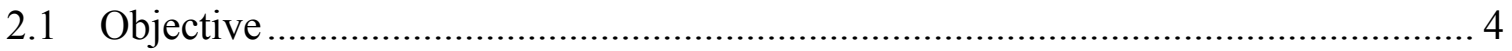

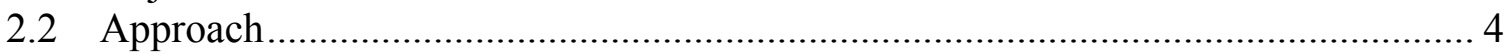

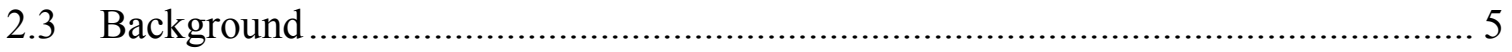

3.0 SALTSTONE CHARACTERIZATION ..............................................................

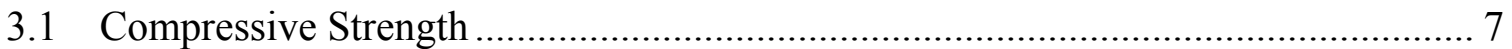

3.2 Pore Solution Composition .............................................................................. 8

3.3 Flow and Transport Properties .................................................................... 9

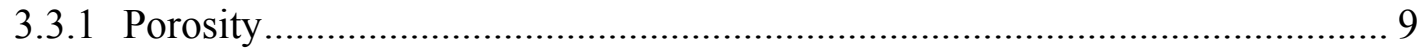

3.3.2 Tortuosity and Diffusion Coefficients...................................................... 9

3.3.3 Moisture Diffusivity and Permeability ..................................................... 11

3.3.3.1 Moisture Diffusivity ............................................................. 11

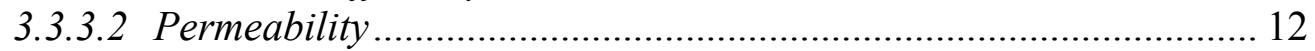

4.0 MICROSTRUCTURE CHARACTERIZATION ................................................13

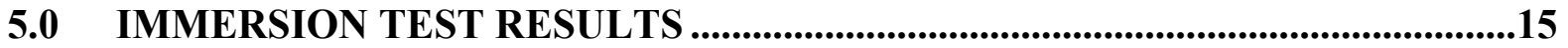

6.0 CONCLUSIONS AND RECOMMENDATIONS ................................................18

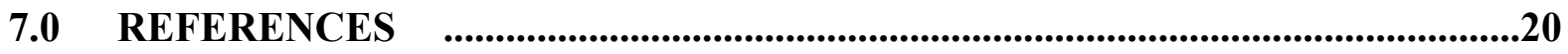

8.0 ATTACHMENT 1 Summary of Subcontract No. AC 48992N Work

Requirements................................................A1-1

9.0 ATTACHMENT 2 Characterization of a Saltstone Mixture....................A2-1 


\section{LIST OF TABLES}

Table 3-1. Compressive strength for SIMCO Saltstone

Table 3-2. Compressive Strength for the MCU Saltstone Grout (Cast 3/31/2008) [Dixon, et al, 2008].

Table 3-3 Chemical analyses of SIMCO saltstone pore fluids extracted after 28 and 123 days curing.

Table 3-4. Tortuosity and intrinsic diffusion coefficients as a function of age for SIMCO saltstone

\section{LIST OF FIGURES}

Figure 4-1. BSE image of Saltstone.............................................................................. 13

Figure 4-2. BES image illustrating cement agglomerate ................................................. 13

Figure 4-3. Particle morphology and microstructure of saltstone cured for 137 days.......... 14

Figure 5-1. Calcium and sulfur profiles through a saltstone sample immersed in water for 31 days............................................................................................ 15

Figure 5-2. SEM image of leached saltstone magnified 20X. Depth of leaching is about

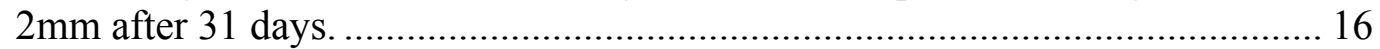

Figure 5-3. SEM image of leached saltstone (6000X) at the leaching front transition zone. 16 Figure 5-4. Estimated decalcification front based on SEM analysis compared to simulated calcium content profiles, 


\section{List of Acronyms}

\begin{tabular}{|c|c|}
\hline ASTM & American Society for Testing \& Materials \\
\hline BSE & Back Scattered Electron \\
\hline $\mathrm{cm}$ & centimeters \\
\hline $\mathrm{C}-\mathrm{S}-\mathrm{H}$ & Calcium silicate hydrate (non to poorly crystalline solid) \\
\hline $\mathrm{CV}$ & coefficient of variance \\
\hline $\mathrm{d}$ & day \\
\hline DI & De-Ionized (water) \\
\hline $\mathrm{E} \& \mathrm{CPT}$ & Engineering and Chemical Process Technology \\
\hline $\mathrm{g} / \mathrm{kg}$ & grams per kilogram \\
\hline $\mathrm{mg} / \mathrm{L}$ & milligram per liter \\
\hline $\mathrm{mm}$ & millimeter \\
\hline $\mathrm{mol} / \mathrm{L}$ & mole per liter \\
\hline $\mathrm{m}^{2}$ & square meter \\
\hline $\mathrm{m}^{2} / \mathrm{s}$ & meter squared per second \\
\hline MCU & Modular Caustic Side Solvent Extraction Unit \\
\hline $\mathrm{Mol} / \mathrm{L}$ & Moles per liter \\
\hline $\mathrm{MPa}$ & Mega Pascal \\
\hline PA & Performance Assessment \\
\hline $\mathrm{pH}$ & $\begin{array}{l}\text { Measure of the hydrogen ion concentration in an aqueous solution (acidic } \\
\text { solutions, } \mathrm{pH} \text { from } 0-6 \text {; basic solutions, } \mathrm{pH}>7 \text {; and neutral solutions, } \mathrm{pH}=7 \text { ) }\end{array}$ \\
\hline PS\&E & Process Science and Engineering \\
\hline Psi & pounds per square inch \\
\hline Psig & $\begin{array}{l}\text { Pound-force per square inch gauge (pressure relative to the surrounding } \\
\text { atmosphere }\end{array}$ \\
\hline $\begin{array}{l}\text { RI\&BM } \\
\mathrm{S}\end{array}$ & $\begin{array}{l}\text { Regulatory Integration and Business Management } \\
\text { seconds }\end{array}$ \\
\hline SE & Secondary Electron \\
\hline SEM & Scanning Electron Microscopy \\
\hline SIMCO & SIMCO Technologies, Inc. \\
\hline SRNL & Savannah River National Laboratory \\
\hline SRNS & Savannah River Nuclear Solutions \\
\hline SRR & Savannah River Remediation \\
\hline SRS & Savannah River Site \\
\hline STR & Subcontract Technical Representatives \\
\hline WSRC & Washington Savannah River Company \\
\hline yr & year \\
\hline $\mathrm{X}$ & times (e.g., $20 \mathrm{X}=20$ times magnification) \\
\hline$\mu \mathrm{m}$ & micrometer \\
\hline
\end{tabular}


SRNS-STI-2009-00477 Revision 0

July 30, 2009

Page v

\section{BLANK PAGE}




\subsection{EXECUTIVE SUMMARY}

SIMCO Technologies, Inc. was contracted to evaluate the durability of the saltstone matrix material and to measure saltstone transport properties. This information will be used to:

- Parameterize the STADIUM ${ }^{\circledR}$ service life code developed by SIMCO Technologies Inc. to predict service life of concrete structures. The STADIUM ${ }^{\circledR}$ code is a one dimensional diffusion transport code that predicts the rate of penetration of corrosive chemical fronts into concrete.

The code is supported by a set of test protocols and is validated by exposure tests of actual structures and on laboratory samples. (SIMCO Technologies Inc. has developed a concrete material data base that is useful for durability screening of a wide range of mix designs.)

- Predict the leach rate (degradation rate) for the saltstone matrix over 10,000 years using the STADIUM ${ }^{\circledR}$ concrete service life code, and

- Validate the modeled results by conducting leaching (water immersion) tests. ${ }^{1}$

This work was originally requested by J. L. Newman, REGULATORY INTEGRATION \& BUISINESS MANAGEMENT, and T. C. Robinson Jr., WASTE DETERMINATIONS. Since initiation of this work, Savannah River Remediation (SRR) has assumed responsibility for the liquid waste operations contract at the Savannah River Site. This work was coordinated through H. H. Burns, Engineering and Chemical Process Technology / Savannah River National Laboratory (E\&CPT / SRNL) and will support the Saltstone Performance Analysis (PA).

This report summarizes results obtained to date which include: characterization data for saltstone cured up to 365 days and characterization of saltstone cured for 137 days and immersed in water for 31 days. Longer term testing is in progress and will be summarized in a subsequent revision to this report. Deionized water adjusted to a $\mathrm{pH}$ of 10.5 was selected as the exposure medium to simulate the important chemistry in anticipated vadose zone water chemistry (water in equilibrium with a moderately aged concrete vault).

Samples of a simulated non-radioactive saltstone waste form were prepared. Physical and hydraulic properties of this simulated waste form were characterized by SIMCO Technologies, Inc. using methods specifically developed for cementitious materials. Results indicate that saltstone has a tortuous microstructure that is responsible for low intrinsic diffusion coefficients and low decalcification rates despite a high porosity.

The durability (stability) of the saltstone matrix upon immersion in water was found to be better than that of portland cement paste with a similar water to cement ratio and a lower total porosity. This conclusion was based on the very limited amount of decalcification that was inferred from

\footnotetext{
${ }^{1}$ Leaching of non matrix constituents such as radionuclides and hazardous constituents present in trace quantities is not considered in this study. Appropriate representation of soluble constituents that are present in more than trace quantities but do not contribute to conventional cementitious binder phases (e.g. sodium) is still being studied.
} 
SEM elemental scans on cross sections of immersed samples. After immersion in DI water with a $\mathrm{pH}$ of 10.5 , the thickness of the leached zone was estimated to be about $2 \mathrm{~mm}$.

Longer term immersion tests of thin specimens along with SEM and microprobe analyses are required to generate samples that can be used for hydraulic property determination of leached saltstone material. Longer term experiments are required because the matrix alteration rate due to immersion in deionized water with a $\mathrm{pH}$ of 10.5 is slow. Desorption / adsorption isotherm methods described in this report are suitable for these determination. Quantitative x-ray diffraction analyses are also required to determine initial and leached phase assemblages.

Sulfate attack is the key degradation mechanism in the saltstone vault concrete degradation model. Consequently, the sulfate concentration in the pore water is important. The model currently assumes a corrosive fluid composition with a $1.5 \mathrm{x}$ increase in sulfate concentration relative to the salt feed solution [Flach, 2009]. Sulfate in the pore solution extracted from the SIMCO simulated samples cured 123 days was concentrated $2.7 x$ relative to the salt solution used to prepare the samples. Consequently, the rate of sulfate attack in the saltstone vault degradation model may not be conservative. No additional vault degradation simulations for the Saltstone PA are recommended until pore solution data are obtained for simulated saltstone containing the $10-40-40$ weight percent cement - slag - fly ash pre mix blend.

The intrinsic permeability determined by SIMCO Technologies Inc. for SIMCO saltstone is $4.0 \mathrm{E}-19 \mathrm{~m}^{2}$. This value corresponds to a saturated hydraulic conductivity of $1.97 \mathrm{E}-10 \mathrm{~cm} / \mathrm{s}$ which is about 20x lower than the value determined for simulated MCU saltstone prepared at SRNL and measured by a Darcy Lay permeation method, 3.4E-09 cm/s [Dixon, 2008], and about $5 \mathrm{x}$ lower than the value $(1 \mathrm{E}-09 \mathrm{~cm} / \mathrm{s})$ used in the Saltstone PA. The method of determination used by SIMCO Technology is based on a drying isotherm method rather than Darcy-law permeation method. The SIMCO method is a property of the saltstone matrix without micro cracks.

Recommendations include evaluating the cured and immersed samples for chemical, mineralogical, and physical signs of degradation as a function of longer times. Additional work recommended includes the following activities:

- Continue curing the current SIMCO saltstone samples and determine evolution of this material over longer times.

- Continue the SIMCO immersion testing on thin samples and determine the hydraulic properties of immersed (leached) material.

- Verify the modeled water exposure results using actual sample data.

- Determine the composition and mineralogy of the unidentified phase(s).

- Characterize the mineralogical evolution of saltstone exposed to water for multiple $\mathrm{pH}$ conditions.

- Evaluate the effects of unsaturated conditions on saltstone mineralogy, microstructure, and hydraulic properties.

- Evaluate the effects of intermittent saturated / unsaturated conditions on saltstone mineralogy, microstructure, and hydraulic properties.

- Develop a technique to stop hydration of the cementitious matrix that does not leach soluble salts out of the sample so the complete material can be characterized. 
Characterize the mineralogy, microstructure and hydraulic properties of the matrix plus salt samples.

SIMCO Technologies, Inc. made an error in preparing the saltstone samples. The premix used was lower in slag $(21 \mathrm{wt.} \%)$ than the reference material (45 wt. \%). SIMCO Technologies, Inc. is currently repeating the work described in this report using the correct MCU saltstone reference formulation at no cost to SRR. Although this mistake is unfortunate, it does provide properties for a low slag saltstone at no extra cost. This information will be useful in evaluating the impact of "off spec" saltstone. The low slag samples prepared by SIMCO Technologies, which contained about $50 \%$ less slag than the reference premix, had higher porosity and a higher saturated hydraulic conductivity about 3.5 times higher than the value currently used in the saltstone PA. 


\subsection{INTRODUCTION}

\subsection{Objective}

SIMCO Technologies, Inc. was contracted to evaluate the durability of the saltstone matrix material and to measure saltstone transport properties. This information will be used to:

- Parameterize the STADIUM ${ }^{\circledR}$ service life code,

- Predict the leach rate (degradation rate) for the saltstone matrix over 10,000 years using the STADIUM ${ }^{\circledR}$ concrete service life code, and

- Validate the modeled results by conducting leaching (water immersion) tests. ${ }^{2}$ Saltstone durability for this evaluation is limited to changes in the matrix itself and does not include changes in the chemical speciation of the contaminants in the saltstone.

This report summarized results obtained to date which include: characterization data for saltstone cured up to 365 days and characterization of saltstone cured for 137 days and immersed in water for 31 days.

This work was originally requested by J. L. Newman, REGULATORY INTEGRATION \& BUISINESS MANAGEMENT, and T. C. Robinson Jr., WASTE DETERMINATIONS. Since initiation of this work, Savannah River Remediation (SRR) has assumed responsibility for the liquid waste operations contract at the Savannah River Site. This work was coordinated through H. H. Burns, Engineering and Chemical Process Technology / Savannah River National Laboratory (E\&CPT / SRNL) and will support the Saltstone Performance Analysis (PA) [Burns, 2008].

\subsection{Approach}

Samples of the saltstone binder reagents, cement, slag and fly ash, were shipped from SRS to SIMCO Technologies, Inc. and were used to prepare simulated saltstone samples. Chemicals for preparing simulated non-radioactive salt solution were obtained from chemical suppliers. The saltstone slurry was mixed according to directions provided by SRNL. However SIMCO Technologies Inc. personnel made a mistake in the premix proportions.

The formulation SIMCO personnel used to prepare saltstone premix was not the reference mix proportions: $45 \mathrm{wt} \%$ slag, $45 \mathrm{wt} \%$ fly ash, and $10 \mathrm{wt} \%$ cement. SIMCO Technologies Inc. personnel used the following proportions: $21 \mathrm{wt} \%$ slag, $65 \mathrm{wt} \%$ fly ash, and $14 \mathrm{wt} \%$ cement. The mistake was acknowledged and new mixes have been prepared and are curing. The results presented in this report are assumed to be conservative since the excessive fly ash was used in the SIMCO saltstone. The SIMCO mixes are low in slag which is very reactive in the caustic salt solution.

\footnotetext{
${ }^{2}$ Leaching of non matrix constituents such as radionuclides and hazardous constituents present in trace quantities is not considered in this study. Appropriate representation of soluble constituents that are present in more than trace quantities but do not contribute to conventional cementitious binder phases (e.g. sodium) is still being studied.
} 
The impact is that the results presented in this report are expected to be conservative since the samples prepared were deficient in slag and contained excess fly ash. The hydraulic reactivity of slag is about four times that of fly ash so the amount of hydrated binder formed per unit volume in the SIMCO saltstone samples is less than that expected for saltstone containing the reference amount of slag ( $45 \mathrm{wt}$. \% of the total cementitious mixture versus $21 \mathrm{wt} . \%$ used in the SIMCO samples). Consequently the SIMCO saltstone samples are expected to have lower strengths, and tortuosity and higher porosity, water diffusivity, and intrinsic permeability compared to the reference case MCU saltstone. MCU reference saltstone contains nonradioactive salt solution with a composition designed to simulate the product of the Modular Caustic Side Solvent Extraction (MCU) Unit [Harbour, 2009]).

The SIMCO saltstone samples were cast in molds and cured for three days under plastic with a source of water to prevent drying. Details of the sample preparation process are presented in Attachment 2. The molds were then removed and the samples were cured at a constant temperature $\left(76^{\circ} \mathrm{F}, 24^{\circ} \mathrm{C}\right)$ and 100 percent relative humidity for up to one year. Selected samples were periodically removed and characterized the evolution of the matrix as a function of age. In order to preserve the age dependent microstructure at the specified curing times it is necessary to stop hydration. This was accomplished by immersing the samples in isopropanol for 5 days to replace water with alcohol. ${ }^{3,4}$ The microstructure of the matrix material was also characterized as a function of aging. This information was used as a base line for comparison with leached microstructures.

After curing for 137 days, specimens were cut into $20 \mathrm{~mm}$ disks and exposed to deionized water with a $\mathrm{pH}$ maintained at 10.5. Microstructure and calcium sulfur leaching results for samples leached for 31 days are presented in this report. Insufficient leached material was generated during the testing to date to obtain physical and mineralogical properties for leached saltstone. Longer term experiments are required because the matrix alteration rate due to immersion in deionized water is slow.

\subsection{Background}

The saltstone waste form contains high concentrations of sodium salts distributed in a cementitious matrix consisting of calcium silicate hydrates $(\mathrm{C}-\mathrm{S}-\mathrm{H})$ and other relatively insoluble matrix phases. Prediction of the matrix durability over a long time (10,000 years) is required for performance assessment of the saltstone disposal facility.

A subcontract was awarded to SIMCO Technologies, Inc., to use existing expertise, the STADIUM $^{\circledR}$ concrete service life prediction code, and cementitious material characterization methodology to predict the evolution of the saltstone matrix as a function of curing time and to predict the durability of saltstone matrix immersed in deionized water.

\footnotetext{
${ }^{3}$ Certain salts, such as sodium nitrate, are soluble in alcohol and were therefore removed as the result of this sample preparation technique which focused on the cementitious matrix.

${ }^{4}$ SIMCO Technologies, Inc. personnel have been requested to identify a technique for arresting hydration of SEM evaluation that does not leach soluble salts.
} 
The requirements in the SIMCO Technologies Inc. Subcontract Statement of Work are provided in Attachment 1 [Contract SIMCORD08009, 2008]. Task 6 addresses evaluation of the saltstone material.

Results of the study will be used as supporting documentation for the Saltstone Performance Assessment, which predicts transport of radionuclides from the saltstone waste form into the surrounding environment and water table. 


\subsection{SALTSTONE CHARACTERIZATION}

Properties of the SIMCO saltstone mixture ${ }^{5}$ are tabulated in Tables 3-1 to 3-4. A description of ingredients and proportions, sample preparation method, and property measurement methods are provided in the SIMCO report which is provided in Attachment 2.

\subsection{Compressive Strength}

The average 28 day compressive strength of saltstone samples prepared by SIMCO personnel was only 460 psi which is lower than values measured for 2 inch MCU saltstone cubes measured by another subcontractor. See Table 3-2. The reason for this is that the SIMCO saltstone samples were not prepared with the reference premix blend. Although the SIMCO saltstone samples were deficient in slag and had an excess of fly ash, they continued to hydrate over the 365 day test period. The strength gain for the SIMCO saltstone samples was about 40 $\%$ between 28 and 365 days of curing compared to $17 \%$ for simulated MCU samples prepared with the proper reference case reagent proportions.

Table 3-1. Compressive strength for SIMCO Saltstone

\begin{tabular}{|l|c|c|}
\hline & average & CV (\%) \\
\hline $\mathrm{f}_{\mathrm{c}}$ 7d $(\mathrm{MPa})$ & 2.1 & 7.4 \\
$(p s i)$ & 300 & \\
\hline $\mathrm{f}_{\mathrm{c}} 28 \mathrm{~d}(\mathrm{MPa})$ & 3.2 & 6.3 \\
$(p s i)$ & 460 & \\
\hline $\mathrm{f}_{\mathrm{c}} 123 \mathrm{~d}(\mathrm{MPa})$ & 4.0 & 7.2 \\
$(p s i)$ & 580 & \\
\hline $\mathrm{f}_{\mathrm{c}} 365 \mathrm{~d}(\mathrm{MPa})$ & 5.3 & 3.9 \\
$(p s i)$ & 770 & \\
\hline
\end{tabular}

*Three $2 \times 2$ inch cubic specimens.

Table 3-2. Compressive Strength for the MCU Saltstone Grout (Cast 3/31/2008) [Dixon, et al, 2008].

\begin{tabular}{|c|c|c|c|c|c|}
\hline & & \multicolumn{4}{|c|}{$\begin{array}{c}\text { Compressive Strength } \\
\text { (psig) }\end{array}$} \\
\cline { 3 - 6 } $\begin{array}{c}\text { Days } \\
\text { Aged }\end{array}$ & Date Tested & \multicolumn{3}{|c|}{ Measured } & Average \\
\hline 16 & $4 / 16 / 2008$ & 970 & 1000 & 920 & 963 \\
\hline 28 & $4 / 28 / 2008$ & 1000 & 1000 & 1030 & 1010 \\
\hline 56 & $5 / 26 / 2008$ & 1130 & 1120 & 1170 & 1140 \\
\hline 90 & $6 / 29 / 2008$ & 1200 & 1230 & 1210 & 1213 \\
\hline
\end{tabular}

Samples were 2-in cube mold samples and were tested per ASTM C 109. Lab Batch ID 080014.

\footnotetext{
${ }^{5}$ The simulated saltstone material prepared by SIMCO personnel had more fly ash and less slag than the reference saltstone. Consequently, all physical and hydraulic property results probably represent a conservative case.
} 


\subsection{Pore Solution Composition}

Pore solutions were extracted from the SIMCO samples after curing for 28 and 123 days were analyzed by atomic absorption, ion chromatography, and $\mathrm{pH}$ titration. Details of the extraction method are presented elsewhere [Langton, 2008]. Pore solution results are presented in Table 3-3 along with data collected on an early saltstone formulation [Langton, 1987].

Concentrations of $\mathrm{OH}^{-}, \mathrm{Na}^{+}$, and $\mathrm{N}$ decreased as a function of curing time. Concentrations of $\mathrm{K}^{+}, \mathrm{SO}_{4}{ }^{-2}, \mathrm{Cl}^{-}$and $\mathrm{CO}_{3}{ }^{2-}$ stayed relatively constant for samples cured 28 and 123 days. The concentration of $\mathrm{Ca}^{2+}$ in the pore solution increased for the samples tested. Additional data are required to determine the statistical significance of these general observations.

The SIMCO saltstone pore solution composition is concentrated in sulfate relative to the salt solution used to prepare the samples. The concentration factor for solution extracted at 123 days is about $2.7 \mathrm{x}$ relative to the concentration in the salt feed solution used to make up the SIMCO saltstone samples. The mixing solution contained $52 \mathrm{mmol} / \mathrm{L} \mathrm{SO}^{2-}$. The pore solution extracted after curing for 28 days contained $139 \mathrm{mmol} / \mathrm{L} \mathrm{SO}^{2-}$.

Table 3-3 Chemical analyses of SIMCO saltstone pore fluids extracted after 28 and 123 days curing.

\begin{tabular}{|c|c|c|c|c|c|}
\hline \multirow{3}{*}{ Ions } & \multicolumn{3}{|c|}{ 28-days old } & \multirow{2}{*}{\multicolumn{2}{|c|}{$\begin{array}{c}\text { 123-days old } \\
\text { Current Saltstone }\end{array}$}} \\
\hline & \multicolumn{2}{|c|}{ Current Saltstone } & \multirow{2}{*}{$\begin{array}{c}\text { Surrogate } \\
\mathrm{mg} / \mathrm{L}\end{array}$} & & \\
\hline & $\mathrm{mmol} / \mathrm{L}$ & $\mathrm{mg} / \mathrm{L}$ & & $\mathrm{mmol} / \mathrm{L}$ & $\mathrm{mg} / \mathrm{L}$ \\
\hline $\mathrm{OH}^{-}$ & 484.56 & 8,241 & 16,315 & 151.18 & 2,571 \\
\hline $\mathrm{Na}^{+}$ & $4,419.76$ & 101,610 & 85,000 & $3,639.28$ & 83,667 \\
\hline $\mathrm{K}^{+}$ & 119.34 & 4,666 & 7,000 & 141.84 & 5,546 \\
\hline $\mathrm{SO}_{4}{ }^{2-}$ & 120.32 & 11,558 & 25,000 & 139.00 & 13,353 \\
\hline $\mathrm{Ca}^{2+}$ & 0.85 & 34 & 29 & 3.88 & 156 \\
\hline $\mathrm{Cl}^{-}$ & 8.89 & 315 & 1,280 & 11.50 & 408 \\
\hline $\mathrm{N}^{\dagger}$ & $3,575.75$ & 215,978 & 248,000 & $3,153.22$ & 190,471 \\
\hline $\mathrm{CO}_{3}{ }^{2-}$ & 115.48 & 6,930 & 1,000 & 97.49 & 5,850 \\
\hline
\end{tabular}

Note *: from similar saltstone formulation at Penn State University in the mid 1980s,

Note ${ }^{\dagger}$ : nitrogen includes both $\mathrm{NO}_{2}{ }^{-}$and $\mathrm{NO}_{3}{ }^{-}$, the mass $(\mathrm{mg} / \mathrm{L})$ is calculated based on $\mathrm{NO}_{2}$ to $\mathrm{NO}_{3}$ molar ratio similar to the mixing liquid used to batch saltstone (Table 3) 


\subsection{Flow and Transport Properties}

\subsubsection{Porosity}

Porosity of the SIMCO saltstone samples was determined according to a modified ASTM C 642 procedure which is described in Attachment 2. Porosities of the SIMCO saltstone samples ranged from 64.3 to 65.4 volume percent for samples cured for 82, 123, and 365 days. These values are higher than that reported for MCU saltstone ( 58 volume percent) prepared by SRNL [Dixon, 2008]. The change in bulk porosity as a function of curing time was negligible after the samples were cured for at least three months. ${ }^{6}$ However, based on compressive strength data and estimates of the tortuosity as a function of curing time, it can be inferred that the pore structure of the matrix changes over 365 days.

\subsubsection{Tortuosity and Diffusion Coefficients}

The tortuosity as a function of age was determined using a modification of the ASTM C 1202 test method: Standard test method for Electrical Indication of Concrete's Ability to Resist Chloride Ion Penetration. Intrinsic diffusion coefficients reported by SIMCO Technologies Inc., personnel (effective diffusion coefficients per SRNL terminiology) ${ }^{7}$ for selected ions were calculated by dividing the free ion (or molecular ion) diffusion coefficient by the intrinsic tortuosity. See Section 4.4 of Attachment 2. The resulting intrinsic ionic diffusion coefficients are consequently a function of only the material microstructure and are not influenced by chemical reactions within the sample.

Tortuosity values and intrinsic diffusion coefficients for the SIMCO saltstone samples cured for 28,123 , and 365 days are presented in Table 3-4. The results indicate that continued hydration of the material between 123 days and 365 days, i.e., evolution of the matrix microstructure has an impact of about a factor of three on tortuosity and hence intrinsic diffusion coefficients. Intrinsic diffusion coefficients and tortuosity values for the saltstone Vault $1 / 4$ and Vault 2 concretes are included in Table 3-4 for comparison.

Although the SIMCO saltstone material has a relatively high water to cement ratio of 0.6 and the porosity is about 65 volume \%, the tortuosity after 365 days is about $2 \mathrm{X}$ less that the tortuosity of neat cement paste with a porosity of 52 volume percent [Samson and Marchand, 2007]. The low tortuosity of saltstone is attributed to the particle morphology and paste microstructure.

\footnotetext{
${ }^{6}$ Data for younger samples was not collected.

7 The Savannah River Site Performance Assessment and the key supporting documentation, such as WSRCTR_2006-00198, refer to the free / molecular ion diffusion coefficient divided by the tortuosity as an effective diffusion coefficient rather that using the intrinsic diffusion coefficient terminology used by SIMCO Technologies, Inc. and also used in this report which summarizes the SIMCO results.

Furthermore, authors of SRNL reports related to PAs, such as WSRC-STI-2006-00198, apply the term intrinsic diffusion coefficient to the free / molecular ion diffusion coefficient divided the tortuosity and multiplied by porosity.
} 
Table 3-4. Tortuosity and intrinsic diffusion coefficients as a function of age for SIMCO saltstone.

\begin{tabular}{|c|c|c|c|c|c|c|}
\hline \multirow{3}{*}{ Species } & \multirow{3}{*}{$\begin{array}{l}\text { Free Ion } \\
\text { Diffusion } \\
\text { Coefficient } \\
\left(\text { E-09 } \mathrm{m}^{2} / \mathrm{s}\right)\end{array}$} & \multirow{2}{*}{\multicolumn{3}{|c|}{$\begin{array}{l}\text { SIMCO Saltstone Intrinsic } \\
\text { Diffusion Coefficients } \\
\left(\mathrm{E}-11 \mathrm{~m}^{2} / \mathrm{s}\right)\end{array}$}} & $\begin{array}{l}\text { Saltstone } \\
\text { Vault } 1\end{array}$ & \begin{tabular}{|} 
Saltstone \\
Vault 2
\end{tabular} \\
\hline & & & & & \multicolumn{2}{|c|}{$\begin{array}{l}\text { Intrinsic Diffusion } \\
\text { Coefficient } \\
{[\text { Langton } 2009 \text { (a)] }} \\
\left(\text { E-11 } \text { m }^{2} / \mathbf{s}\right)\end{array}$} \\
\hline & & $28 d$ & $123 d$ & 365d & 365d & 365d \\
\hline $\mathrm{OH}^{-}$ & 5.273 & 7.50 & 7.00 & 2.50 & 3.50 & 0.40 \\
\hline $\mathrm{Na}^{+}$ & 1.334 & 1.90 & 1.77 & 0.63 & 0.89 & 0.10 \\
\hline $\mathrm{K}^{+}$ & 1.957 & 2.78 & 2.60 & 0.93 & 1.30 & 0.15 \\
\hline $\mathrm{SO}_{4}{ }^{2-}$ & 1.065 & 1.51 & 1.41 & 0.51 & 0.71 & 0.08 \\
\hline $\mathrm{Ca}^{2+}$ & 0.792 & 1.13 & 1.05 & 0.38 & 0.53 & 0.06 \\
\hline $\mathrm{Al}(\mathrm{OH})_{4}^{-}$ & 0.541 & 0.77 & 0.72 & 0.26 & 0.36 & 0.06 \\
\hline $\mathrm{Cl}^{-}$ & 2.032 & 2.89 & 2.70 & 0.96 & 1.35 & 0.15 \\
\hline Tortuosity & & $1.42 \mathrm{E}-02$ & $1.33 \mathrm{E}-02$ & $4.74 \mathrm{E}-03$ & $6.6 \mathrm{E}-03$ & $7.6 \mathrm{E}-04$ \\
\hline
\end{tabular}

NOTE: The Savannah River Site Performance Assessment and the key supporting documentation, such as WSRCTR_2006-00198, refer to the free / molecular ion diffusion coefficient divided by the tortuosity as an effective diffusion coefficient rather that using the intrinsic diffusion coefficient terminology used by SIMCO Technologies, Inc. and also used in this report which summarizes the SIMCO results. Furthermore, authors of SRNL reports related to PAs, such as WSRC-STI-2006-00198, apply the term intrinsic diffusion coefficient to the free / molecular ion diffusion coefficient divided the tortuosity and multiplied by porosity. 


\subsubsection{Moisture Diffusivity and Permeability}

Saltstone moisture diffusivity and permeability values were determined by desorption / adsorption isotherm results obtained from samples equilibrated with moist air at the following relative humidities: $11.3 \%, 33.1 \%, 54.4 \%, 75.5 \%, 85.1 \%, 91.0 \%, 94.6 \%$, and $97.3 \%$. The methodology is described in Attachment 2 and in associated references [Samson, et. al, 2008, and Langton, 2008].

\subsubsection{Moisture Diffusivity}

Water diffusivity and parameters were also determined for the SIMCO saltstone material. These parameters are used to predict moisture transport under unsaturated conditions. Water mass losses over time for samples with one side exposed to $50 \%$ relative humidity (other surfaces sealed) were measured. The mass loss curves provided the empirical water diffusivity defined according to Equation 3-1. The methodology is also described elsewhere [Samson, et. al., 2008, Langton, 2008]. Assuming an exponential relationship between moisture diffusivity and water content, the constants, $A$ and $B$ in Equation 3-1, were adjusted to reproduce the mass loss measured during the drying test according to Richards' model as shown in Equation 3-2.

Equation 3-1. $\quad D_{w}=A e^{B w}$

Where: $\quad w=$ the volumetric water content

$D_{w}=$ the nonlinear water diffusivity parameter

$A$ and $B$ need to be experimentally determined and $B$ is positive

Equation 3-2. $\quad \frac{\partial w}{\partial t}-\operatorname{div}\left(A e^{B w} \operatorname{grad}(w)\right)=0$

Where: $\quad t=$ time

For a porosity of 64.3 volume percent (See section 3.3), the constants, $A$ and $B$, for the SIMCO saltstone material were determined and used to calculate the water diffusivity. The values are provided below:

$$
\begin{aligned}
& A=92 \mathrm{E}-14 \mathrm{~m}^{2} / \mathrm{s} \\
& B=-10 \\
& D_{w}=6.1 \mathrm{E}-10 \mathrm{~m}^{2} / \mathrm{s} \text { at saturation }
\end{aligned}
$$




\subsubsection{Permeability}

The drying test results were also used to estimate the intrinsic permeability ${ }^{8}$ of the SIMCO saltstone material. The moisture mass loss versus time data were reproduced using a moisture transport model that separately considered both liquid and water vapor transport. The method is described in Attachment 2. The estimated intrinsic permeability for the SIMCO saltstone is $4.0 \mathrm{E}-19 \mathrm{~m}^{2}$.

Intrinsic permeability, $K\left(\mathrm{~cm}^{2}\right)$, is related to hydraulic conductivity, $k(\mathrm{~cm} / \mathrm{s})$, through a fluid viscosity term and a fluid density term as indicated in Equation 3-3. The intrinsic permeability determined by SIMCO Technologies Inc. for SIMCO saltstone ${ }^{9}$ is $4.0 \mathrm{E}-19 \mathrm{~m}^{2}$. This value corresponds to a saturated hydraulic conductivity of $1.97 \mathrm{E}-10 \mathrm{~cm} / \mathrm{s}$ which is about $20 \mathrm{x}$ lower than the value determined for simulated MCU saltstone prepared at SRNL and measured by a Darcy Lay permeation method, 3.4E-09 $\mathrm{cm} / \mathrm{s}$ [Dixon, 2008], and about $5 \mathrm{x}$ lower than the value $(1 \mathrm{E}-09 \mathrm{~cm} / \mathrm{s})$ used in the Saltstone PA.

Equation 3-3.

$$
k=\frac{K \mu}{\rho g}
$$

Where:

$$
\begin{aligned}
k= & \text { intrinsic permeability }\left(\mathrm{cm}^{2}\right) \\
K= & \text { saturated hydraulic conductivity relative to concentrated simulant }(\mathrm{cm} / \mathrm{sec}) \\
\mu= & \text { dynamic viscosity of concentrated MCU simulant }(0.0249 \mathrm{~g} / \mathrm{cm}-\mathrm{sec}) \\
& \quad[\text { Dixon, } 2008] \\
\rho= & \text { density of concentrated MCU simulant }\left(1.253 \mathrm{~g} / \mathrm{cm}^{3}\right) \text { [Dixon, 2008] } \\
g= & \text { gravity }\left(981 \mathrm{~cm} / \mathrm{sec}^{2}\right)
\end{aligned}
$$

For modeling purposes an internally consistent set of hydraulic property data is needed. The SIMCO method for determining intrinsic permeability is consistent with their model parameterization needs and is suitable for characterizing moisture transport through cementitious materials.

\footnotetext{
${ }^{8}$ SIMCO Technologies Inc. personnel do not measure permeability of cementitious materials by Darcy flow-type measurements because moisture transport through concrete that is not cracked typically occurs through a combination of capillary suction and diffusion (not advection) because the matrix consists of very small interconnected capillary pores. The interconnected pores are typically less than 10 to $0.05 \mu \mathrm{m}$ in diameter. Advective flow described by permeability or conductivity typically occurs through fractures or a system of larger interconnected pores.

${ }^{9}$ SIMCO Technologies Inc. personnel have prepared saltstone with the correct premix proportions and are currently performing tests at no charge. The permeability of the new samples is expected to be lower than that measured for the sample reported here since the new sample will have more slag and less fly ash.
} 


\subsection{MICROSTRUCTURE CHARACTERIZATION}

Saltstone microstructure was characterized using Scanning Electron Microscopy (SEM) back scattered electron (BSE) images of polished surfaces and secondary electron (SE) images of fractured surfaces. Polished surface observations are summarized below:

- The SIMCO saltstone samples cured for 137 days in sealed containers contained a large number of voids and a significant amount of unreacted cement, slag, and fly ash as shown in Figure 4-1.

- Hydrated phases surrounding unreacted cement, slag and even fly ash grains are clearly visible.

- Agglomerates of portland cement (200 to 400 um in diameter) were found in the cured saltstone. It is unknown at this time whether these particles were in the cement reagent used to make up the premix or whether they represent some form of false set. See Figure 4-2 for an example. Additional work will be performed to determine the nature of these agglomerates.
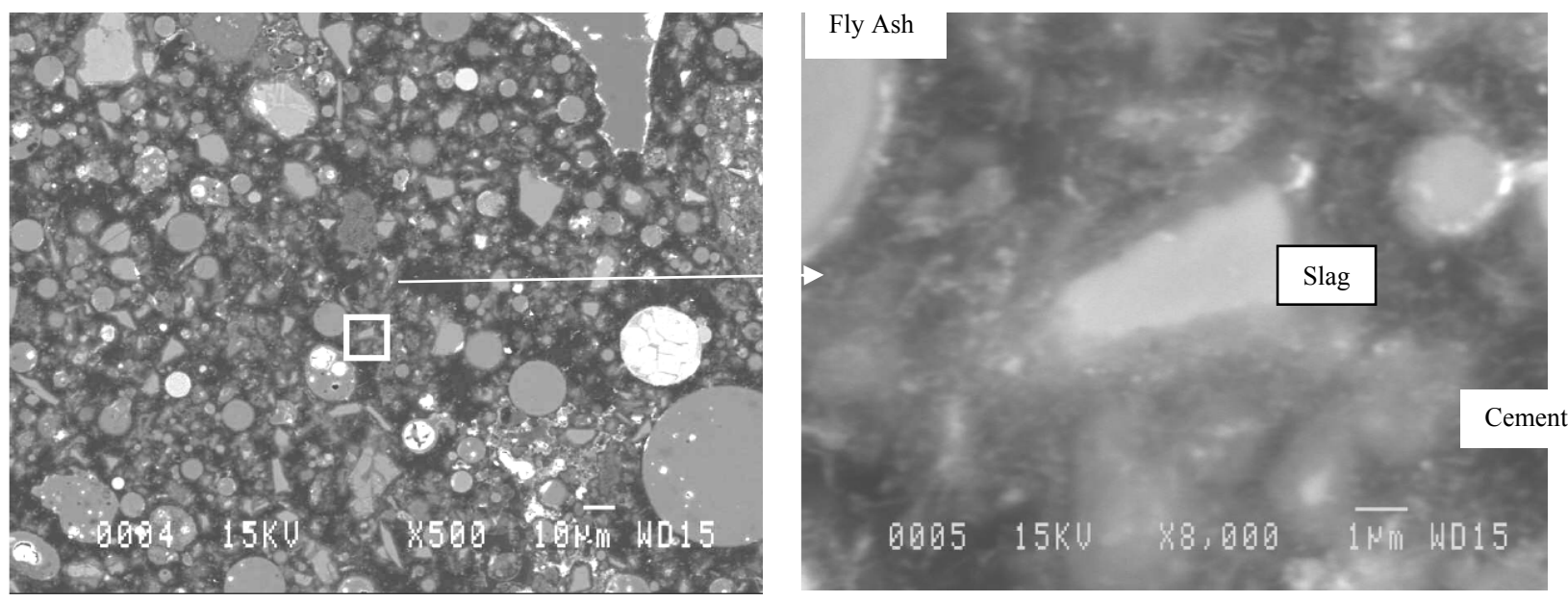

Figure 4-1. BSE image of Saltstone.

Cement, slag and fly ash are surrounded by hydration products. Black areas are voids.

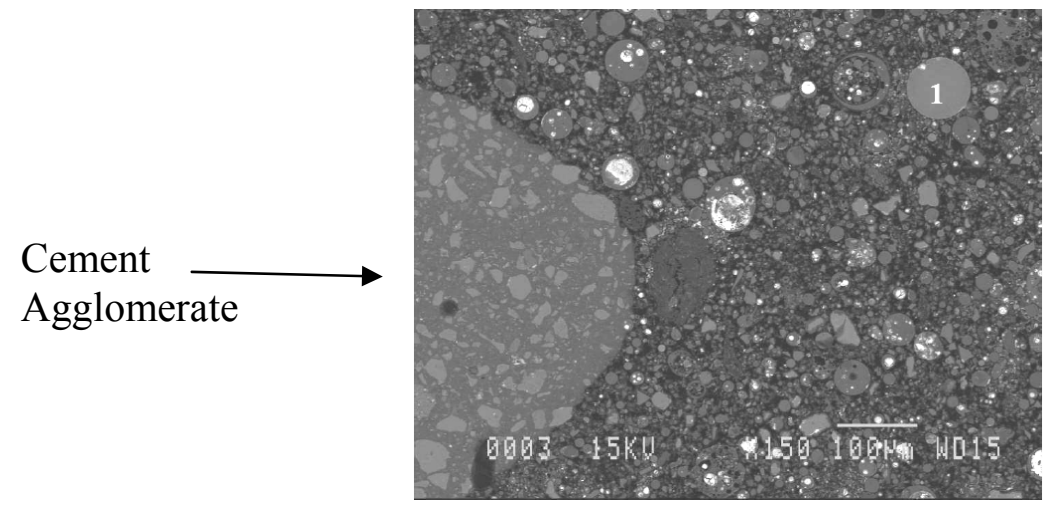

Figure 4-2. BES image illustrating portland cement agglomerate. 
Secondary electron images of fractured surfaces provided information on the particle morphology of the hydrated phases. See Figures 4-3 and 4-4 for examples. At $150 \mathrm{X}$ magnification the fly ash spheres are clearly visible and are imbedded in the calcium silicate hydrate binder. The fly ash hydration rims are visible on close examination. The honey comb texture of the binder phase suggests a tortuous pore structure. ${ }^{10}$ Microprobe and energy dispersive x-ray analyses are underway to determine the composition of the unidentified crystalline phase in the micrographs.

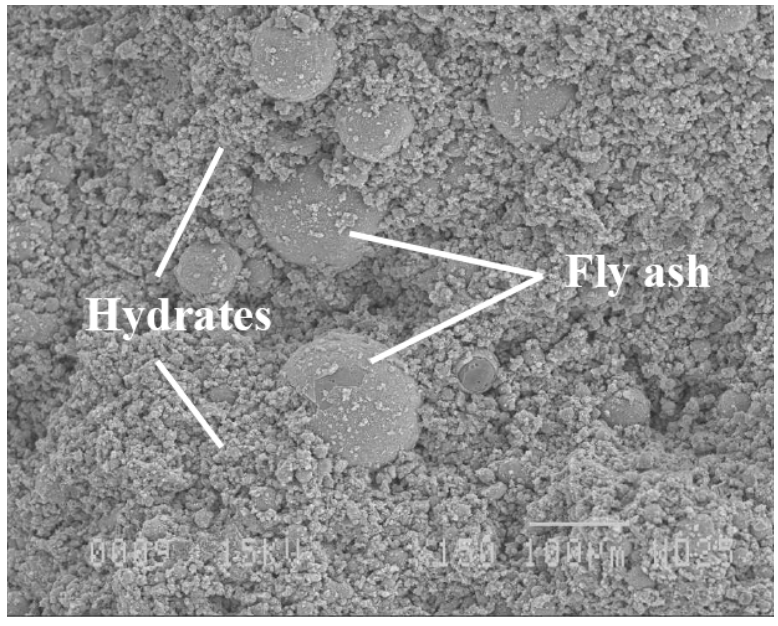

(a)

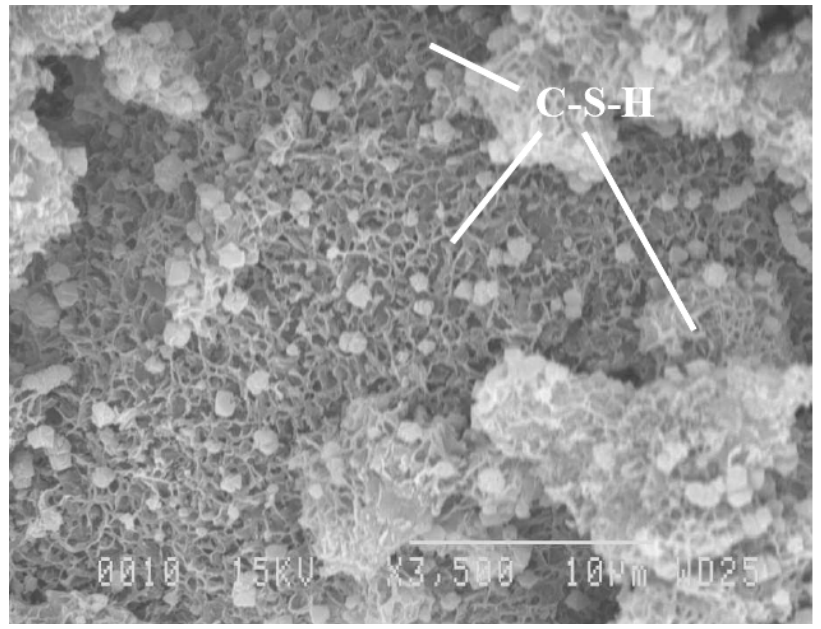

(b)

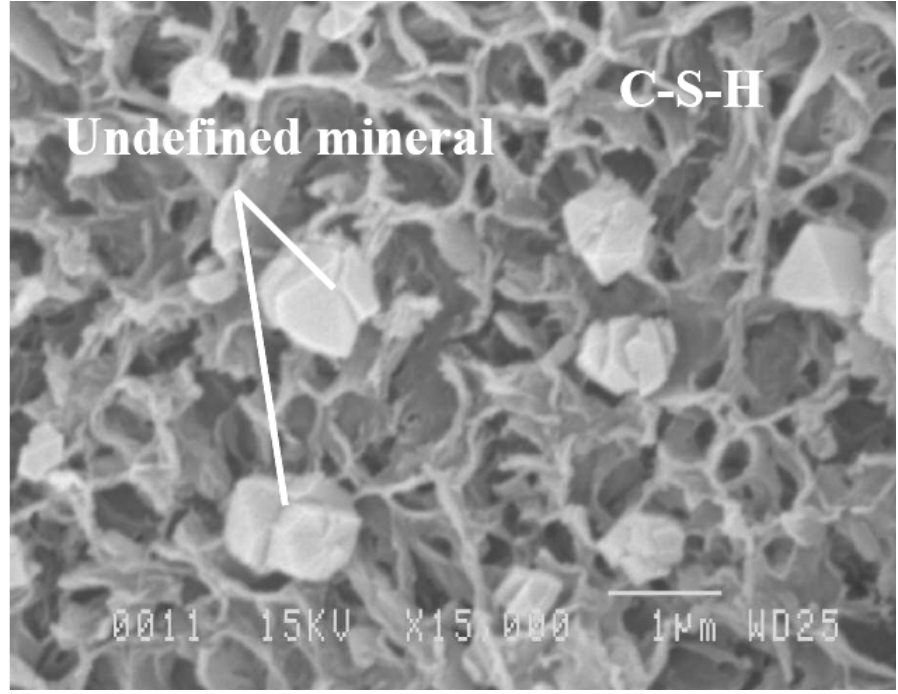

(c)

Figure 4-3. Particle morphology and microstructure of saltstone cured for 137 days.

(a) magnified 150X, (b) magnified 3,500X, (c) magnified 15000X.

\footnotetext{
${ }^{10}$ The samples characterized in the SEM micrographs were soaked in alcohol to stop evolution (hydration) of the matrix material. Salt phases soluble in alcohol were removed in the sample preparation. Additional study is required to characterize the microstructure of the actual saltstone material.
} 


\subsection{IMMERSION TEST RESULTS}

A series of water immersion tests were conducted to determine the effect of water leaching on the saltstone matrix. Microprobe scans for $\mathrm{Ca}$ and $\mathrm{S}$ and SEM imaging of fractured surfaces were performed to determine the elemental profiles from the exposed surface to the center of the leached samples. Since the focus of this testing was on the matrix structure, leachates were not analyzed to determine $\mathrm{Ca}$ and $\mathrm{S}$ extraction factors.

Samples were cured for 137 days before leaching for 31 days. The $\mathrm{pH}$ of the leachate solutions was maintained at 10.5 to control the chemical boundary conditions of the experiment. Both microprobe analyses and SEM micrographs and qualitative x-ray analyses were used to determine calcium and sulfur profiles from the edge to the center of the samples. SEM micrographs were also used to determine the depth to which the microstructure was affected by immersion in water. Results are summarized below:

- Microbe Profiles:

O Immersion in water with a $\mathrm{pH}$ of 10.5 for 31 days did not significantly alter the calcium or sulfur profiles of the sample. (Experimental results shown in Figure 5-1.) The STADIUM ${ }^{\circledR}$ model results are also shown in Figure 5-1 and correspond well to the observed calcium and sulfur microprobe profiles.

○ This observation is consistent with the initial solid phase assemblage estimated from the SIMCO Technologies Inc. thermodynamic calculation, i.e., portlandite, $\mathrm{Ca}(\mathrm{OH})_{2}$, which is responsible for initial decalcification of typical cementitious materials was absent in the initial saltstone phase assemblage.

- Polished microprobe samples showed no obvious signs of degradation after 31 days of immersion in water. (See polished microprobe micrographs in Attachment 2.)

$\circ$ The matrix of the SIMCO saltstone samples is less affected by leaching in deionized water (more stable) than the matrix of cement paste prepared with a water to cement ratio of 0.6 due to the absence of portlandite. (Additional details of the comparison of these two materials are provided in the SIMCO Technologies Inc. report in Attachment 2.)

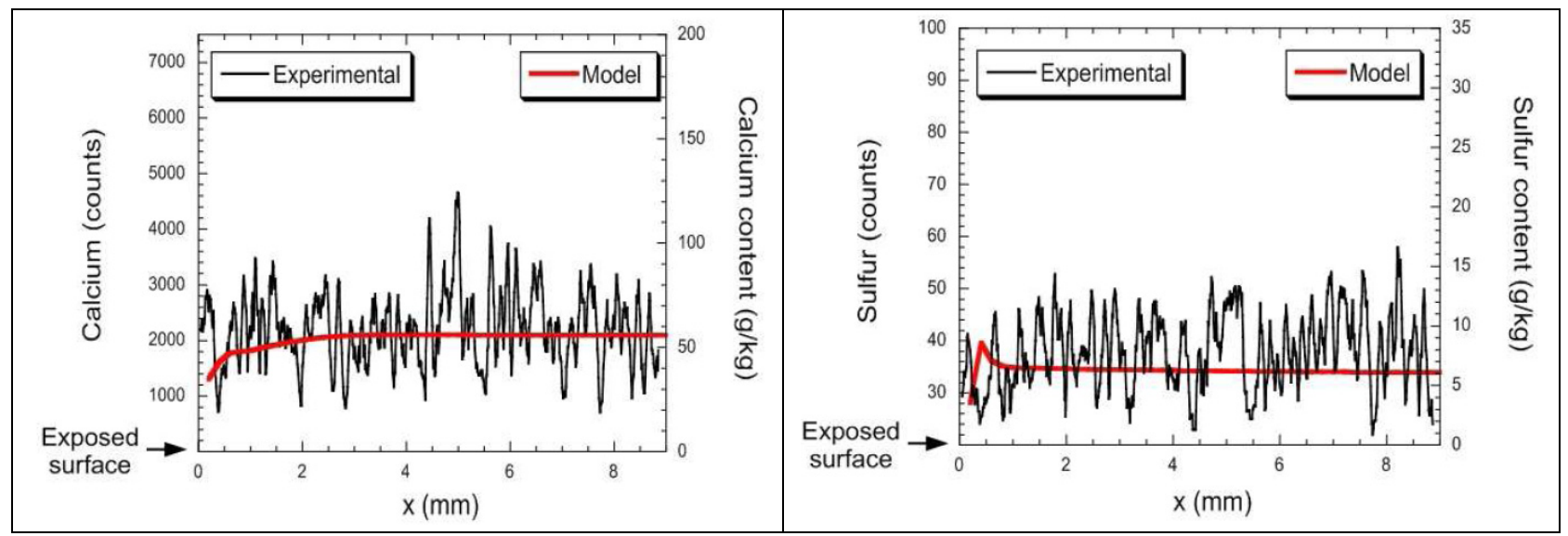

Figure 5-1. Calcium and sulfur profiles through a saltstone sample immersed in water for 31 days. 
- SEM Microstructure and Particle Morphology Profiles:

○ Immersion in water with a $\mathrm{pH}$ of 10.5 for 31 days resulted in an altered zone about 2 $\mathrm{mm}$ wide. See Figures 5-2 and 5-3.

$\circ$ A calcium profile obtained from SEM analyses indicated a very slight amount of decalcification over the $2 \mathrm{~mm}$ thick altered zone. See Figure 5-4.

- Numerical simulation of the calcium profile indicated a thicker slightly decalcified zone of about $2.5 \mathrm{~mm}$. Consequently, the STADIUM ${ }^{\circledR}$ predictions are conservative relative to observed results.

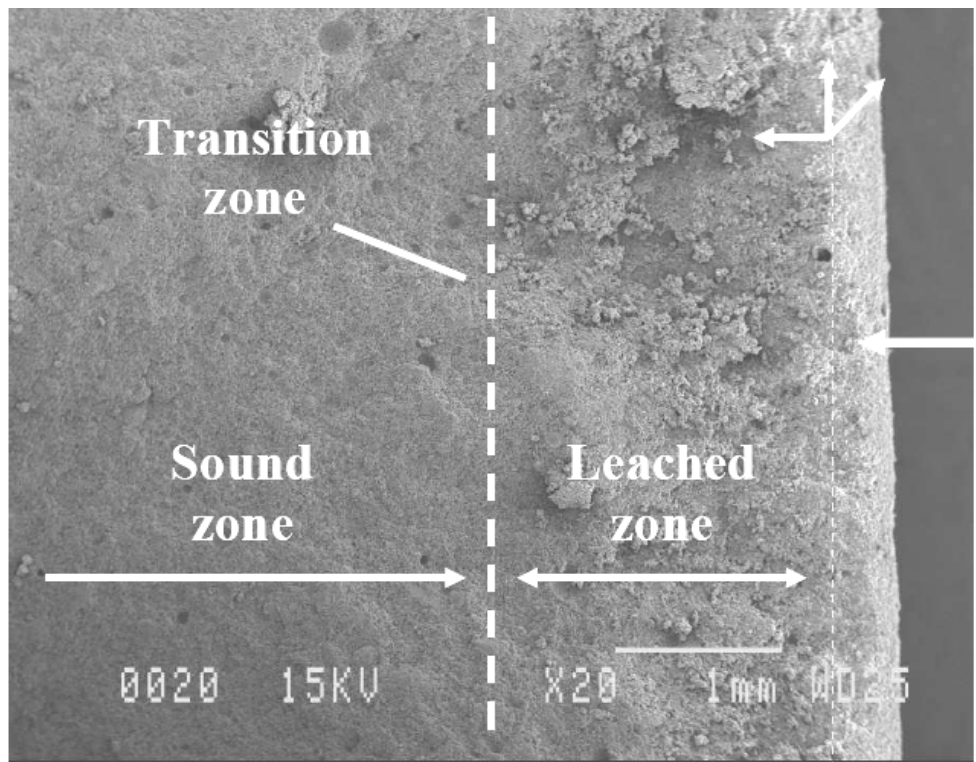

Surface

exposed to

pure water

Figure 5-2. SEM image of leached saltstone magnified 20X. Depth of leaching is about $2 \mathrm{~mm}$ after 31 days.

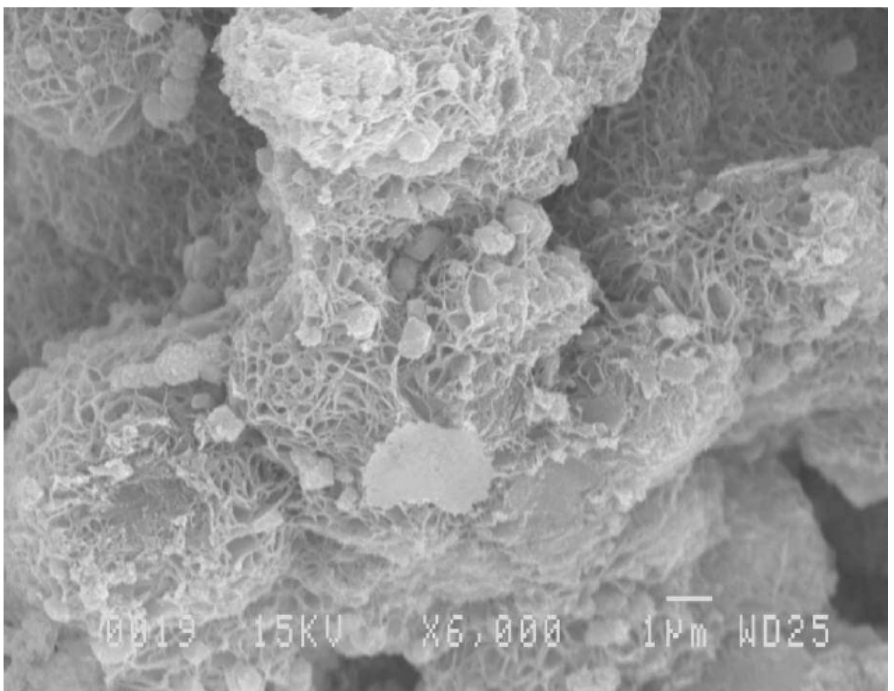

Figure 5-3. SEM image of leached saltstone $(6000 \mathrm{X})$ at the leaching front transition zone. 


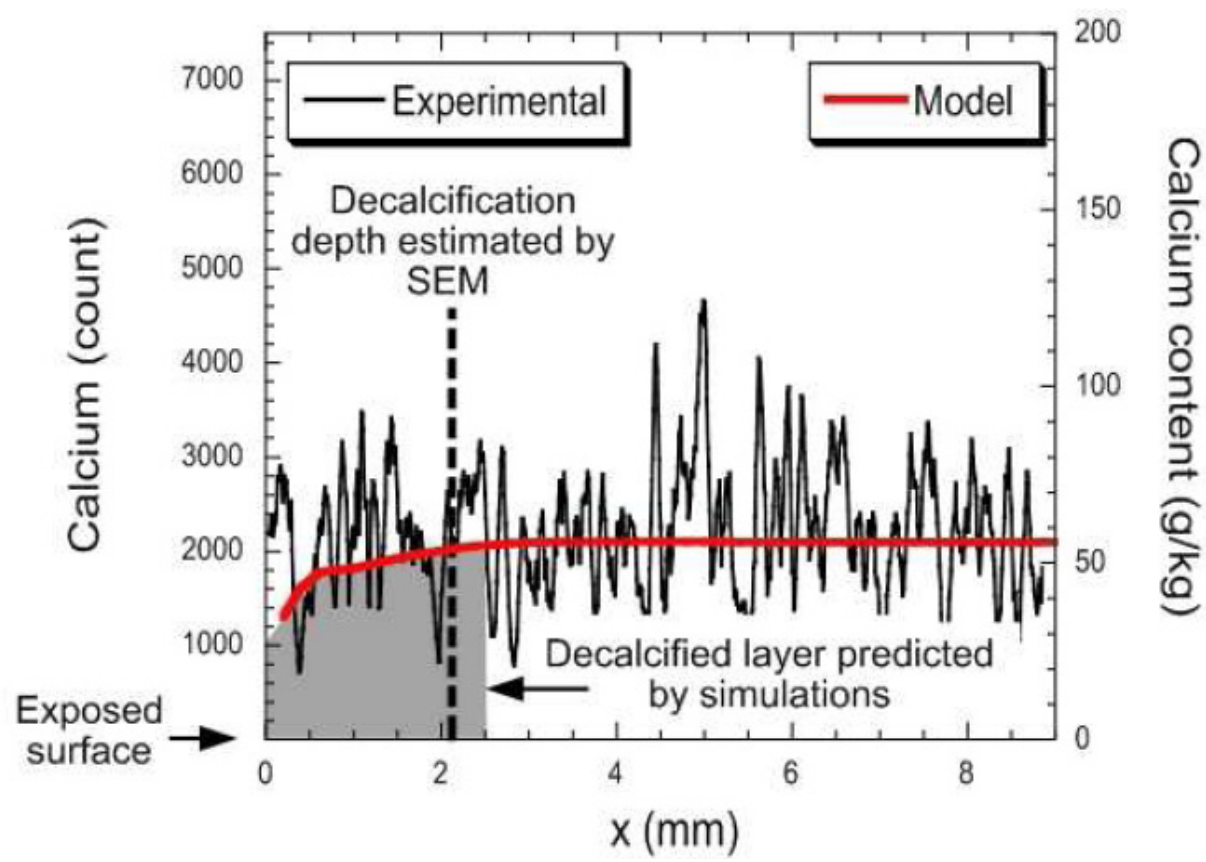

Figure 5-4. Estimated decalcification front based on SEM analysis compared to simulated calcium content profiles. 


\subsection{CONCLUSIONS AND RECOMMENDATIONS}

The durability (stability) of the saltstone matrix upon immersion in water was found to be better than that of portland cement paste with a similar water to cement ratio and a lower total porosity. This conclusion was based on the very limited amount of decalcification that was inferred from SEM elemental scans on cross sections of immersed samples. After immersion in DI water with a $\mathrm{pH}$ of 10.5 , the thickness of the leached zone was estimated to be about $2 \mathrm{~mm}$.

Longer term immersion tests of thin specimens along with SEM and microprobe analyses are required to generate samples that can be used for hydraulic property determination of leached saltstone material. Desorption / adsorption isotherm methods described in this report are suitable for these determinations. Quantitative x-ray diffraction analyses are also required to determine initial and leached phase assemblages.

Sulfate attack is the key degradation mechanism in the saltstone vault concrete degradation model. Consequently, the sulfate concentration in the pore water is important. The model currently assumes a corrosive fluid composition with a $1.5 \mathrm{x}$ increase in sulfate concentration relative to the salt feed solution [Flach, 2009]. Sulfate in the pore solution extracted from the SIMCO simulated samples cured 123 days was concentrated $2.7 \mathrm{x}$ relative to the salt solution used to prepare the samples. Consequently, the rate of sulfate attack in the saltstone vault degradation model may not be conservative. No additional vault degradation simulations for the Saltstone PA are recommended until pore solution data are obtained for simulated saltstone containing the $10-40-40$ weight percent cement - slag - fly ash pre mix blend.

The intrinsic permeability determined by SIMCO Technologies Inc. for SIMCO saltstone is $4.0 \mathrm{E}-19 \mathrm{~m}^{2}$. This value corresponds to a saturated hydraulic conductivity of $1.97 \mathrm{E}-10 \mathrm{~cm} / \mathrm{s}$ which is about 20x lower than the value determined for simulated MCU saltstone prepared at SRNL and measured by a Darcy Lay permeation method, 3.4E-09 cm/s [Dixon, 2008], and about $5 \mathrm{x}$ lower than the value $(1 \mathrm{E}-09 \mathrm{~cm} / \mathrm{s})$ used in the Saltstone PA. The method of determination used by SIMCO Technology is based on a drying isotherm method rather than Darcy-law permeation method. The SIMCO method is a property of the saltstone matrix without micro cracks.

SIMCO Technologies, Inc. made an error in preparing the saltstone samples. The premix used was lower in slag (21 wt. \%) than the reference material (45 wt. \%). SIMCO Technologies, Inc. is currently repeating the work described in this report using the correct MCU saltstone reference formulation at no cost to SRR. Although this mistake is unfortunate, it does provide properties for a low slag saltstone at no extra cost. This information will be useful in evaluating the impact of "off spec" saltstone. The low slag samples prepared by SIMCO Technologies, which contained about $50 \%$ less slag than the reference premix, had higher porosity and a higher saturated hydraulic conductivity, about 3.5 times higher, than the value currently used in the saltstone PA.

Recommendations include evaluating the cured and immersed samples for chemical, mineralogical, and physical signs of degradation as a function of longer times. Additional work recommended includes the following activities: 
- Continue curing the current SIMCO saltstone samples and determine evolution of this material over longer times.

- $\quad$ Continue the SIMCO immersion testing on thin samples and determine the hydraulic properties of immersed (leached) material.

- Verify the modeled water exposure results using actual sample data.

- $\quad$ Determine the composition and mineralogy of the unidentified phase(s).

- Characterize the mineralogical evolution of saltstone exposed to water for multiple $\mathrm{pH}$ conditions.

- Evaluate the effects of unsaturated conditions on saltstone mineralogy, microstructure, and hydraulic properties.

- Evaluate the effects of intermittent saturated / unsaturated conditions on saltstone mineralogy, microstructure, and hydraulic properties.

- Develop a technique to stop hydration of the cementitious matrix that does not leach soluble salts out of the sample so the complete material can be characterized.

- Characterize the mineralogy, microstructure and hydraulic properties of the matrix plus salt samples. 


\subsection{REFERENCES}

Burns, H. H. 2008. "Program Plan for the Science and Modeling Tasks in Support of the ZArea Saltstone Disposal facility Performance Assessment (U)," SRNL-ECP-2008-00001 Rev. 0, Washington Savannah River Company, Savannah River National Laboratory, Savannah River Site, Aiken, SC 2008.

Contract No. SIMCORD08009, Order No. AC48992N, 2008. "Saltstone Vault Sulfate Attack and Saltstone Durability," SIMCO Technologies, Inc.

Dixon, K. L., J. Harbour, M. Phifer, 2008. Hydraulic and Physical Properties of Saltstone Grouts and Vault Concretes," SRNS-STI-2008-00042, Rev. 0, Savannah River Nuclear Solutions, LLC, Savannah River Site, Aiken, SC 2008.

Flach, G. P., 2009. E-Mail correspondence to C. A. Langton, August 19, 2009, Savannah River Nuclear Solutions, LLC, Savannah River Site, Aiken, SC 2008.

Langton, C. A., 1987. Analysis of Saltstone Pore Solutions - PSU Progress Report IV, DPST87-530, July 7, 1987, E. I. du Pont de Nemours and Company, Aiken, SC 2008.

Langton, C. A., 2009. Evaluation of Sulfate Attack on Saltstone Evaluation of Sulfate Attack on Saltston vault Concrete and Saltstone SIMCO Technologies, Inc. PART I: Final Report, SRNS-STI-2008-00052, Rev. 0, Savannah River Nuclear Solutions, LLC, Savannah River Site, Aiken, SC 2008.

Langton, C. A., 2009 (a). Evaluation of Sulfate Attack on Saltstone Evaluation of Sulfate Attack on Saltston vault Concrete and Saltstone SIMCO Technologies, Inc. PART I: Final Report, SRNS-STI-2008-00052, Rev. 1, Savannah River Nuclear Solutions, LLC, Savannah River Site, Aiken SC 2008.

Phifer, M. A., Millings, M. R., and G. P. Flach, 2006. "Hydraulic Property Data Package for the E-Area and Z-Area Soils, Cementitious Materials, and Waste Zones," WSRC-STI-200600198, September 2006, Washington Savannah River Company, Savannah River Site, Aiken, SC, 2008.

Samson, E., K. Maleki, J. Marchand, T. Zhang, "Determination of the Water Diffusivity of Concrete Using Drying / Absorption Test Results," J. of the ASTM Inst. 5, 2008. 
SRNS-STI-2009-00477 Revision 0 July 30, 2009

Page 21 of 21

BLANK PAGE 
SRNS-STI-2009-00477 Revision 0 July 30, 2009

Page A1-1

\subsection{ATTACHMENT 1}

Summary of Subcontract No. AC 48992N Work Requirements 
SRNS-STI-2009-00477 Revision 0 July 30, 2009

Page A1-2

\section{BLANK PAGE}




\section{SUBCONTRACT No. AC 48992N WORK REQUIREMENTS}

\section{Task Descriptions}

\section{Task 1. Preliminary estimate of service life.}

Predict degradation using literature data for concrete properties using mixes similar to the WSRC mixes or actual data supplied by SRNL for exposure to up to three (3) different corrodent solutions as specified by the STR at a later date.

Use Stadium and/or other modeling capabilities to predict the depth of penetration (diffusion front) of corrodents, including sulfate, aluminate, chloride, sodium, etc., in 2 different concretes exposed to 3 different solutions for extended time (up to 10,000 years):

a. Estimates values for the important parameters from data provided by SRNL and by analogy to similar materials previously tested by SIMCO, Inc.

b. Run the Stadium code for a rough estimate of depth of penetration.

c. Estimate service life taking into consideration penetration depth, formation of expansive phases, and consequence of formation of expansive phases including effect of reinforcement and post tensioning steel.

d. Estimate the effective transport properties (effective permeability, effective diffusivity coefficient, effective porosity, etc.), according to in-house protocol in addition to providing an estimate assuming the concrete is fully degraded behind the advancing front and intact (not degraded) ahead of the front with respect to computing effective transport properties if the two approaches are different.

\section{Task 2. Measure relevant properties for SRS mixes.}

Measure parameters for 2 concrete mix designs (on samples cured for 28 and/or 90 days) required to support Stadium and/or other service life prediction modeling. Up to two (2) different curing times may be requested by the STR.

\section{Task 3. Estimate for SRS mixes.}

Run Stadium using data on SRS mixes. Predict depth of penetration of the corrodent species using data generated in 3.1 .2 for the 2 concrete mix designs.

Estimate the effective transport properties (effective permeability, effective diffusivity, effective porosity, etc.), according to in-house protocol in addition to providing an estimate assuming the concrete is fully degraded behind the advancing front and intact (not degraded) ahead of the front with respect to computing effective transport properties - if the two approaches are different.

\section{Task 4. Confirm short term predictions.}

Expose samples for 2 concrete mix designs to up to three (3) different corrodent solutions to support calculated depth of penetration and service life predictions. The exact number of 
corrodent solutions and the compositions of those solutions will be specified by the STR at a later date.

Analyze samples for relevant data after exposure for 4 months to compare with model predictions. (A request may be made to continue testing to obtain additional data points.) Monitor volumetric changes due to sulfate reactions with the two different concretes. The corrodent solutions will contain at a minimum sulfate, aluminate, chloride, and sodium.

\section{Task 5. Provide approach and methodology.}

The SIMCO, Inc. proposal will document the approach and methodology, identify information and testing required, identify the number of samples and sample geometry required, recommend laboratory prepared samples or actual samples (Vault 4) or test samples (Disposal Unit 2), and include a cost for preparing samples from materials supplied by SRNL. In the event that certain test methods for quantifying advancing fronts of both sulfate (sulfur) and aluminate (aluminum) in concrete (which already contain significant concentrations of $\mathrm{S}$ and $\mathrm{Al}$ ) are determined to involve the use of radio tracers, a joint work scope with SRNL should also be prepared for the proposal.

\section{Task 6. Characterize MCU Saltstone and predict durability.}

Prepare MCU saltstone samples and measure properties that are required to run the STADIUM code. Predict the durability of saltstone exposed to infiltrating water.

\section{Task 7. Final Report.}

A draft final report is due on August 15, 2008.

A final reviewed and accepted report is due on September 30, 2008.

Data and modeling runs performed after September 30, 2008 will be submitted in Revisions of the final report within one month after being generated. 
SRNS-STI-2008-00477 Revision 0

July 30, 2009

Page A2-1

\subsection{ATTACHMENT 2}

Characterization of a Saltstone Mixture

Subcontract No. AC48992N Task 6 Report 
SRNS-STI-2008-00477 Revision 0 July 30, 2009

Page A2-2

\section{BLANK PAGE}




\section{0 \\ SI MCO \\ Technologies inc.}

\section{SIMCO Report}

See separate file 


\section{0 \\ SIMCO \\ Technologies inc.}

\section{Washington Savannah River Company}

Subcontract no. AC48992N

Report

Task 6 - Characterization of a Saltstone mixture

July 29, 2009

Prepared by:

SIMCO Technologies Inc.

203-1400 Boul. du Parc-Technologique

Quebec QC G1P 4R7

Canada

(418) 656-0266 tel | (418) 656-6083 fax 
LIMITED LIABILITY STATEMENT: THIS REPORT IS FOR THE EXCLUSIVE USE OF SIMCO'S CLIENT AND IS PROVIDED ON AN “AS IS” BASIS WITH NO WARRANTIES, IMPLIED OR EXPRESSED, INCLUDING, BUT NOT LIMITED TO, WARRANTIES OF MERCHANTABILITY AND FITNESS FOR A PARTICULAR PURPOSE, WITH RESPECT TO THE SERVICES PROVIDED. SIMCO ASSUMES NO LIABILITY TO ANY PARTY FOR ANY LOSS, EXPENSE OR DAMAGE OCCASIONED BY THE USE OF THIS REPORT. ONLY THE CLIENT IS AUTHORIZED TO COPY OR DISTRIBUTE THIS REPORT AND THEN ONLY IN ITS ENTIRETY. THE ANALYSIS, RESULTS AND RECOMMENDATIONS CONTAINED IN THIS REPORT REFLECT THE CONDITION OF THE SAMPLES TESTED EXCLUSIVELY, WHICH WERE MANUFACTURED FROM MATERIALS PROVIDED TO SIMCO BY THE CLIENT OR BY THIRD PARTIES. THE REPORT'S OBSERVATIONS AND TEST RESULTS ARE RELEVANT ONLY TO THE SAMPLES TESTED AND ARE BASED ON IDENTICAL TESTING CONDITIONS. FURTHERMORE, THIS REPORT IS INTENDED FOR THE USE OF INDIVIDUALS WHO ARE COMPETENT TO EVALUATE THE SIGNIFICANCE AND LIMITATIONS OF ITS CONTENT AND RECOMMENDATIONS AND WHO ACCEPT RESPONSIBILITY FOR THE APPLICATION OF THE MATERIAL IT CONTAINS.

THE STADIUM $^{\circledR}$ MODEL IS A HELPFUL TOOL TO PREDICT THE FUTURE CONDITIONS OF CONCRETE MATERIALS. HOWEVER, ALL DURABILITY-MODELING PARAMETERS HAVE A STATISTICAL RANGE OF ACCEPTABLE RESULTS. THE MODELING USED IN THIS REPORT USES MEAN LABORATORY- OR FIELD-DETERMINED SINGLE VALUES AS INPUT PARAMETERS. THIS PROVIDES A SINGLE RESULT, WHICH PROVIDES A SIMPLE ANALYSIS EVALUATING CORROSION PROTECTION OPTIONS. PREVIOUS CONDITIONS ARE ASSUMED TO CARRY FORWARD IN THE PREDICTION MODEL; THERE ARE NO ASSURANCES THAT THE STRUCTURE WILL BE EXPOSED TO A SIMILAR ENVIRONMENT AS IN THE PAST. 


\section{REPORT UPDATE - JULY 2009}

This report includes the latest results obtained on the saltstone paste mixture. These results concern the compressive strength, porosity measurements and migration tests performed on saltstone paste disks hydrated one year in a fog room. The results were updated in Tables 7 (compressive strength), 9 (porosity), 10 (diffusion coefficients) and 12 (summary).

The results indicate that there are no significant changes in the porosity values. However, the migration tests exhibited a significant drop in the measured current values, which translated into a drop in the diffusion coefficients. Although the diffusion coefficient showed a slight drop between 28 and 123 days, the reduction is a lot more significant after 365 days of hydration. These results further emphasize the good durability of this type of material despite its high porosity. 


\section{OBJECTIVE}

The objectives of Task 6 are to measure the transport properties for the saltstone slurry designed by SNRL and to generate data on the leaching behavior of saltstone in contact with water to validate modeling results.

This report is divided as follow: section 2 presents the characteristics of raw materials, section 3 details the formulation of the mixture and the procedures of mixing and curing, and section 4 describes the experiment and gives the results on transport properties. Section 5 concerns the leaching tests performed for this study. Finally, SEM microstructural observations are provided in Appendix A as a complement to section 5 results.

\section{RAW MATERIALS}

This section presents the characteristics of the cements, supplementary cementing materials, and salt solution used to prepare the saltstone mixtures.

The relative density (specific gravity) of binders is useful to calculate the compositions of the mixture. The data are given in Table 1.

Table 1 - Relative density of binders

\begin{tabular}{cccc}
\hline & $\begin{array}{c}\text { Type I/II } \\
\text { cement } \\
\text { Lafarge }\end{array}$ & GGBFS & $\begin{array}{c}\text { Class F } \\
\text { Fly Ash } \\
\text { SEFA }\end{array}$ \\
\hline $\begin{array}{c}\text { Relative } \\
\text { Density }\end{array}$ & 3.271 & 2.990 & 2.355 \\
\hline
\end{tabular}

The chemical composition of binders is an input of the chemical equilibrium code in STADIUM $^{\circledR}$. It is used to estimate the initial mineral content of hydrated paste. Data are given in Table 2. They were evaluated using the X-ray fluorescence technique. 
Table 2 - Chemical composition of binders (\%)

\begin{tabular}{cccc}
\hline Oxides & $\begin{array}{c}\text { Type I/II } \\
\text { cement } \\
\text { Lafarge }\end{array}$ & GGBFS & $\begin{array}{c}\text { Class F } \\
\text { Fly Ash } \\
\text { SEFA }\end{array}$ \\
\hline $\mathrm{CaO}$ & 64.3 & 35.8 & 1.41 \\
$\mathrm{SiO}_{2}$ & 21.0 & 39.1 & 53.1 \\
$\mathrm{Al}_{2} \mathrm{O}_{3}$ & 4.91 & 10.1 & 28.4 \\
$\mathrm{Fe}_{2} \mathrm{O}_{3}$ & 3.50 & 0.36 & 7.99 \\
$\mathrm{SO}_{3}$ & 2.64 & 1.99 & $<0.10$ \\
$\mathrm{MgO} \mathrm{O}$ & 0.95 & 12.6 & 1.00 \\
$\mathrm{~K}_{2} \mathrm{O}$ & 0.37 & 0.27 & 2.99 \\
$\mathrm{Na}_{2} \mathrm{O}$ & 0.09 & 0.22 & 0.44 \\
$\mathrm{LOI}$ & 1.32 & 0 & 2.39 \\
\hline
\end{tabular}

\section{MiXTure}

\subsection{Saltstone mixture}

The mix design of the saltstone slurry was provided by SNRL. The solution for mixing with premix blend of saltstone was prepared following the composition presented in Table 3.

Table 3 - Product content for saltstone mixing solution

\begin{tabular}{c|c|c|c|c|}
\hline Chemicals & M.M. & $\begin{array}{c}(\mathrm{mmol} / \mathrm{L} \\
\text { of DI water })\end{array}$ & $\begin{array}{c}(\mathrm{g} / \mathrm{L} \\
\text { of DI water })\end{array}$ & $\begin{array}{c}\text { (mmol/L } \\
\text { of solution) }\end{array}$ \\
\hline \hline $\mathrm{NaOH}$ & 39.99734 & 1590 & 63.6 & 1381 \\
\hline $\mathrm{NaNO}_{3}$ & 84.9949 & 3160 & 268.58 & 2745 \\
\hline $\mathrm{NaNO}_{2}$ & 68.9955 & 370 & 25.53 & 321 \\
\hline $\mathrm{Na}_{2} \mathrm{CO}_{3}$ & 105.9889 & 180 & 19.08 & 156 \\
\hline $\mathrm{Na}_{2} \mathrm{SO}_{4}$ & 142.0426 & 60 & 8.52 & 52 \\
\hline $\mathrm{Al}_{3}\left(\mathrm{NO}_{3}\right)_{3}\left(9 \mathrm{H}_{2} \mathrm{O}\right)$ & 429.09522 & 50 & 21.45 & 43 \\
\hline $\mathrm{Na}_{3} \mathrm{PO}_{4}\left(12 \mathrm{H}_{2} \mathrm{O}\right)$ & 388.124721 & 10 & 3.8 & 9 \\
\hline $\mathrm{TOTAL}$ & & 410.56 & \\
\hline
\end{tabular}


The salt solution was prepared one day before batching. All of the ingredients were dissolved during the mixing. The relative density of the solution at $24^{\circ} \mathrm{C}$ was 1.2235 .

Table 4 - Saltstone slurry formulation

\begin{tabular}{|c|c|c|c|}
\hline \multirow[t]{2}{*}{ Raw materials } & & \multicolumn{2}{|c|}{ Formulation } \\
\hline & & $\left(\mathrm{kg} / \mathrm{m}^{3}\right)$ & $\left(\mathrm{lb} / \mathbf{y d} \mathbf{d}^{3}\right)$ \\
\hline Type I/II cement & Lafarge & 135 & 230 \\
\hline GGBFS & Holcim & 195 & 330 \\
\hline Class F Fly Ash & SEFA & 600 & 1015 \\
\hline Salt solution & & 780 & 1320 \\
\hline DI water & & 553 & 935 \\
\hline Salt & & 227 & 385 \\
\hline $\mathrm{w} / \mathrm{b}$ & & 0.595 & 0.595 \\
\hline
\end{tabular}

Table 4 gives the saltstone slurry formulation. A special procedure for mixing and casting samples of the saltstone slurry was applied based on ASTM C938 - 02 Standard Practice for proportioning grout mixture for preplaced-aggregate concrete as follow:

- The 3 solid binders were premixed. The materials needed for a batch of ten liters were weighted and transferred into a 5-gallon plastic bucket. The container was shaken to mix the ingredients.

- The solution was weighed into a mixing container (5-gallon plastic bucket).

- The premixed blend was poured in less than 1 minute while stirring using a helicoid impeller.

- $\quad$ The mixing of the slurry lasted 5 minutes. It was then poured into plastic cylinders (4 in. diameter, 8 in. length) and into 2 -in. cubic molds.

Table 5 presents the properties of the fresh saltstone slurry. Four batches of ten liters ( 0.35 cubic foot) provided four sets of six cylinders and three cubic specimens. 
Table 5 - Properties of fresh saltstone slurry

\begin{tabular}{c|c}
\hline Properties & Values \\
\hline \hline Unit Weigth $\left(\mathrm{kg} / \mathrm{m}^{3}\right)$ & 1680 \\
$\left(\mathrm{lb} / \mathrm{ft}^{3}\right)$ & 105 \\
\hline Relative Yield $\left(\mathrm{ft}^{3} / \mathrm{yd}^{3}\right)$ & 27.6 \\
\hline
\end{tabular}

For the initial curing phase, the samples were kept in molds and placed under a plastic sheet in the laboratory. A wet burlap was placed beside the samples under the plastic sheet to maintain high RH conditions. When the slurry was set, the molds were covered with a wet burlap without marring the top surface of the material and placed under a plastic sheet. After three days, the molds (cylinders and cubes) were sealed in plastic bags and placed in a moist room $(100 \% \mathrm{RH})$.

The cubic samples for compressive strength were demolded after five days. Each specimen was wrapped in a plastic film, put into a sealed plastic bag and stored in a moist room until testing.

\subsection{Initial solid phases}

Using the concrete formulations and the chemical composition of the cementitious materials, it is possible to estimate the mineral composition of the hydrated cement paste. The approach proposed by SIMCO Technologies inc. assumes that the hydrated cement paste is composed of the following phases: C-S-H, portlandite, monosulfate (sulfate $\mathrm{AFm}$ ) and $\mathrm{C}_{4} \mathrm{AH}_{13}$ (hydroxy-AFm). The calculation is based on the total amount of calcium, silica, alumina and sulfur available to participate in the hydration process. This amount is the sum of the contribution of each component of the binder (cement, fly ash, slag, etc.), weighted by their hydration degree. However, it is assumed that the total amount of $\mathrm{SO}_{3}$ contributes to the hydration process due to its high solubility. 
Once the total amount of calcium, silica, alumina, and sulfur is known, the various phases of the hydrated binder are calculated as follow:

- The amount of monosulfate is based on the $\mathrm{SO}_{3}$ content, which removes calcium and alumina from the total amount.

- The amount of C-S-H is based on the silica content, if there is enough calcium left. If not, the remaining calcium is used to form C-S-H and no portlandite and $\mathrm{C}_{4} \mathrm{AH}_{13}$ are present.

- Depending on the amount of calcium and alumina remaining, $\mathrm{C}_{4} \mathrm{AH}_{13}$ is formed.

- The remaining amount of calcium is used to calculate the initial portlandite content.

The initial solid phases were calculated using the binder chemical compositions and the mixture formulation presented previously (Tables 2 and 4). The results, expressed in mass of mineral per total mass of material, are given in Table 6. Although the method is approximate and cannot reproduce the complexity of the hydration process, the results are compared favorably with other methods presented in research papers ${ }^{12}$.

Table 6 - Initial solid phases in the saltstone mixture

\begin{tabular}{cc}
\hline Properties & Saltstone \\
\hline Hydration (\%) & \\
Cement & 0.85 \\
Slag & 0.70 \\
Fly Ash & 0.50 \\
Mineral phases (g/kg) & \\
C-S-H & 140.9 \\
Portlandite & 0.0 \\
Monosulfate & 39.0 \\
$\mathrm{C}_{4} \mathrm{AH}_{13}$ & 0.0 \\
\hline
\end{tabular}

\footnotetext{
${ }^{1}$ Nielsen, EP Herfort, D Geiker, MR 2005, 'Phase equilibria of hydrated Portland cement', Cement and Concrete Research, no. 35, pp. 109-115.

${ }^{2}$ Papadakis, VG 1999, 'Experimental investigation and theoretical modeling of silica fume activity in concrete', Cement and Concrete Research, no. 29, pp. 76-86.
} 


\section{Properties Measurements}

The hydrated saltstone cylinders were kept in their molds sealed in plastic bag and stored in a fog room until testing. At a given testing time, the needed amount of cylinders was demolded. The test samples were cut from cylinders using water for safety concern. The cut specimens were kept in sealed bags right after sawing in order to maintain the saturated condition.

The transport properties that were evaluated are:

- Porosity: evaluated on the basis of the ASTM C642 standard procedure: Standard Test Method for Density, Absorption and Voids in Hardened Concrete. The analysis was modified to take into account the density of thesalt solution in the pores.

- Diffusion coefficients: evaluated on the basis of migration test results, which is a modified version of the ASTM C1202 procedure: Standard Test Method for Electrical Indication of Concrete's Ability to Resist Chloride Ion Penetration.

- Water diffusivity: evaluated from the results of drying tests.

- Adsorption-desorption isotherms: evaluated from small disks equilibrated in boxes maintained at specific RH using saturated salt solutions.

The test procedures to evaluate the diffusion coefficients and water diffusivity are described in the Task 5 report.

\subsection{Compressive strength}

Compressive strength was tested based on ASTM C109 Standard Test Method for Compressive Strength of Hydraulic Cement Mortars (Using 2-in. or [50-mm] Cube 
Specimens). Three cubic specimens were tested for compressive strength. Table 7 presents the results of compressive strength for saltstone slurry.

Table 7 - Compressive strength for saltstone slurry

\begin{tabular}{|c|c|c|}
\hline & average & $\mathrm{CV}(\%)^{1}$ \\
\hline $\begin{array}{c}\mathrm{f}_{\mathrm{c}} \text { 7d (MPa) } \\
(\mathrm{psi})\end{array}$ & $\begin{array}{l}2.1 \\
300\end{array}$ & 7.4 \\
\hline $\begin{array}{c}\mathrm{f}_{\mathrm{c}} 28 \mathrm{~d}(\mathrm{MPa}) \\
(\mathrm{psi})\end{array}$ & $\begin{array}{l}3.2 \\
460\end{array}$ & 6.3 \\
\hline $\begin{array}{c}\mathrm{f}_{\mathrm{c}} 123 \mathrm{~d}(\mathrm{MPa}) \\
(\mathrm{psi})\end{array}$ & $\begin{array}{l}4.0 \\
580\end{array}$ & 7.2 \\
\hline $\begin{array}{c}\mathrm{f}_{\mathrm{c}} 365 \mathrm{~d}(\mathrm{MPa}) \\
(\mathrm{psi})\end{array}$ & $\begin{array}{l}5.3 \\
770 \\
\end{array}$ & 3.9 \\
\hline
\end{tabular}

(1) Coefficient of variation obtained on three cubic specimens

The average compressive strength at twenty-eight days for saltstone slurry was only 460 psi. Moreover, the cohesion of the saltstone was very weak. However, the strength kept increasing after twenty-eight days.

\subsection{Chemical composition of expressed pore fluids}

Data concerning the pore solution chemistry of concrete is required to determine the diffusion coefficients and to simulate the long-term evolution of material exposed to various exposure conditions. Accordingly, pore solution extractions were made on the saltstone mixture at different curing ages. Similar to the other tests, the specimens for pore solution extraction were sawn from cylinders sealed in plastic bags. Samples were broken in small pieces, placed in a cell, and crushed at a pressure of approximately 3,000 psi (20 MPa). Pore solution analyses were carried out shortly after extraction by Atomic Absorption Analyzer and Ion Chromatography as well as $\mathrm{pH}$ titrator to obtain the contents of the main ions in the pore solution: $\mathrm{OH}^{-}, \mathrm{Na}^{+}, \mathrm{K}^{+}, \mathrm{SO}_{4}{ }^{2-}, \mathrm{Ca}^{2+}, \mathrm{Cl}^{-}, \mathrm{N}$, and $\mathrm{CO}_{3}{ }^{2-}$. Table 8 presents the results of the chemical composition of expressed pore fluids. 
Table 8 - Chemical analyses of pore fluids extracted from the saltstone mixture

\begin{tabular}{|c|c|c|c|c|c|}
\hline \multirow{3}{*}{ Ions } & \multicolumn{3}{|c|}{ 28-days old } & \multirow{2}{*}{\multicolumn{2}{|c|}{$\begin{array}{c}\text { 123-days old } \\
\text { Current Saltstone }\end{array}$}} \\
\hline & \multicolumn{2}{|c|}{ Current Saltstone } & \multirow{2}{*}{$\begin{array}{c}\text { Surrogate } \\
\mathrm{mg} / \mathrm{L}\end{array}$} & & \\
\hline & $\mathrm{mmol} / \mathrm{L}$ & $\mathrm{mg} / \mathrm{L}$ & & $\mathrm{mmol} / \mathrm{L}$ & $\mathrm{mg} / \mathrm{L}$ \\
\hline $\mathrm{OH}^{-}$ & 484.56 & 8,241 & 16,315 & 151.18 & 2,571 \\
\hline $\mathrm{Na}^{+}$ & $4,419.76$ & 101,610 & 85,000 & $3,639.28$ & 83,667 \\
\hline $\mathrm{K}^{+}$ & 119.34 & 4,666 & 7,000 & 141.84 & 5,546 \\
\hline $\mathrm{SO}_{4}{ }^{2-}$ & 120.32 & 11,558 & 25,000 & 139.00 & 13,353 \\
\hline $\mathrm{Ca}^{2+}$ & 0.85 & 34 & 29 & 3.88 & 156 \\
\hline $\mathrm{Cl}^{-}$ & 8.89 & 315 & 1,280 & 11.50 & 408 \\
\hline $\mathrm{N}^{\dagger}$ & $3,575.75$ & 215,978 & 248,000 & $3,153.22$ & 190,471 \\
\hline $\mathrm{CO}_{3}{ }^{2-}$ & 115.48 & 6,930 & 1,000 & 97.49 & 5,850 \\
\hline
\end{tabular}

Note *: from similar saltstone formulation at Penn State University in the mid 1980s,

Note ${ }^{\dagger}$ : nitrogen includes both $\mathrm{NO}_{2}^{-}$and $\mathrm{NO}_{3}{ }^{-}$, the mass $(\mathrm{mg} / \mathrm{L})$ is calculated based on $\mathrm{NO}_{2}$ to $\mathrm{NO}_{3}$ molar ratio similar to the mixing liquid used to batch saltstone (Table 3)

\subsection{Porosity measurements}

The porosity measurements were made based on the ASTM C642 standard procedure: Standard Test Method for Density, Absorption and Voids in Hardened Concrete.

Trial tests showed that samples sawn from cured cylinders lost mass when they were submerged in water or placed in a fog room due to salt leaching. It is impossible to soak samples to improve their saturation without changing the ions composition of the pore solution. Given the highly charged pore solution, this leaching affects the overall mass of the samples. Also, the drying at $110^{\circ} \mathrm{C}$ damaged the saltstone samples. Because of these problems, the procedure needed to be adjusted and the porosity after 28 days of curing could not be measured.

The ASTM C642 procedure was modified as follow. The mass of samples after they were cut from the cylinders became the initial saturated surface dry mass (Mass A, g). Then, 
the saturated sample mass was measured in water (Mass B, g). The dry mass (Mass C, g) was determined from broken samples kept in the oven at $110^{\circ} \mathrm{C}$. The volume $V_{t o t}\left[\mathrm{~cm}^{3}\right]$ of the tested specimens is given by:

$$
V_{\text {tot }}=\text { Mass } A-\text { Mass } B
$$

The mass loss of evaporable water $M_{H 2 O}[\mathrm{~g}]$ is defined as:

$$
\mathrm{M}_{\mathrm{H}_{2} \mathrm{O}}=\text { Mass A-Mass C }
$$

Since the pore solution of saltstone is highly concentrated, the mass of evaporable water is associated to a volume of pore solution, which is not equivalent to the volume of lost water. The mass of the pore solution $M_{\text {sol }}[\mathrm{g}]$ is given by:

$$
M_{\text {sol }}=M_{\mathrm{H}_{2} \mathrm{O}}+M_{\text {salts }}
$$

where $M_{H 20}$ and $M_{\text {salts }}$ are the mass of water and the mass of salts dissolved in the pore solution. The pore solution volume $\left[\mathrm{cm}^{3}\right]$ is then given by:

$$
V_{\text {sol }}=\frac{\left(M_{\mathrm{H}_{2} \mathrm{O}}+M_{\text {salts }}\right)}{d_{\text {sol }}}
$$

where $d_{\text {sol }}$, the density of the pore solution $\left[\mathrm{g} / \mathrm{cm}^{3}\right]$. The mass of salts depends on the ion concentrations and on the pore solution volume:

$$
M_{\text {salts }}=c_{\text {salts }} \times V_{\text {sol }}
$$

where $c_{\text {salts }}$ is the mass of all the salts dissolved in the pore solution per unit volume, expressed in $\left[\mathrm{g} / \mathrm{cm}^{3}\right]$.

The volume of pore solution, i.e. the pore volume, is then given by:

$$
V_{\text {sol }}=\frac{M_{\mathrm{H}_{2} \mathrm{O}}}{d_{\text {sol }}-c_{\text {salts }}}
$$

The porosity of saltstone, expressed in $\left[\mathrm{m}^{3} / \mathrm{m}^{3}\right]$, can then be evaluated by the following equation:

$$
\phi=\frac{V_{s o l}}{V_{t o t}}
$$


where $V_{t o t}$, is the volume of the tested specimen (see Table 9).

As the pore solution is mainly composed of sodium nitrate, it is assumed to be equivalent to a $\mathrm{NaNO}_{3}$ solution. The $\mathrm{NaNO}_{3}$ concentration of this approximated pore solution is set at $4.0 \mathrm{~mol} / \mathrm{L}$, according to the pore solution compositions given in Table 8 . The relative density $d_{\text {sol }}$ for a $4.0 \mathrm{~mol} / \mathrm{L} \mathrm{NaNO}_{3}$ solution is $1.17^{3}$, which is in agreement with the relative density measured on the batching solution (1.22). The concentration $c_{\text {salts }}$ of the $4.0 \mathrm{~mol} / 1 \mathrm{NaNO}_{3}$ solution is equal to $0.34 \mathrm{~g} / \mathrm{cm}^{3}$. The volume of the solution, $V_{\text {sol }}$, is related to the $M_{H 2 O}$ mass loss by the following equation:

$$
\frac{M_{\mathrm{H}_{2} \mathrm{O}}}{V_{\text {sol }}}=0.83 \quad\left(\mathrm{~g} / \mathrm{cm}^{3}\right)
$$

The correlation between mass loss and pore volume filled with evaporable water leads to the porosity of the saltstone mixture. Table 9 gives the results of the porosity tests on the saltstone mixture after curing periods of 82,123 and 365 days of hydration. The porosity evolution, after a curing period of 82 days and 124 days, is negligible.

Table 9 - Porosity of the saltstone mixture

\begin{tabular}{lccccccc}
\hline & & \multicolumn{2}{c}{$\mathbf{8 2}$ days } & \multicolumn{2}{c}{$\mathbf{1 2 3}$ days } & \multicolumn{2}{c}{$\mathbf{3 6 5}$ days } \\
& & $\mathbf{\#}$ & $\mathbf{\# ~ 2}$ & $\mathbf{\# ~ 1}$ & $\mathbf{\# ~ 2}$ & $\mathbf{\# ~ 1}$ & $\mathbf{\# 2}$ \\
\hline Mass A - saturated & $(\mathrm{g})$ & 679.8 & 696.9 & 705.8 & 709.5 & 356.3 & 338.7 \\
Mass B - immersed & $(\mathrm{g})$ & 278.0 & 283.9 & 289.4 & 292.0 & 145.1 & 137.9 \\
Mass C - dried & $(\mathrm{g})$ & 459.1 & 470.6 & 480.7 & 483.1 & 242.3 & 229.9 \\
M $_{\text {H2O }}$ & $(\mathrm{g})$ & 220.7 & 226.3 & 225.1 & 226.4 & 114.0 & 108.8 \\
$\mathrm{~V}_{\text {tot }}$ & $\left(\mathrm{cm}^{3}\right)$ & 401.8 & 413.0 & 416.4 & 417.5 & 211.2 & 200.8 \\
Porosity & $(\%$ vol $)$ & 65.4 & 65.2 & 64.3 & 64.6 & 65.0 & 65.3 \\
\hline
\end{tabular}

\footnotetext{
${ }^{3}$ Handbook of Chemistry and Physics, CRC Press, 1985/86.
} 


\subsection{Migration tests - Diffusion coefficients}

The diffusion coefficients were evaluated on the basis of the migration test, which is a modified version of the ASTM C1202 procedure: Standard Test Method for Electrical Indication of Concrete's Ability to Resist Chloride Ion Penetration. Similar to the standard procedure, a saturated disk of cementitious material is placed between two cells filled with electrolytes. A potential is then applied to the set-up in order to accelerate the diffusion of ions in the sample. The analysis of the migration test results provides the intrinsic diffusion coefficient of each ionic species, defined as:

$$
D_{i}=\tau^{s} D_{i}^{o}
$$

where $\tau^{s}[-]$ is the intrinsic tortuosity of the material and $D_{i}^{o}\left[\mathrm{~m}^{2} / \mathrm{s}\right]$ the diffusion coefficient of the $i^{\text {th }}$ species in freewater. The values in freewater can be found in textbooks ${ }^{4}$.

The method devised by SIMCO Technologies consists in monitoring the intensity of electrical current passed through a cylindrical test specimen during a 15-day testing period. A constant DC potential around 1 Volt was maintained across the specimen by an electrical power supply. A potential of $15-20 \mathrm{~V}$ is usually used for migration tests on concrete samples. But the high porosity and strong concentrations in the pore solution of the salstone samples prompted the use of such a low potential. The upstream cell is filled with a chloride-containing electrolytic solution $(0.5 \mathrm{M} \mathrm{NaCl}$ and $0.3 \mathrm{M} \mathrm{NaOH})$ and connected to the negative electrode, while the downstream cell is filled with a base solution $(0.3 \mathrm{M} \mathrm{NaOH})$ and connected to the positive electrode. The specimens were 100 $\mathrm{mm}$ in diameter and $50 \mathrm{~mm}$ thick. The measured currents are analyzed to provide the

\footnotetext{
${ }^{4}$ See for instance the Handbook of Chemistry and Physics, CRC Press. Values used for this study are (in E$\left.9 \mathrm{~m}^{2} / \mathrm{s}\right): \mathrm{OH}^{-}: 5.27, \mathrm{Na}^{+}: 1.33, \mathrm{~K}^{+}: 1.96, \mathrm{SO}_{4}{ }^{2-}: 1.07, \mathrm{Ca}^{2+}: 0.79, \mathrm{Al}(\mathrm{OH})_{4}^{-}: 0.54, \mathrm{NO}_{3}^{-}: 1.90, \mathrm{NO}_{2}^{-}: 1.16$.
} 
diffusion coefficients by following the method described in Ref. ${ }^{5}$. The analysis requires the initial pore solution (Table 8) and the porosity of the material. The porosity values estimated from the porosity test analysis were used for the analysis (Table 9).

During the migration tests, the solution in the downstream cell was periodically measured to determine $\mathrm{Cl}^{-}$and $\mathrm{OH}^{-}$concentrations to verify that the boundary conditions are constant. However, the measurements showed a regular decrease of the $\mathrm{OH}^{-}$ concentration in the downstream cell from $300 \mathrm{mmol} / \mathrm{L}$ down to $100 \mathrm{mmol} / \mathrm{L}^{6}$ (Figure 1). This concentration drop may be explained by the migration of $\mathrm{NO}_{3}{ }^{-}$in the downstream cell. By increasing the negative charge in the downstream cell, $\mathrm{NO}_{3}{ }^{-}$ions may have forced the diffusion of $\mathrm{OH}^{-}$in the material to maintain electroneutrality. Chemical reactions involving $\mathrm{OH}^{-}$at the positive electrode may also have occurred as a result of the strong influx of $\mathrm{NO}^{-}$from the test specimen.

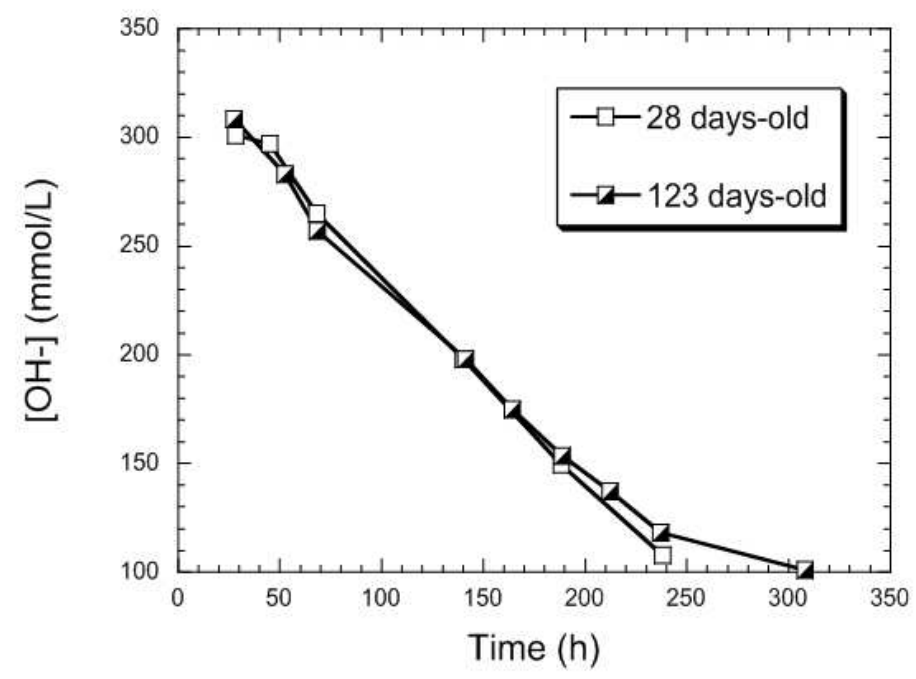

\section{Figure 1 - Measured $\mathrm{OH}^{-}$concentration in downstream cell during migration tests at 28 days and 123 days.}

\footnotetext{
${ }^{5}$ Samson, E Marchand, J Henocq, P, Beausejour, P May 2008, 'Recent advances in the determination of ionic diffusion coefficients using migration test results', Int. RILEM Symp. on Concrete ModellingCONMOD08, vol. 26-28 (Delft, The Netherlands), pp. 65-78.

${ }^{6}$ The concentration dropped to $150 \mathrm{mmol} / \mathrm{L}$ during the one-year migration tests. The current were analyzed accordingly.
} 
The influence of this drop is investigated by simulating the migration test with a constant $\mathrm{OH}^{-}$concentration in the downstream cell equal to $100 \mathrm{mmol} / \mathrm{L}$ and $300 \mathrm{mmol} / \mathrm{L}$. These two simulated curves, identified by symbols * and ** respectively on Figure 3, are assumed to encompass the $\mathrm{OH}^{-}$evolution during the test. The measured currents after 28 , 123 and 365 days are presented in Figures 2. A small drop of the current values is observed between 28 and 123 days. A much more important reduction of the current can be seen at 365 days. This translates into a significant reduction of the diffusion coefficients. The simulation results are presented on Figure 3. The simulations demonstrate a reliable correlation with the experimental current evolutions. Diffusion coefficients $D_{\mathrm{OH}}=7.5 \mathrm{E}-11 \mathrm{~m} / \mathrm{s}, \quad \mathrm{D}_{\mathrm{OH}}=7.0 \mathrm{E}-11 \quad \mathrm{~m}^{2} / \mathrm{s} \quad$ and $\quad \mathrm{D}_{\mathrm{OH}}=2.5 \mathrm{E}-11 \mathrm{~m}^{2} / \mathrm{s}$ are respectively estimated at 28, 123 and 365 days (Table 10), which corresponds to tortuosity values of $0.0142,0.0133$ and 0.00474 . The 365 -days results indicate that the hydration of the material has a strong impact on the transport properties.

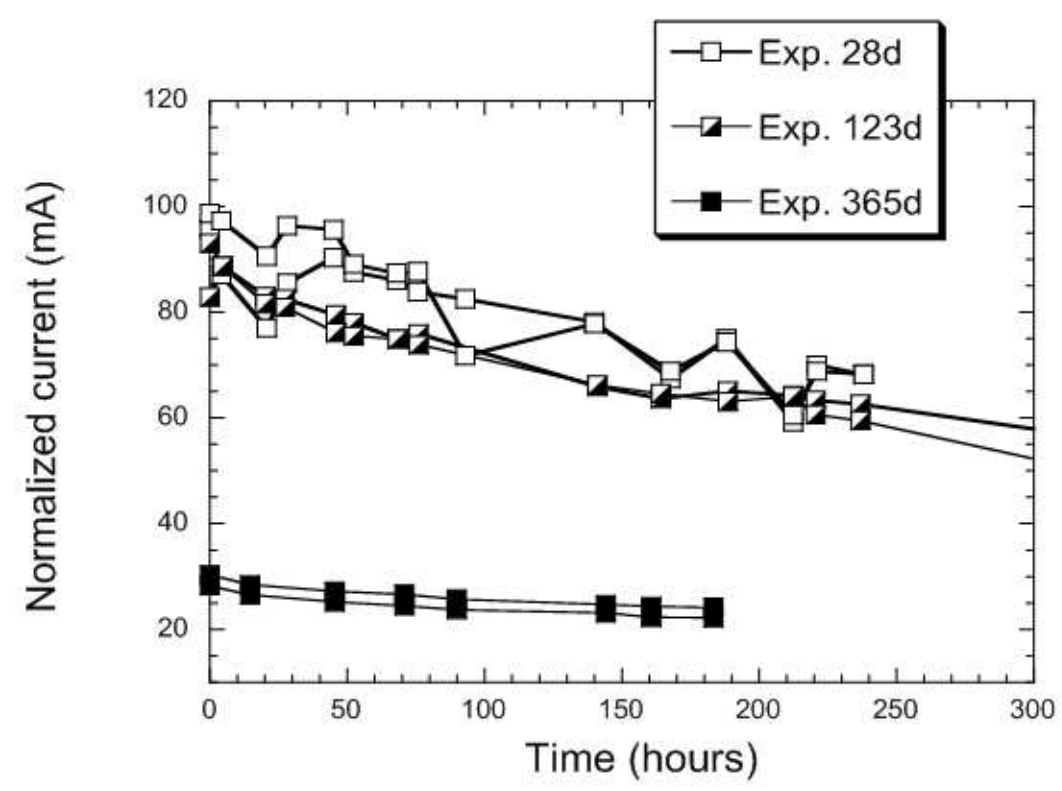

Figure 2 - Currents measured during the migration tests. The values were normalized to take into account the small variations in potential used during the different tests. 


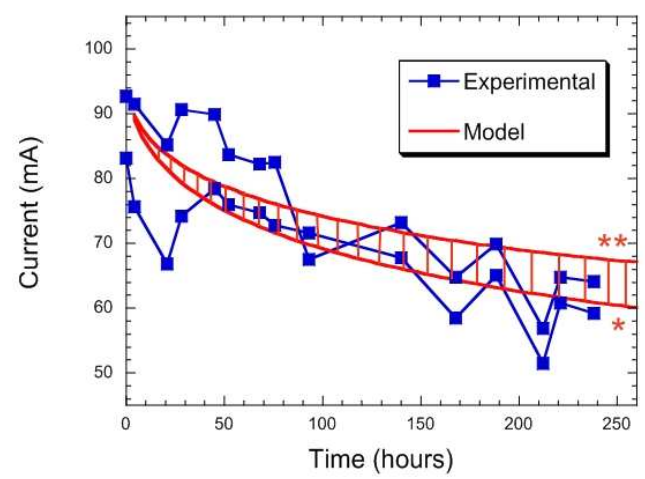

a) 28 days

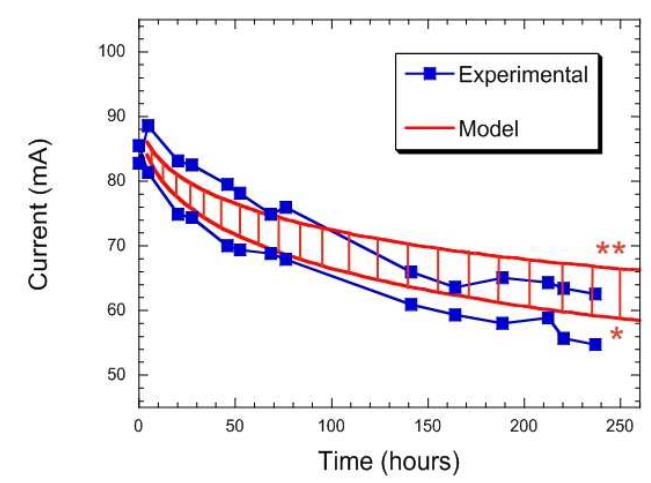

b) 123 days

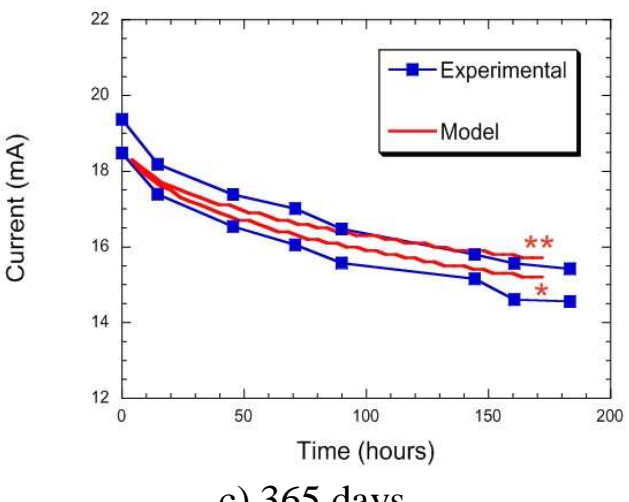

c) 365 days

Figure 3 - Numerical analysis of the migration tests.

The symbols * and ** denotes the $\mathrm{OH}^{-}$concentration in the downstream cell used to simulate: 100 and $300 \mathrm{mmol} / \mathrm{L}$ respectively

Table 10- Migration test results

\begin{tabular}{cccc}
\hline Species & \multicolumn{3}{c}{$\begin{array}{c}\text { Diffusion coefficients }\left(\mathbf{E}-11 \mathbf{~ m}^{2} / \mathbf{s}\right) \\
\text { Material hydration } \\
\mathbf{1 2 3 d}\end{array}$} \\
\hline $\mathrm{OH}^{-}$ & $\mathbf{2 8 d}$ & 7.00 & $\mathbf{3 6 5 d}$ \\
$\mathrm{Na}^{+}$ & 7.50 & 1.77 & 2.50 \\
$\mathrm{~K}^{+}$ & 1.90 & 2.60 & 0.63 \\
$\mathrm{SO}_{4}^{2-}$ & 2.78 & 1.41 & 0.93 \\
$\mathrm{Ca}^{2+}$ & 1.51 & 1.05 & 0.51 \\
$\mathrm{Al}(\mathrm{OH})_{4}^{-}$ & 1.13 & 0.72 & 0.38 \\
$\mathrm{Cl}^{-}$ & 0.77 & 2.70 & 0.26 \\
\hline Tortuosity & 2.89 & $1.33 \mathrm{E}-02$ & 0.96 \\
\hline
\end{tabular}


The diffusion coefficient values at 28 days and 123 days are very close, as mentioned previously. The diffusion coefficient usually decreases as the hydration process evolves. The function $H(t)$ characterizes this evolution of the diffusion coefficient value:

$$
H(t)=\frac{a}{1+(a-1) e^{-\alpha\left(t-t^{\mathrm{ref}}\right)}}
$$

where $t^{\text {ref }}$ is a reference time; $t^{\text {ref }}=28$ days in this case. The parameter $a$, represents the fraction of the diffusion coefficient at 28 days when the hydration process is completed $(t \rightarrow \infty)$, and $\alpha[1 / \mathrm{s}]$ provide the rate of hydration. For the saltstone slurry, the hydration parameters are: $a=0.3$ and $\alpha=0.003 \mathrm{~s}^{-1}$.

It is important to note that most values of diffusion coefficients found in the literature (see for instance reference ${ }^{7}$ ) are apparent diffusion coefficients, which hide the effect of the chemical reactions between the pore solution and the hydrated paste and to a lesser extent of the effect of the boundary conditions, within $D_{i}$. As mentioned previously, the diffusion coefficients estimated in this study are only a function of the material microstructure, which is characterized by the intrinsic tortuosity. In STADIUM $^{\circledR}$, the chemical reactions are considered in a separate module. As discussed in reference ${ }^{8}$, the apparent diffusion coefficient is highly dependent on the test conditions from which it was evaluated. Using it to model ionic transport with other materials and boundary conditions causes erroneous durability predictions.

\footnotetext{
${ }^{7}$ Leng F., Feng N., Lu X., An experimental study on the properties of resistance to diffusion of chloride ions of fly ash and blast furnace slag concrete, Cement and Concrete Research 30 (2000) 989-992.

${ }^{8}$ Marchand J., Samson E., Predicting the service-life of concrete - Limitations of simplified models, Canadian Conf. on Effective Design of Structures II, May 20-23, McMaster Univ. (Canada), 2008. To be published in a special issue of Cement and Concrete Composites.
} 


\subsection{Moisture storage - Desorption/adsorption tests}

The estimation of the permeability, discussed in the next section, requires the evaluation of the moisture capacity of cementitious mixtures. This material characteristic, also called desorption/adsorption isotherms, provides the water content in the material as a function of the external relative humidity for an equilibrium state.

Tests for desorption and adsorption isotherms were performed on 1-cm samples cut from cylinders after 28 days of hydration in a mold kept in sealed plastic bags. The cut samples were then stored in sealed bags. The tests were delayed due to uncertainty about conditioning procedure. They were started after 123 days of hydration. All thin samples (i.e. $4.5 \mathrm{~kg}$ of saltstone materials) were immersed in $1.7 \mathrm{~L}$ of DI water until mass equilibrium. The mass loss of saltstone samples, due to the leaching of salts, was about $3.5 \%$ from the initial mass. Water was not changed until mass equilibrium, which was reached after one week. At this time, the $1.7-\mathrm{L}$ solution reached a $\mathrm{pH}$ of 12.4 at $19.3^{\circ} \mathrm{C}$.

For desorption tests, the thin samples were distributed in different RH-controlled boxes: $11.3 \%, 33.1 \%, 54.4 \%, 75.5 \%, 85.1 \%, 91.0 \%, 94.6 \%$, and $97.3 \%$. The relative humidity level in each box was controlled by a specific saturated salt solution (Table 11). Five disks per RH level were prepared.

Thin samples were also conditioned for adsorption tests. They were placed in a $40^{\circ} \mathrm{C}$ chamber to reduce their water content level prior to adsorption. However, this conditioning method proved unsuited for that material since the samples broke into small pieces. Other conditioning methods are being considered for this portion of the work.

The preliminary desorption results after two months in the $\mathrm{RH}$ boxes are presented in Table 11. Figure 4 shows the correlations between water content and $\mathrm{RH}$ after two months of desorption. Each data is the average of five separate mass measurements. 
Table 11 - Water content Desorption isotherms after 2 months in RH-controlled boxes (preliminary results)

\begin{tabular}{|c|c|c|c|}
\hline \multirow[t]{2}{*}{ Salt } & \multirow{2}{*}{$\begin{array}{c}\text { RH } \\
(\%)\end{array}$} & \multicolumn{2}{|c|}{$\begin{array}{c}\text { Water content } \\
\left(\mathrm{m}^{3} / \mathrm{m}^{3} \text { of concrete }\right)\end{array}$} \\
\hline & & Average $^{1}$ & $\mathrm{CV}^{1}(\%)$ \\
\hline $\mathrm{H}_{2} \mathrm{O}^{2}$ & 100.0 & $0.65^{2}$ & $\mathrm{~N} / \mathrm{A}$ \\
\hline $\mathrm{K}_{2} \mathrm{SO}_{4}$ & 97.3 & 0.647 & 0.2 \\
\hline $\mathrm{KNO}_{3}$ & 94.6 & 0.537 & 0.4 \\
\hline $\mathrm{BaCl}_{2} \cdot 2 \mathrm{H}_{2} \mathrm{O}$ & 91.0 & 0.431 & 2.6 \\
\hline $\mathrm{KCl}$ & 85.1 & 0.331 & 1.2 \\
\hline $\mathrm{NaCl}$ & 75.5 & 0.242 & 0.8 \\
\hline $\mathrm{Mg}\left(\mathrm{NO}_{3}\right)_{2} .6 \mathrm{H}_{2} \mathrm{O}$ & 54.4 & 0.171 & 1.8 \\
\hline $\mathrm{MgCl}_{2} .6 \mathrm{H}_{2} \mathrm{O}$ & 33.1 & 0.119 & 1.7 \\
\hline $\mathrm{LiCl} . \mathrm{H}_{2} \mathrm{O}$ & 11.3 & 0.079 & 1.3 \\
\hline
\end{tabular}

Note 1: determined on 5 thin samples for a total concrete volume of about $150 \mathrm{~cm}^{3}$. Note 2: Porosity from section 4.3.
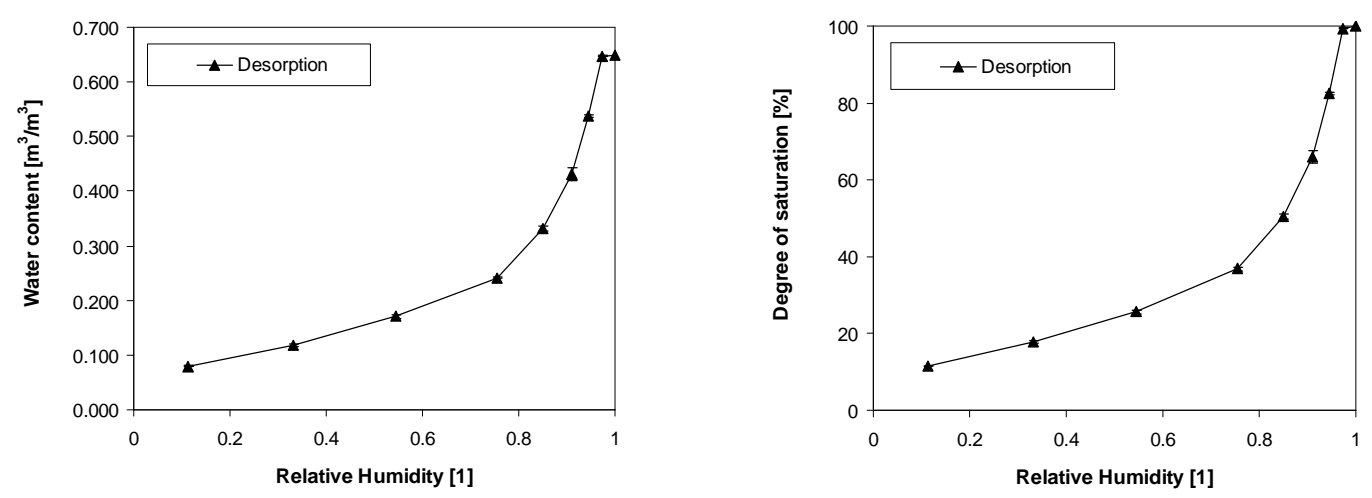

Figure 4 - Desorption isotherms after 2 months in RH-controlled boxes 


\subsection{Drying tests - Moisture diffusivity}

Drying tests were performed to determine the water diffusivity parameters of the saltstone mixture. These parameters are used to model the water movement in unsaturated cementitious materials. Six samples (three $10-\mathrm{mm}$ samples and three $50-\mathrm{mm}$ samples) were cut from two cylinders after 28 days of hydration in a mold kept in sealed plastic bags. They were coated with silicon and placed in a 50\% RH chamber. The mass loss for both sample thicknesses is monitored over time. The analysis of the mass loss curves provided the empirical water diffusivity $D_{w}=A e^{B w}$ based on the method described in reference ${ }^{9}$. It consists in adjusting $A$ and $B$ to reproduce the measured mass loss during the drying test. The mass loss is modeled according to Richards' model:

$$
\frac{\partial w}{\partial t}-\operatorname{div}\left(A e^{B w} \operatorname{grad}(w)\right)=0
$$

where $\mathrm{w}$ is the volumetric water content $\left[\mathrm{m}^{3} / \mathrm{m}^{3}\right]$.

The measured mass losses are presented in Figure 5 along with the simulation results. The analysis gave $A=92 \mathrm{E}-14 \mathrm{~m}^{2} / \mathrm{s}$ and $B=10$, which corresponds to $D_{w}=6.1 \mathrm{E}-10 \mathrm{~m}^{2} / \mathrm{s}$ at saturation $(w=\phi)$. The simulations were performed with the porosity determined in section 4.3 (Table 9).

\footnotetext{
${ }^{9}$ Samson E., Maleki K., Marchand J., Zhang T., Determination of the water diffusivity of concrete using drying/absorption test results, Journal of ASTM Int. 5 (2008) JAI101322.
} 


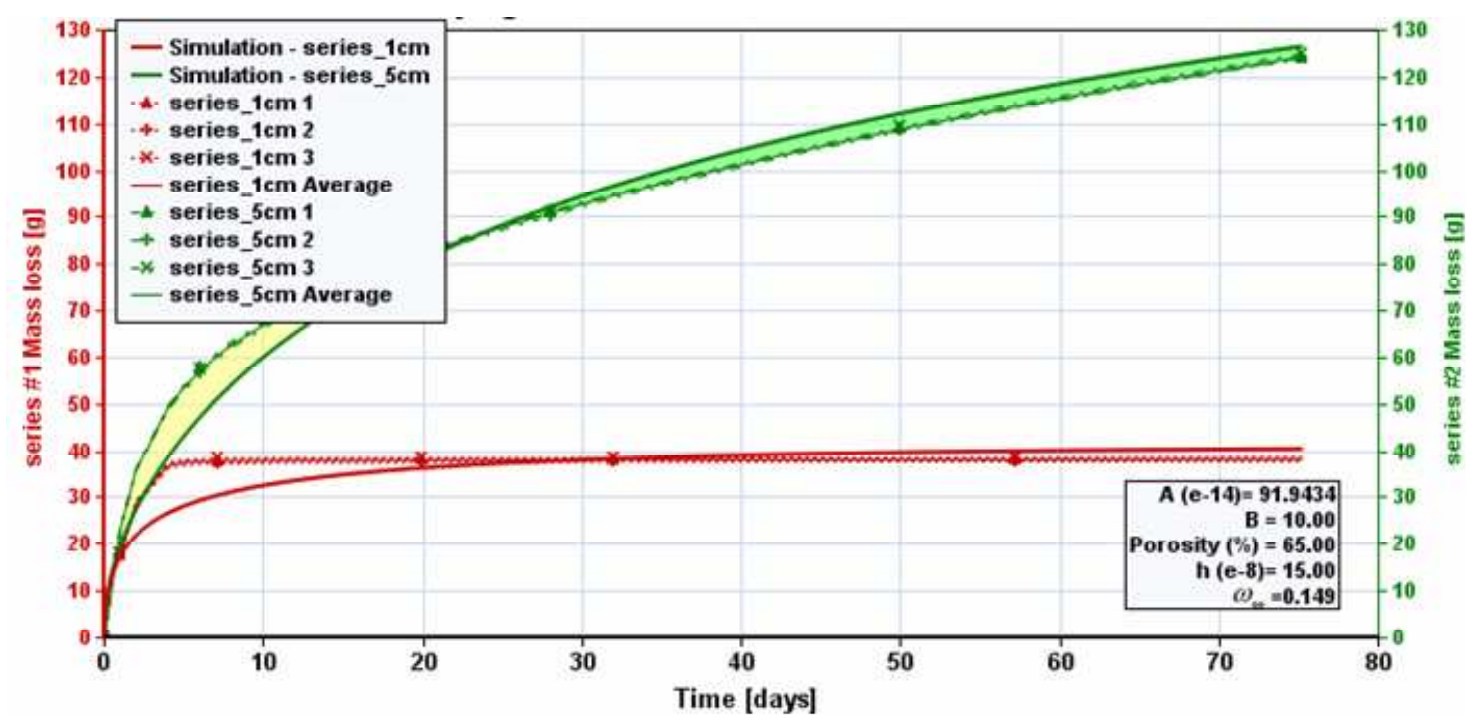

Figure 5 - Measured mass losses and simulation results of drying test for saltstone mixture

The simulation fits well the experimental curve after 10 weeks of drying. Initial measurements may be sensitive to the test setup. Accordingly, we favored the fitting of the mass loss curves on the long term range rather than the period close to the starting point.

In the second approach, the drying test results were used to estimate the intrinsic permeability of the concrete mixtures. The mass loss profiles were reproduced using a moisture transport model that separately considers the liquid and water vapor transport. It is assumed that the liquid flow $\mathbf{v}_{\mathbf{l}}$ follows Darcy's law:

$$
\mathbf{v}_{\mathbf{l}}=-\frac{k_{l}}{\mu} \operatorname{grad}\left(p_{l}\right)
$$

where $k_{l}$ is the permeability [ $\left.\mathrm{m}^{2}\right]$. It can be partitioned according to $k_{l}=k_{r} k_{s}$, where $k_{r}$ is the relative permeability and $k_{s}$ the intrinsic permeability. The water vapor flow $\mathrm{v}_{\mathrm{v}}$ follows the generalized Fick's law of diffusion: 


$$
\mathbf{v}_{\mathbf{v}}=-D_{v} \operatorname{grad}\left(\frac{\rho_{v}}{\rho_{g}}\right)
$$

where the diffusion coefficient $D_{v}\left[\mathrm{~m}^{2} / \mathrm{s}\right]$ can also be partitioned according to $D_{v}=\tau D_{v}^{o}$, where $\tau$ is the tortuosity and $D_{v}{ }^{o}$ the water vapor self-diffusion coefficient. These two expressions can be combined into a single mass conservation equation to yield:

$$
\frac{\partial w}{\partial H} \frac{\partial H}{\partial t}-\operatorname{div}\left([\underbrace{\frac{\rho_{L} R T}{M_{w} \mu} k_{s} S^{n} \frac{1}{H}}_{\text {liquid contribution }}+\underbrace{D_{v}^{o} \tau_{s}(1-S)^{7 / 3}\left(\frac{M_{w}}{\rho_{L} R T}\right) p_{v}^{s}}_{\text {water vapor contribution }}] \operatorname{grad}(H)\right)=0
$$

where $w\left[\mathrm{~m}^{3} / \mathrm{m}^{3}\right]$ is the volumetric water content, $H[1]$ is the relative humidity, $S$ [1] the saturation, $k_{s}\left[\mathrm{~m}^{2}\right]$ the intrinsic permeability of the material, $\tau_{s}[1]$ the intrinsic tortuosity (estimated from the migration tests), $\mu[\mathrm{Pa} . \mathrm{s}]$ the dynamic viscosity of the liquid phase, $\rho_{l}$ [Pa] the density of the liquid phase, $M_{w}[0.018 \mathrm{~kg} / \mathrm{mol}]$ the molar mass of water, $R$ the ideal gas constant $\left[8.3143 \mathrm{~J} / \mathrm{mol} /{ }^{\circ} \mathrm{K}\right], T$ the temperature $\left[{ }^{\circ} \mathrm{K}\right], D_{v}^{o}\left[\mathrm{~m}^{2} / \mathrm{s}\right]$ the water vapor self-diffusion coefficient and $p_{v}{ }^{s}[\mathrm{~Pa}]$ the saturation vapor pressure. The term $\partial w / \partial H$ is estimated from the desorption results obtained in section 4.5. The correlation presented in Figure 6 is given by Bleasdale's relationship:

$$
w(H)=\frac{1}{\left(\frac{1}{\phi^{c}}-b+b H\right)^{\frac{1}{c}}}
$$

where $b$ and $c$ are the fitting parameters. The analysis gave $b=-4.3$ and $c=0.64$. The water content $\left(\omega_{\infty}\right)$ of the $1-\mathrm{cm}$ samples, when their mass is stable at $50 \% \mathrm{RH}$, correlate with the desorption results (Figure 6). 


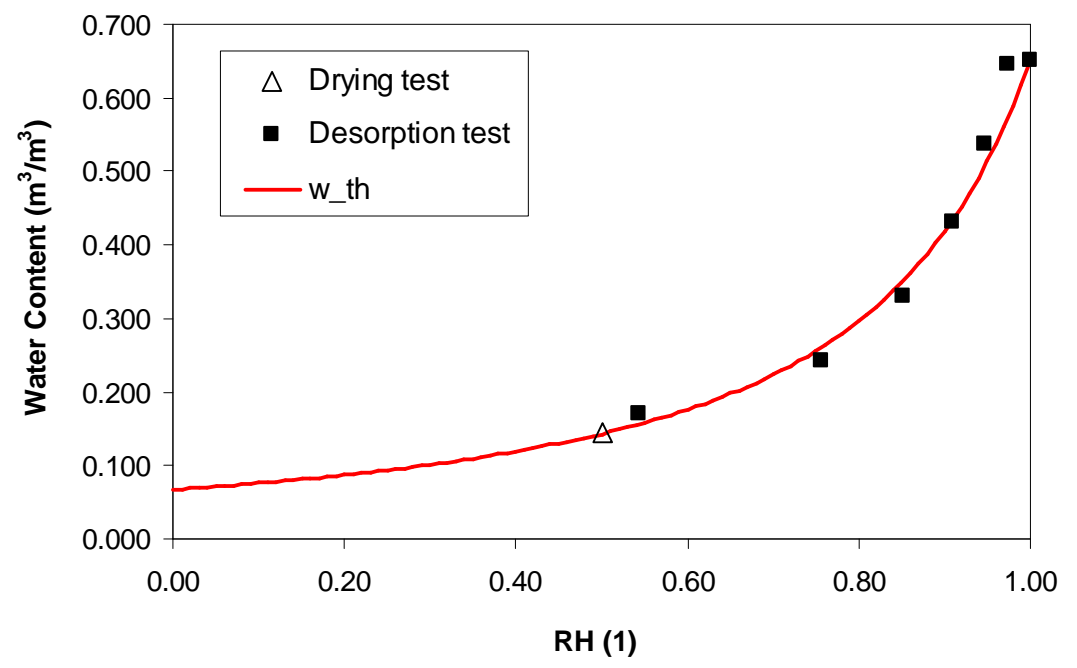

Figure $6-w=f(H)$ correlation estimated from the desorption and drying results

The intrinsic permeability is the only unknown parameter in the model. Similar to the previous approach based on Richards' mass conservation equation, the model is used to reproduce the drying test results by adjusting the intrinsic permeability.

The results are shown in Figure 7 and correspond to the measured mass losses and simulation results. The estimated intrinsic permeability is $400 \mathrm{E}-21 \mathrm{~m}^{2}$ for the saltstone paste. 


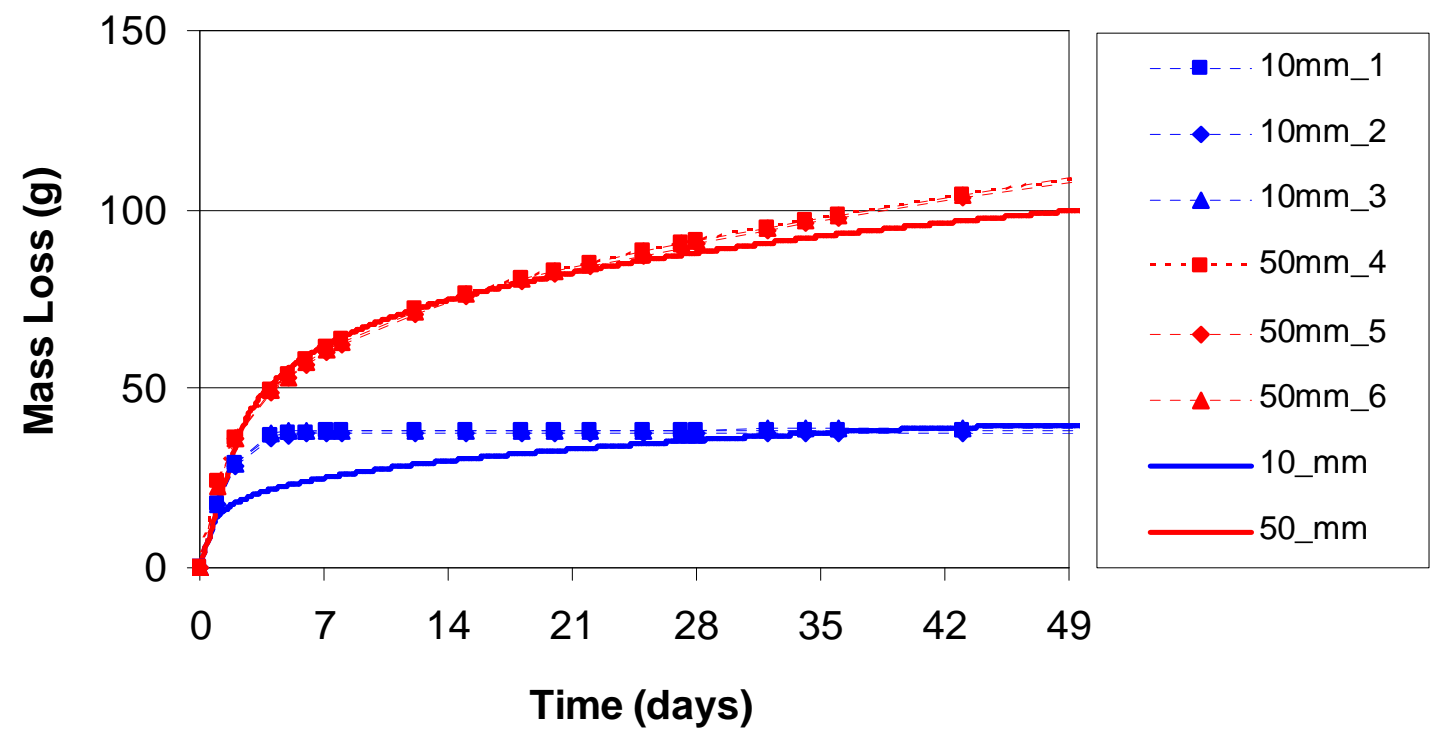

Figure 7 Mass loss measured during the drying test for saltstone mixture and simulation results with $k_{s}=400 \mathrm{E}-21 \mathrm{~m}^{2}$ 


\subsection{Properties summary}

Table 12 summarizes the transport properties of the saltstone mixture tested in this project.

Table 12 - Transport properties for the saltstone mixture

\begin{tabular}{|c|c|c|}
\hline Properties & Units & $\begin{array}{c}\text { Saltstone } \\
\text { mixture }\end{array}$ \\
\hline Water/binder ratio & & 0.595 \\
\hline Cement type & $(-)$ & $\mathrm{I} / \mathrm{II}$ \\
\hline Cement & $\left(\mathrm{kg} / \mathrm{m}^{3}\right)$ & 135 \\
\hline Mineral admixture & $\left(\mathrm{kg} / \mathrm{m}^{3}\right)$ & \\
\hline GGBFS & & 195 \\
\hline Fly ash (F) & & 600 \\
\hline Silica fume & & \\
\hline DI Water & $\left(\mathrm{kg} / \mathrm{m}^{3}\right)$ & 553 \\
\hline Salts & $\left(\mathrm{kg} / \mathrm{m}^{3}\right)$ & 227 \\
\hline Fine aggregate & $\left(\mathrm{kg} / \mathrm{m}^{3}\right)$ & - \\
\hline Coarse aggregate & $\left(\mathrm{kg} / \mathrm{m}^{3}\right)$ & - \\
\hline Compressive strength & (MPa) & \\
\hline $7 d$ & & 2.1 \\
\hline $28 \mathrm{~d}$ & & 3.2 \\
\hline $123 d$ & & 4.0 \\
\hline $365 d$ & & 5.3 \\
\hline Porosity ${ }^{1}$ & (\% vol.) & \\
\hline $82 d$ & & 65.3 \\
\hline $123 d$ & & 64.5 \\
\hline $365 d$ & & 65.1 \\
\hline OH- diffusion coef. & $\left(\mathrm{E}-11 \mathrm{~m}^{2} / \mathrm{s}\right)$ & \\
\hline $28 \mathrm{~d}$ & & 7.5 \\
\hline $123 d$ & & 7.0 \\
\hline $365 d$ & & 2.5 \\
\hline Tortuosity & $(\mathrm{E}-2)$ & \\
\hline $28 \mathrm{~d}$ & & 1.42 \\
\hline $123 d$ & & 1.33 \\
\hline $365 d$ & & 0.47 \\
\hline \multicolumn{3}{|l|}{ Water diffusivity (28d) } \\
\hline$A$ & $\left(\mathrm{E}-14 \mathrm{~m}^{2} / \mathrm{s}\right)$ & 92 \\
\hline$B$ & $(-)$ & 10 \\
\hline Permeability & $\left(\mathrm{E}-22 \mathrm{~m}^{2}\right)$ & 4000 \\
\hline
\end{tabular}

Note 1 : procedure described in section 4.3 


\section{IMMERSION (LEACHING) TEST}

This series of tests consisted in immersing saltstone paste specimens in DI water and evaluating the atomic content profiles by microprobe analysis after a certain exposure time. The objective of these tests was to characterize the leaching of the ionic species in pore solution, and the dissolution of the mineral phases when exposed to an aggressive environment.

\subsection{Leaching test}

After 137 days of curing, specimens were cut into 20-mm disks from a cylinder for the leaching tests. The average thickness was $19 \mathrm{~mm}$ and the exposed surface is about 80 $\mathrm{cm}^{2}$. Both surfaces of the sample were exposed to pure water; resulting in a symmetric leaching (Figure 8). Four specimens were immersed in 5 liters of DI water. The solution was renewed on a regular basis to maintain $\mathrm{pH}$ under 10.5 .

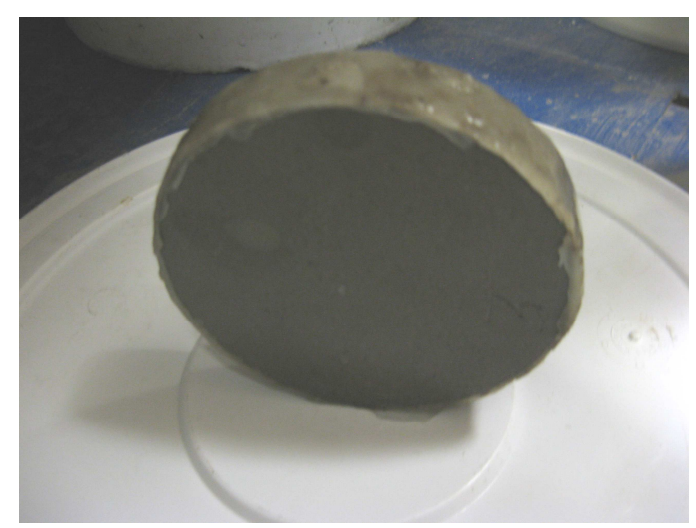

Figure 8 - Saltstone sample for leaching tests.

One sample was removed from the testing solution after 31 days of exposure. A piece of the sample was extracted, about $2 \mathrm{~cm}^{2}$ in the center (Figure 9(a)). This piece was immersed in isopropanol during 5 days in order to stop chemical reactions by replacing 
water with alcohol. Isopropanol was renewed after 3 days of immersion. After 5 days in isopropanol, the sample was conditioned under vacuum for drying during 5 days. The dried saltstone sample was then embedded in resin and polished prior to the microprobe analysis (Figure 9(b)).

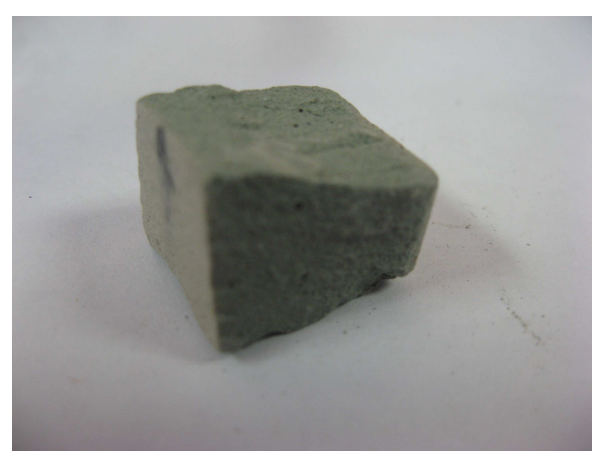

(a)

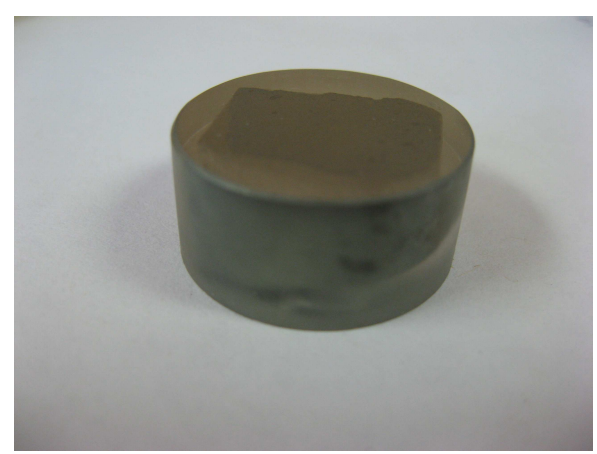

(b)

Figure 9 - Piece of a material extracted from the saltstone sample (a) and after surface preparation (b) for microprobe analysis

\subsection{Microprobe analysis}

The calcium and sulfur contents were determined by electron microprobe (CAMECA SX-100) along the thickness of the sample (Figures 10 and 11). The measurements were performed up to the middle of the thickness from the exposed surface. Calcium and sulfur profiles do not show any effect of leaching on the microstructure of the material. After 31 days of exposure, the microprobe analysis does not show decalcification of the Cabearing phases. This point is in agreement with the initial solid phases contents, given in Table 6: the absence of portlandite, as estimated by the model, induces a very low decalcification of the saltstone paste. Moreover, SEM micrographs of the sound and leached samples do not show any evident signs of degradation (dissolution front for instance) (Figure 12 to Figure 14). Besides, this surface characterization by SEM 
confirms the large porosity by the significant presence of voids. A more detailed characterization of the saltstone microstucture by SEM is available in Appendix A.

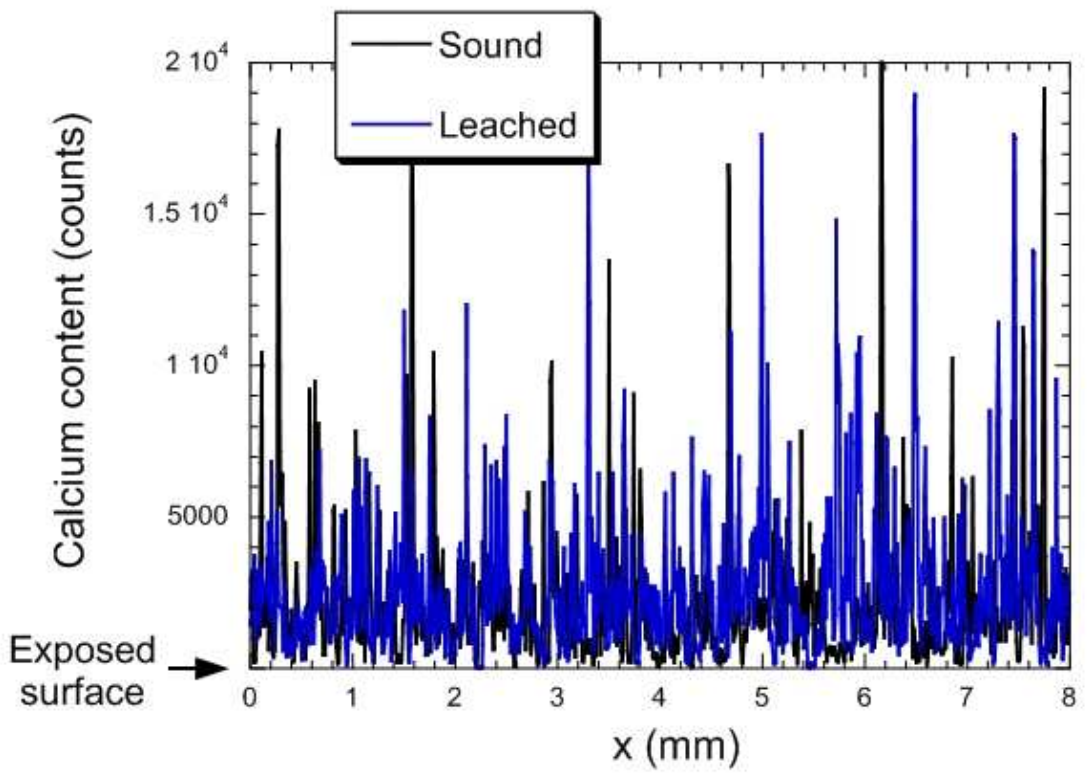

Figure 10 - Calcium content profile along the thickness of the leached saltstone. $x=0$ corresponds to the exposed surface.

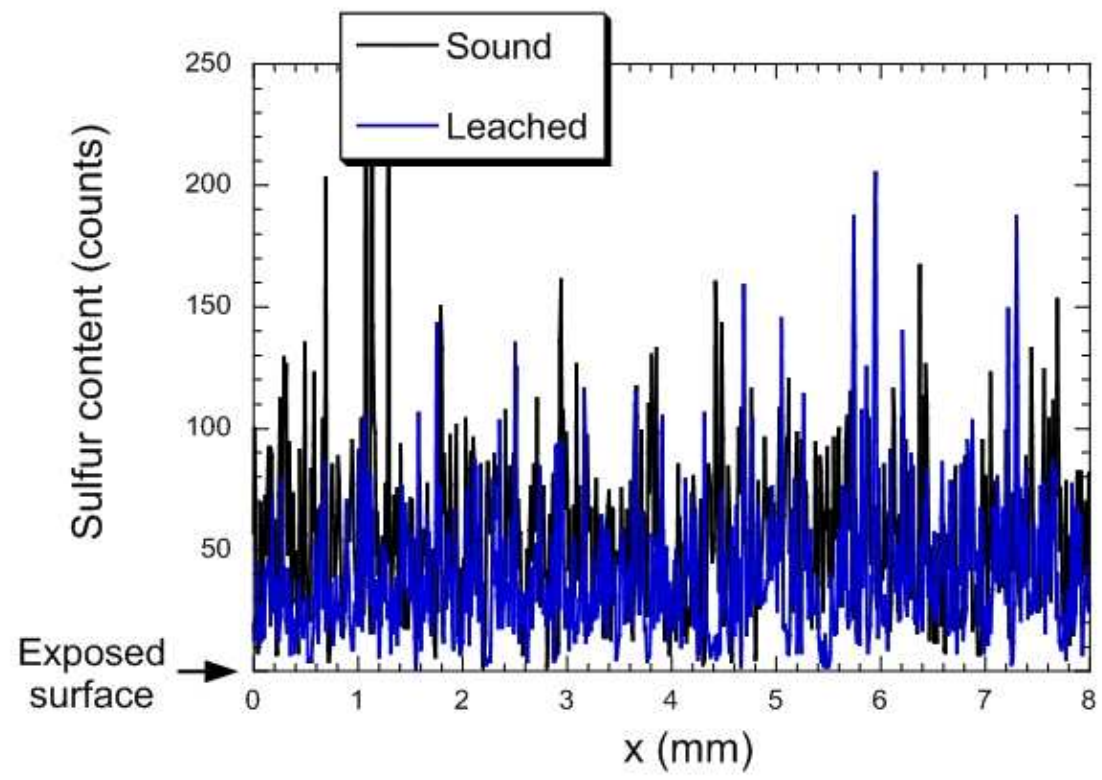

Figure 11 - Sulfur content profile along the thickness of the leached saltstone. $x=0$ corresponds to the exposed surface. 


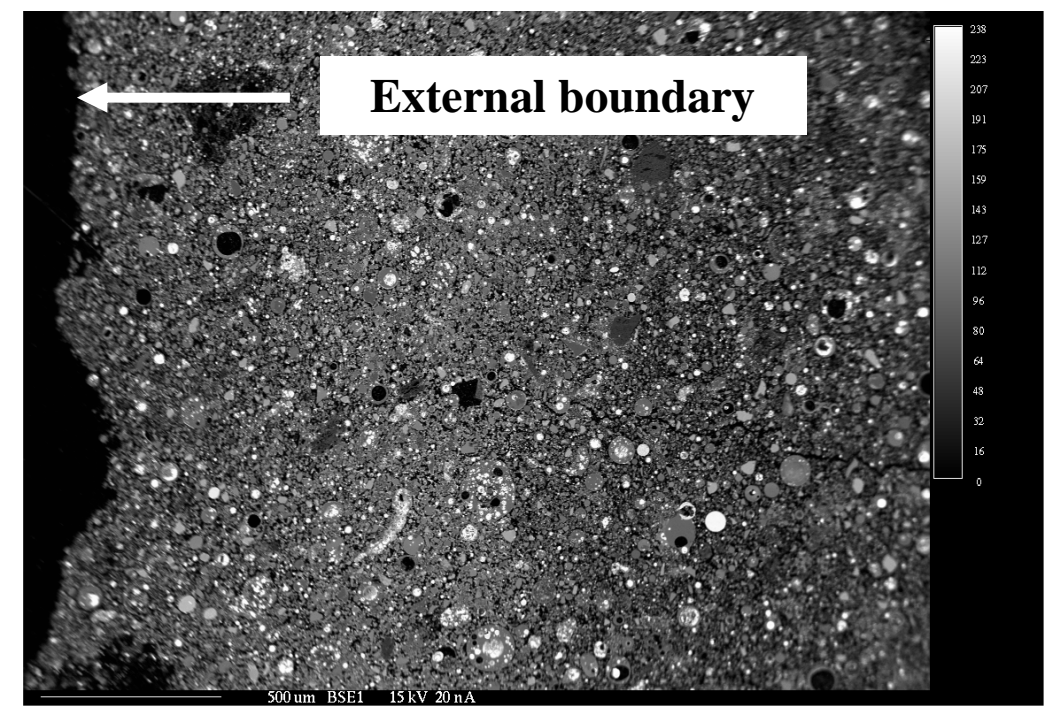

Figure 12 - SEM micrograph of saltstone $\left(2.5 \times 1.8 \mathrm{~mm}^{2}\right)$ before exposure to DI water

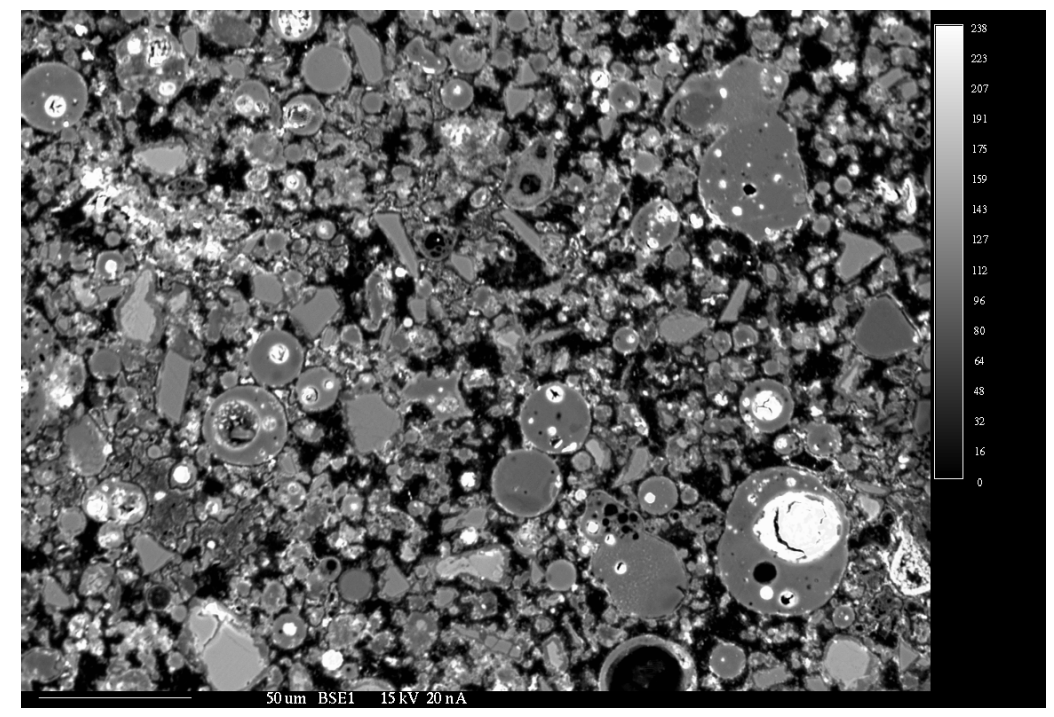

Figure 13 - SEM micrograph of saltstone $\left(0.30 \times 0.24 \mathrm{~mm}^{2}\right)$ before exposure to DI water (magnification of a portion of Figure 12) 


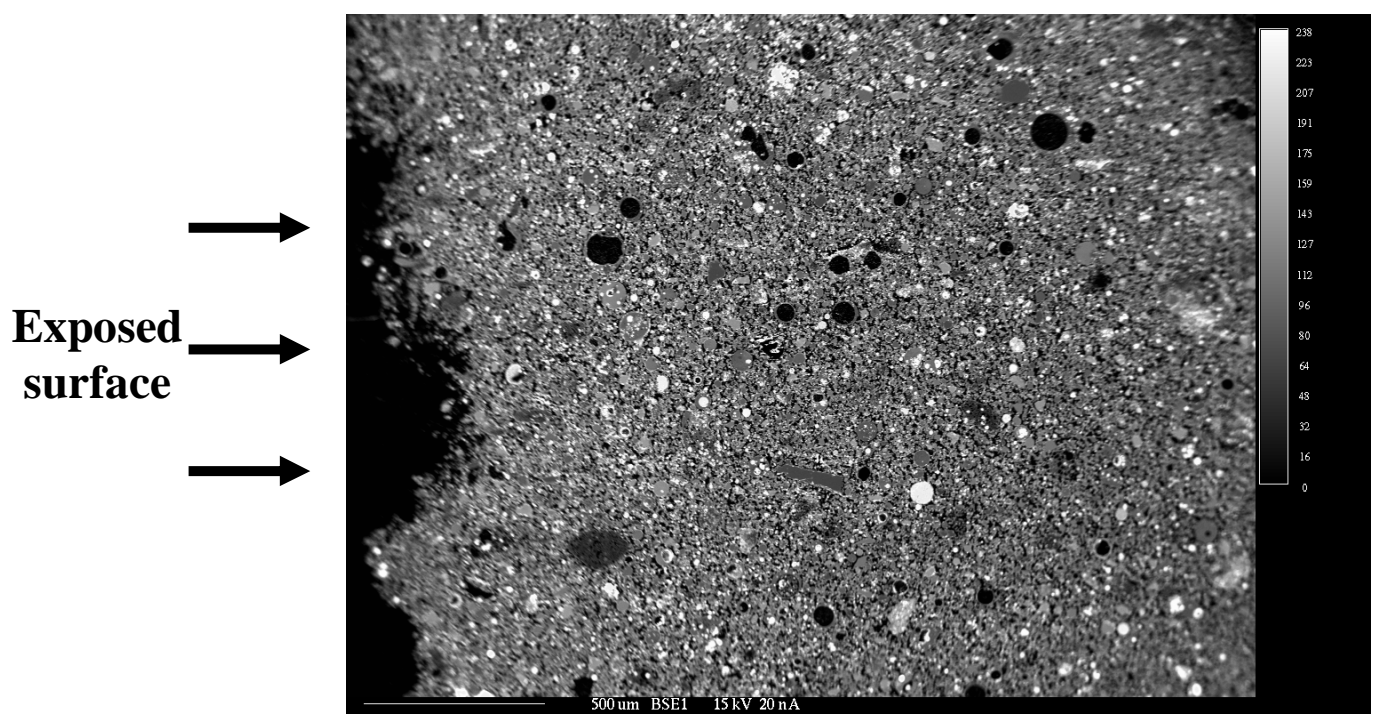

Figure 14 - SEM micrograph of leached saltstone $\left(2.5 \times 1.8 \mathrm{~mm}^{2}\right)$ exposed to DI water for 31 days

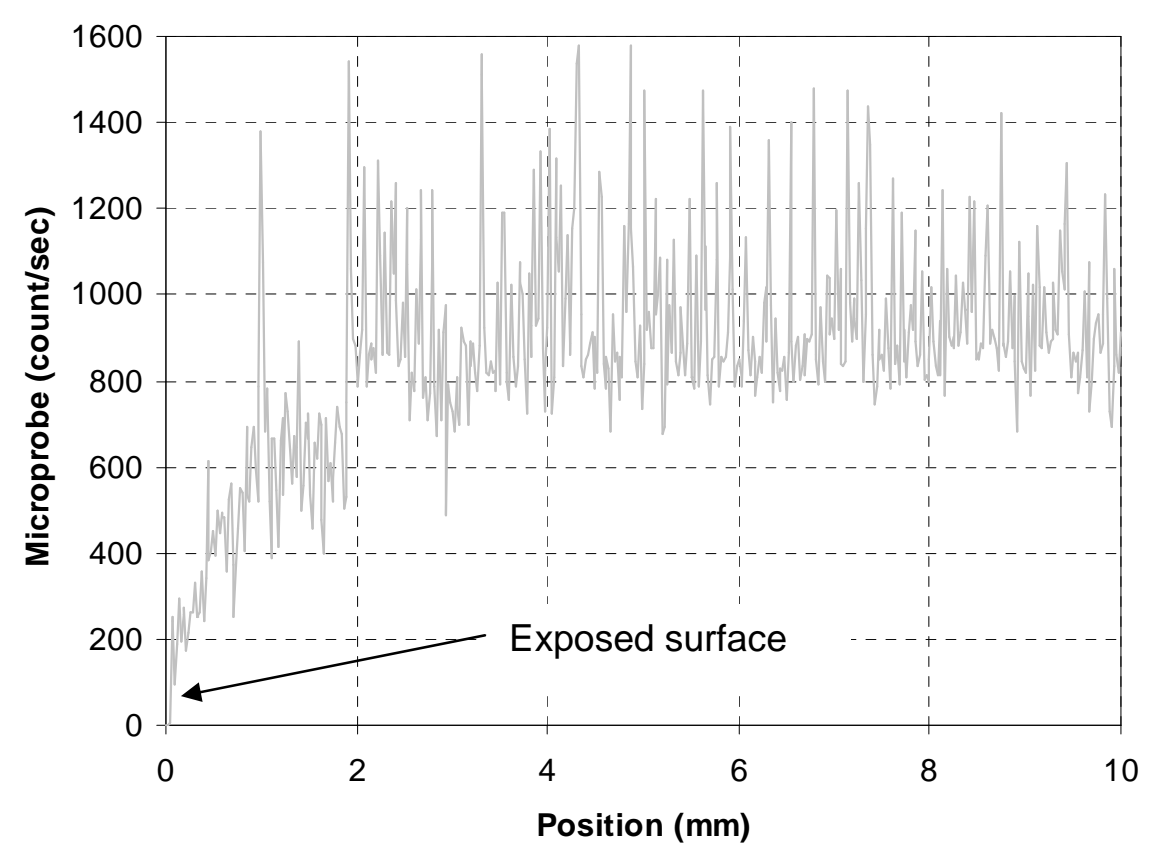

Figure 15 - Microprobe profile of a 0.6 w/c opc exposed to DI water for three months (Data provided by SIMCO Technologies inc.) 
The absence of significant decalcification features is in line with the low tortuosity measured with the migration tests, which slows the rate of leaching of calcium and hydroxide. The next figure shows the result of a similar experiment performed by SIMCO Technologies inc. on an ordinary Portland cement paste made at a water-tocement ratio of $0.6{ }^{10}$. The paste had a $52 \%$ porosity and a tortuosity of 0.0305 , more than two times the tortuosity of the saltstone paste. It has been exposed to DI water for three months. Decalcification features a clearly visible at the water/material interface, which exhibits a clear drop in calcium. Although results after one month of exposure are not available for direct comparison, they still indicate that the saltstone material of more resistant to decalcification and leaching than an ordinary cement paste.

\subsection{Numerical simulations}

Leaching simulations with STADIUM ${ }^{\circledR}$ were performed with the parameters given in Tables 6 and 12. The numerical calcium and sulfur profiles are shown in Figure 16 and Figure 17 and compared to experimental microprobe profiles. The figures present filtered profiles to reduce the scattering observed on Figures 10 and 11. Similar to the experimental observations, the model does not predict any significant change in microstructure after 31 days of exposure in pure water. The model shows an evolution of the calcium and sulfur profiles over a very short distance from the exposed surface $(\sim 0.5$ $\mathrm{mm}$ ). In the case of calcium content, a low decrease initiates around $2.5 \mathrm{~mm}$; that corresponds to the decalcification of C-S-H. It is difficult to precisely correlate this result with experimental profiles since the exposed surface is irregular and the paste is highly heterogeneous (Figure 14). The microstructure characterization by SEM presented in Appendix A provided relevant information on the $\mathrm{C}-\mathrm{S}-\mathrm{H}$ decalcification. These results motivated a complementary presentation of the numerical results (Figure A.23).

\footnotetext{
${ }^{10}$ The results were published in : Samson E., Marchand J., Modeling the transport of ions in unsaturated cement-based materials, Computers and Structures 85 (2007) 1740-1756.
} 


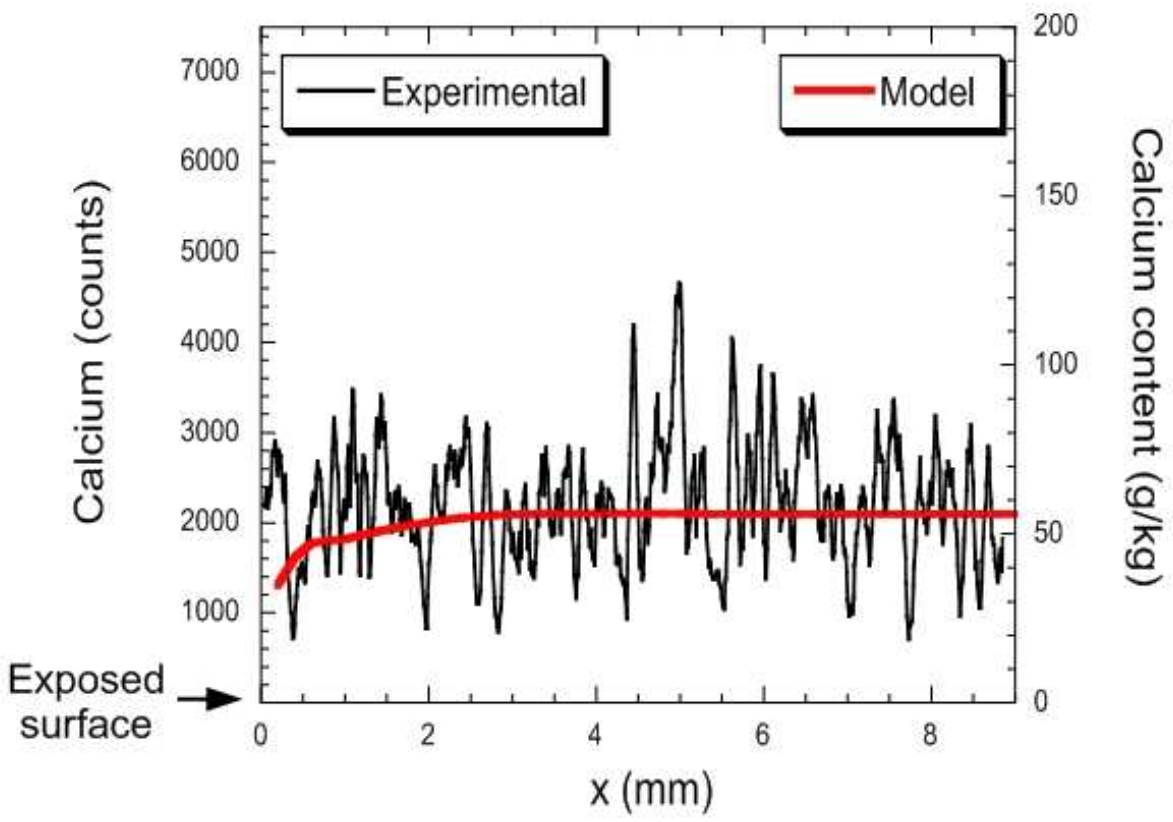

Figure 16 - Calcium content simulation along the thickness of the leached saltstone

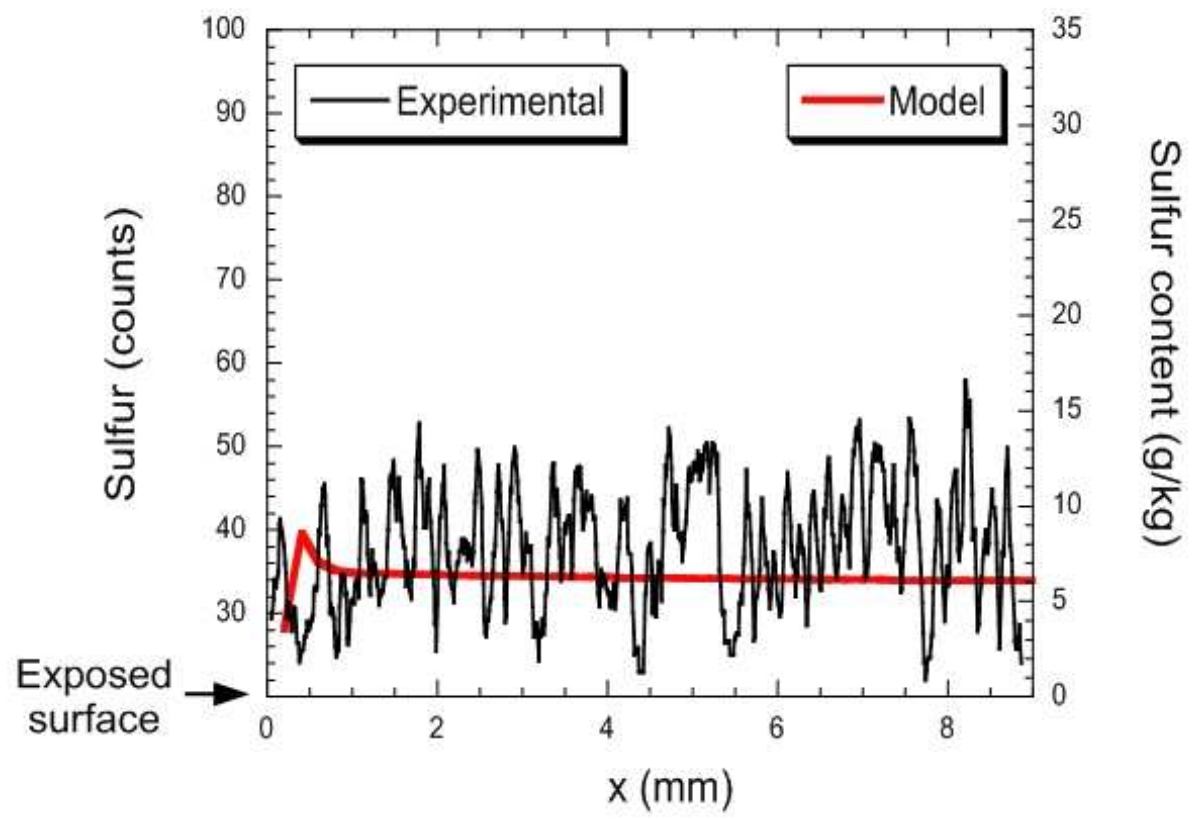

Figure 17 - Sulfur content simulation along the thickness of the leached saltstone 
Given the high water to binder ratio of the material, severe damage was expected from the exposition to DI water. This is why a short exposure period was selected for the microprobe analysis. However, the tortuosity values estimated from the migration tests are low and can be compared to an ordinary paste prepared at a water-to-cement ratio of 0.4. So even though the $\mathrm{w} / \mathrm{b}$ ratio was high, the presence of slag and fly ash contributed to a very tortuous microstructure that is resistant to degradation. Other samples are still maintained in DI water. Similar analyses performed after longer exposure period will provide additional data to estimate the durability of the saltstone mixture.

\section{Conclusion}

The tests performed so far on the saltstone paste shows that the material has low tortuosity and diffusion characteristics that translate into a low decalcification rate, despite a high porosity. Accordingly, the unique microstructure of this material would also reflect on the leaching of soluble contaminants, which would likewise have a low rate.

Results from tests performed after longer curing periods will provide additional data on the long-term durability of saltstone pastes. But the results obtained to this day indicate that the persistence of the material is good. 


\section{A APPENDiX - SALTSTONE SEM MICROGRAPHY}

A SEM microanalysis on sound and leached saltstone was performed. The SEM apparatus was a JSM840A model (JEOL). The electron beam voltage was $15 \mathrm{kV}$. Some EDS measurements were also performed with a Avalon model (PGT) equipped with a germanium detector. Polished and unpolished surfaces were analysed. The polished samples were analysed with back scattering electrons to distinguish the different phases. The unpolished ones were studied with secondary electrons to obtain the 3D aspect of the mineral phases. It was noted that, in the case of polished samples, white spots were detected. They proved to be made of lead, which came from the lead powder used to polish samples.

\section{A.1 Sound Saltstone}

Figure A.1 presents a general overview of the saltstone microstructure. Air bubbles and unhydrated fly ash particles, of various sizes, were observed within the paste. Figure A.1 shows unidentified agglomerates $(\varnothing \sim 200-400 \mu \mathrm{m})$. A few of those were visible throughout the material. These agglomerates seem to be large cement grains and were irregularly observed in the saltstone paste.

Figure A.2 details the agglomerate 1 (as indicated in Figure A.1) which showed light grey particles distributed in the dark bulk phase. EDS measurements were made on particles (light grey) and on the bulk (dark zone) (see Figures A.3 and A.4). These measurements confirmed that the agglomerates are made of cement particles. Moreover, Supplementary Cementitious Materials (SCM) were not identified in the agglomerates. These cement agglomerates must have been present in the cement used to batch the mix. 


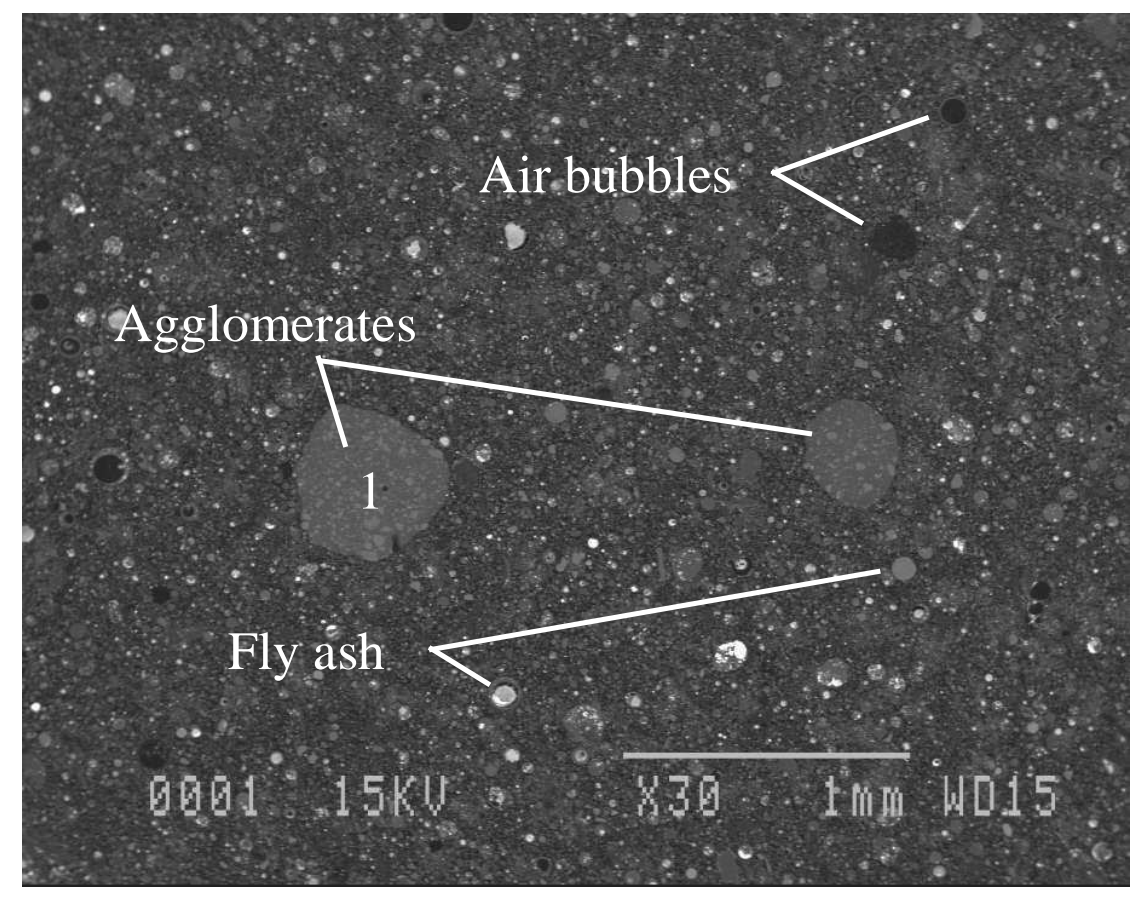

Figure A.1 - SEM micrograph of sound Saltstone (x30)

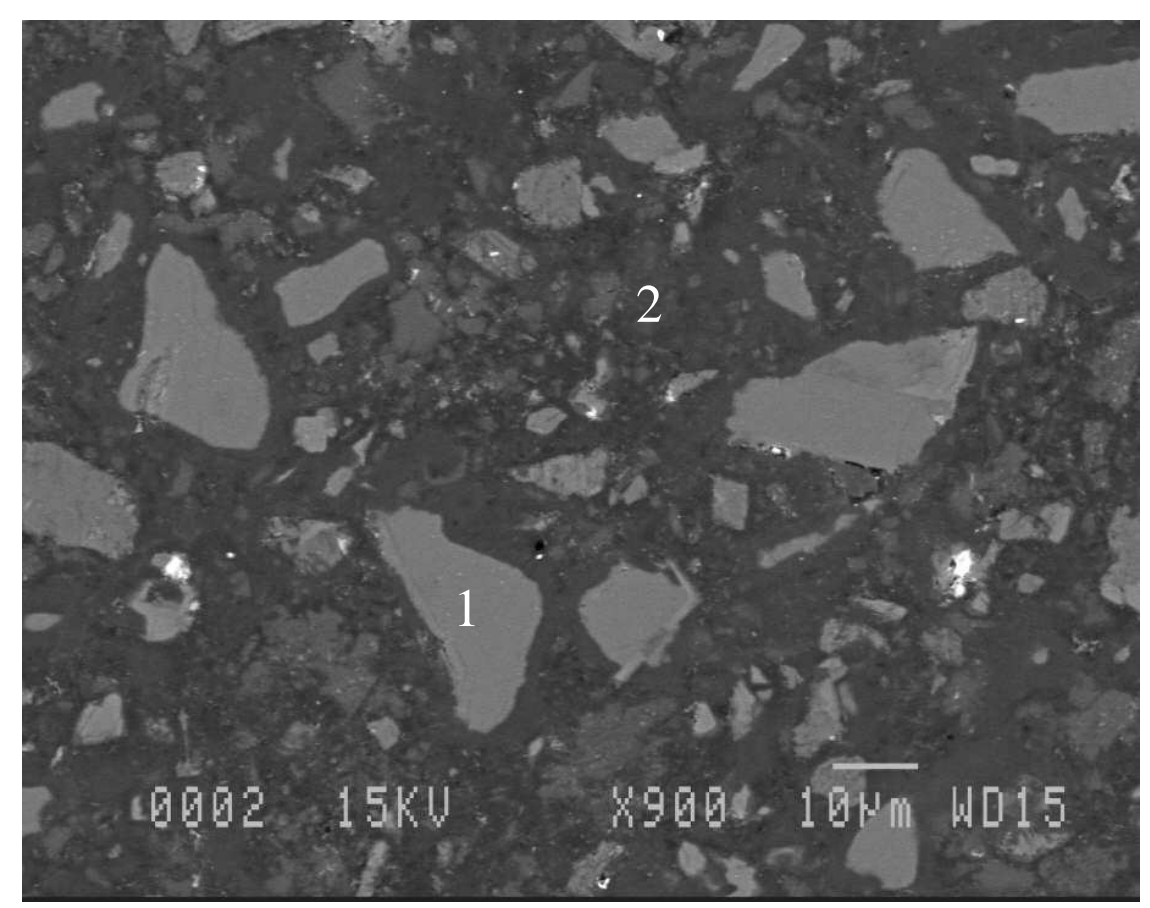

Figure A.2 - SEM micrograph of agglomerate (x900) 


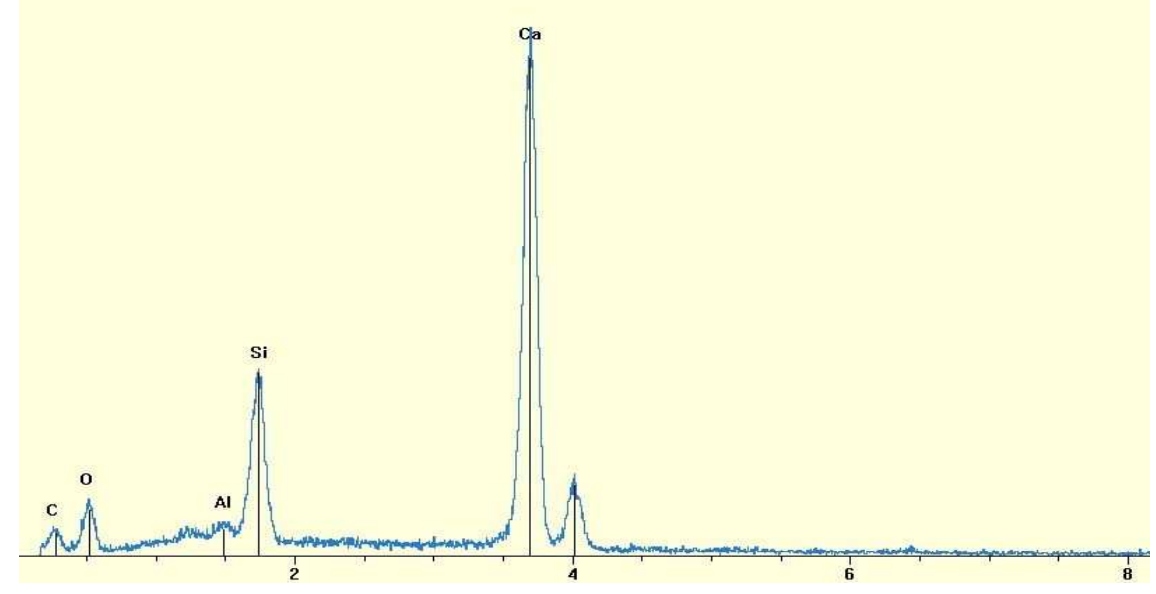

Figure A.3 - EDS analysis on light grey particle in agglomerate (zone 1 in figure A.2)

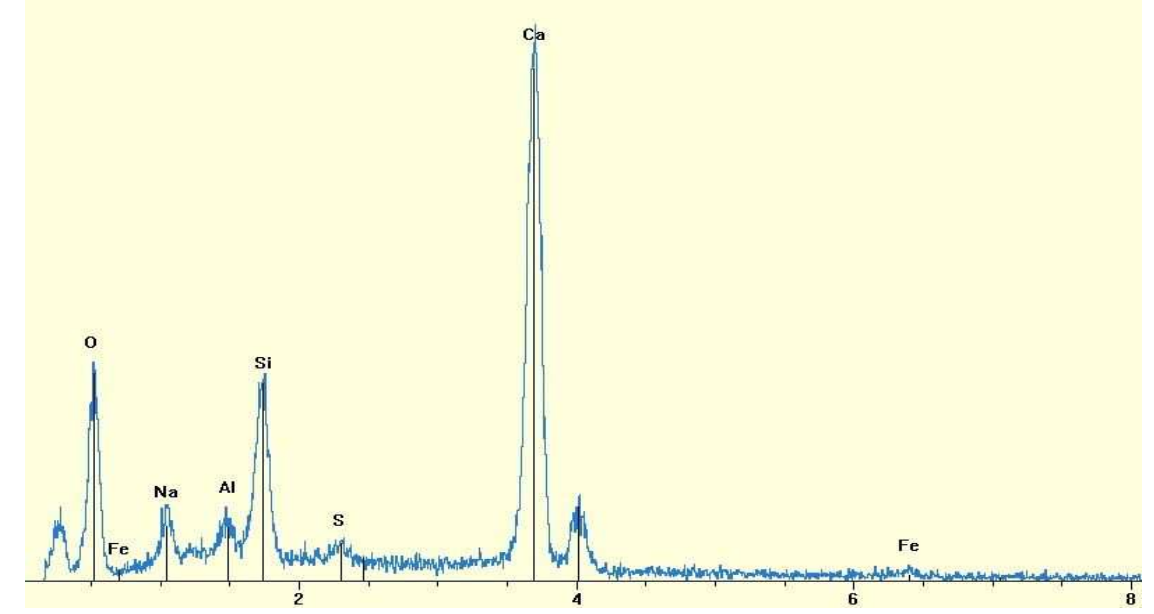

Figure A.4 - EDS analysis on the bulk phase in agglomerate (zone 2 in figure A.2)

Figure A.5 shows the microstructure seen in Figure A.1 with a magnification x150. It reveals the significant presence of voids (in black). Fly ash spheres are clearly identified with a large range of sizes. Also, Figure A.5 really shows the difference between the cement agglomerates and the saltstone paste. 


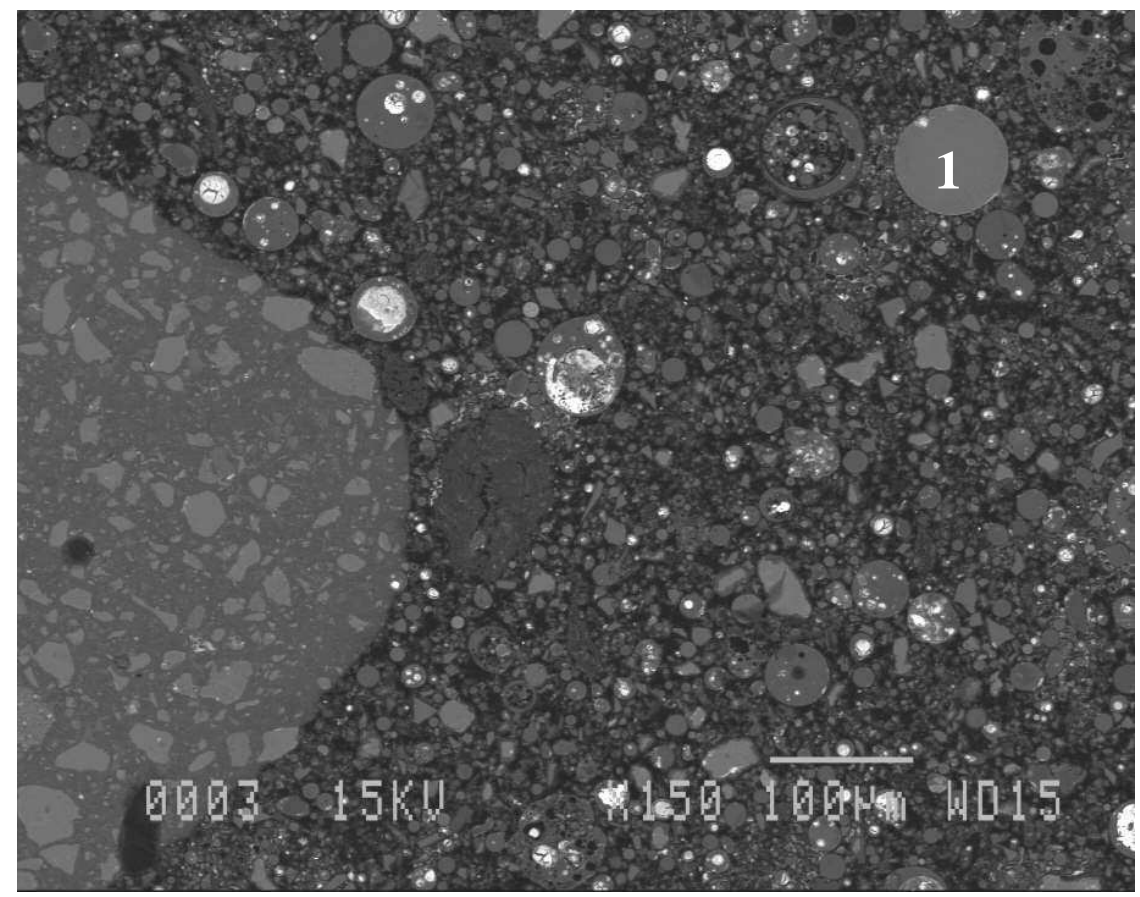

Figure A.5 - SEM micrograph of saltstone microstructure (x150)

EDS analysis on a fly ash sphere (indicated by 1 in Figure A.5) is shown in Figure A.6. This semi-quantitative measurement identifies silicon, alumina, and iron as the major components of fly ash. This is in accordance with the composition of class F fly ash (SEFA) used in the saltstone mix (Table 2).

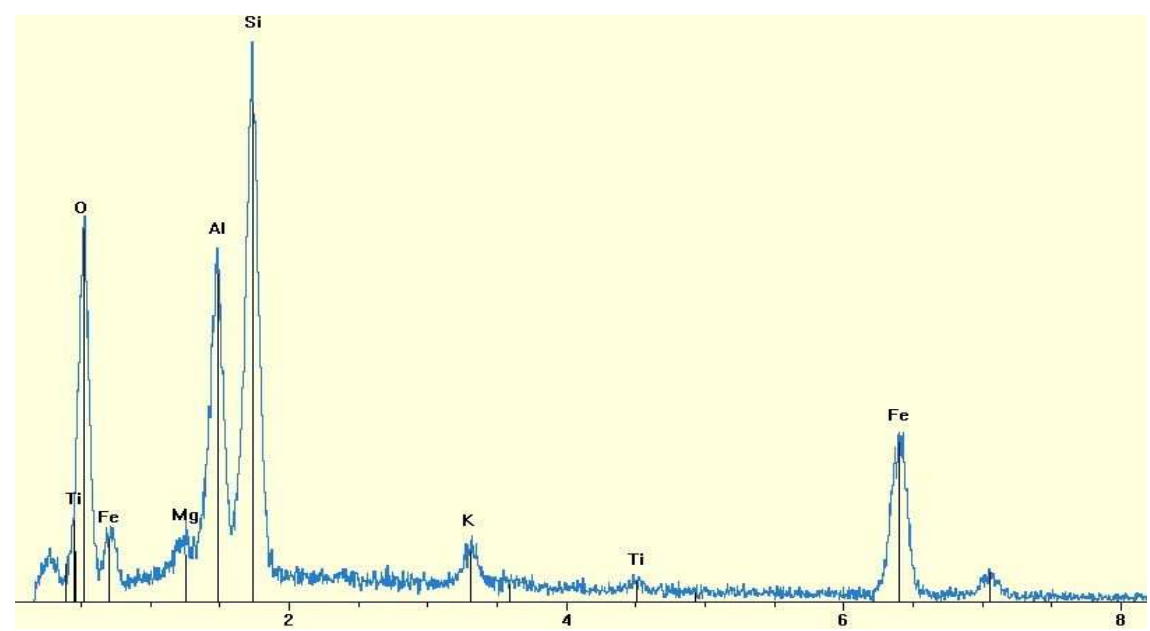

Figure A.6 - EDS measurement on fly ash particle in saltstone microstructure 
Figure A.7 shows the bulk of the saltstone paste with a magnification $\times 500$, which confirms the high density of voids (inter-grain spaces). Figure A.8 shows a detailed view of the white square zone in Figure A.7 (x8000). It shows an unhydrated particle with hydrates in its vicinity. An EDS measurement, performed on the unhydrated particle (Figure A.9), indicates it corresponds to a slag grain according to the composition given in Table 2 (calcium, silicon, magnesium, and alumina).

The growth of hydrates in inter-grains spaces is clearly observed in Figure A.8. The hydration of fly ash is also visible around the spherical particles. The thin hydrate innerlayer indicates that fly ash has a low hydration level.

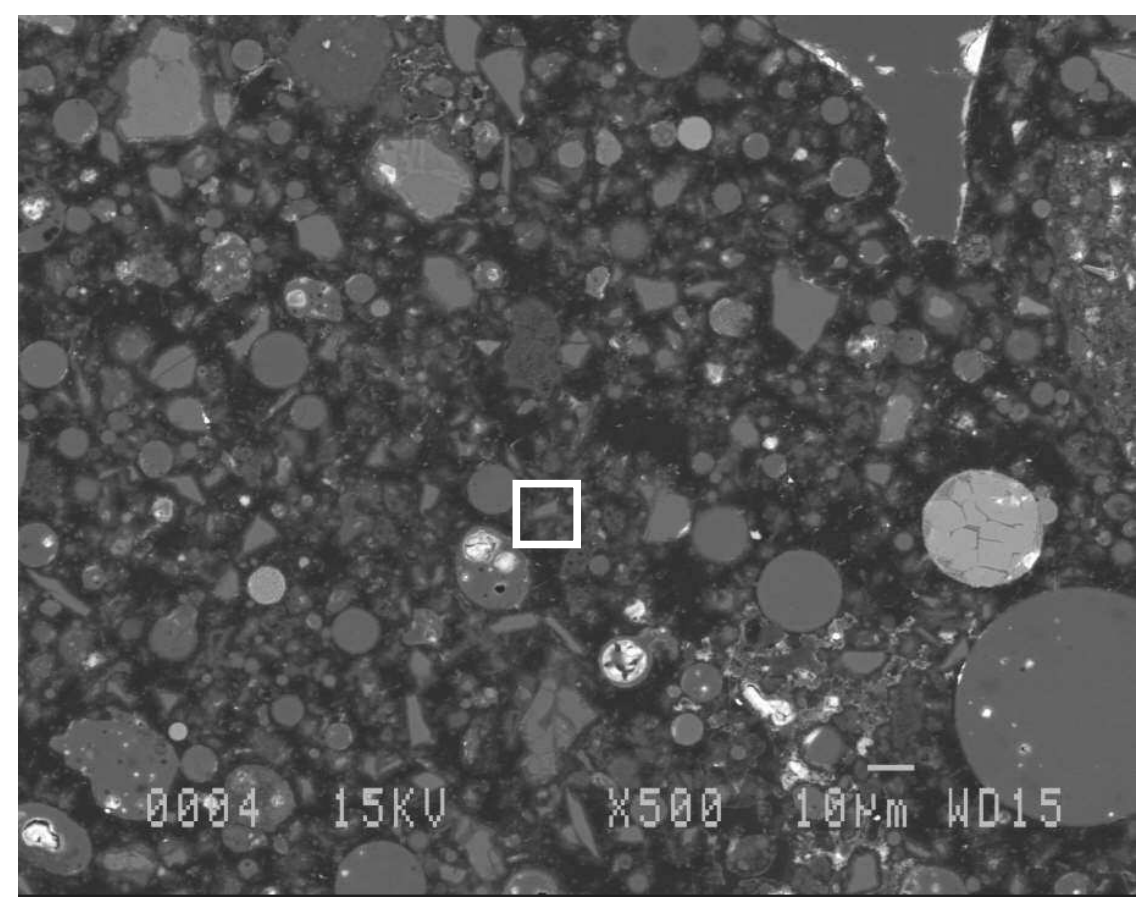

Figure A.7 - SEM micrograph of a saltstone microstructure (x500) 


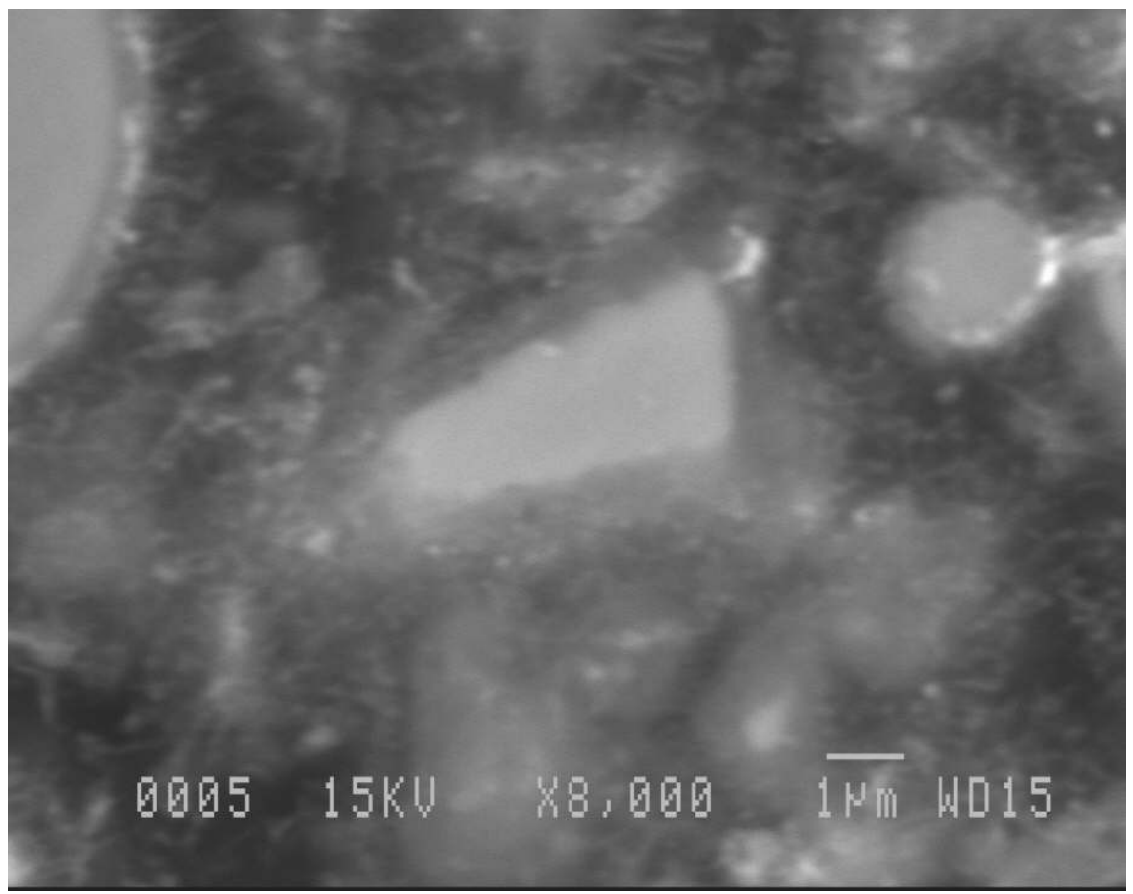

Figure A.8 - SEM micrograph of hydrates formation around anhydrous particles $(\mathbf{x 8 0 0 0})$

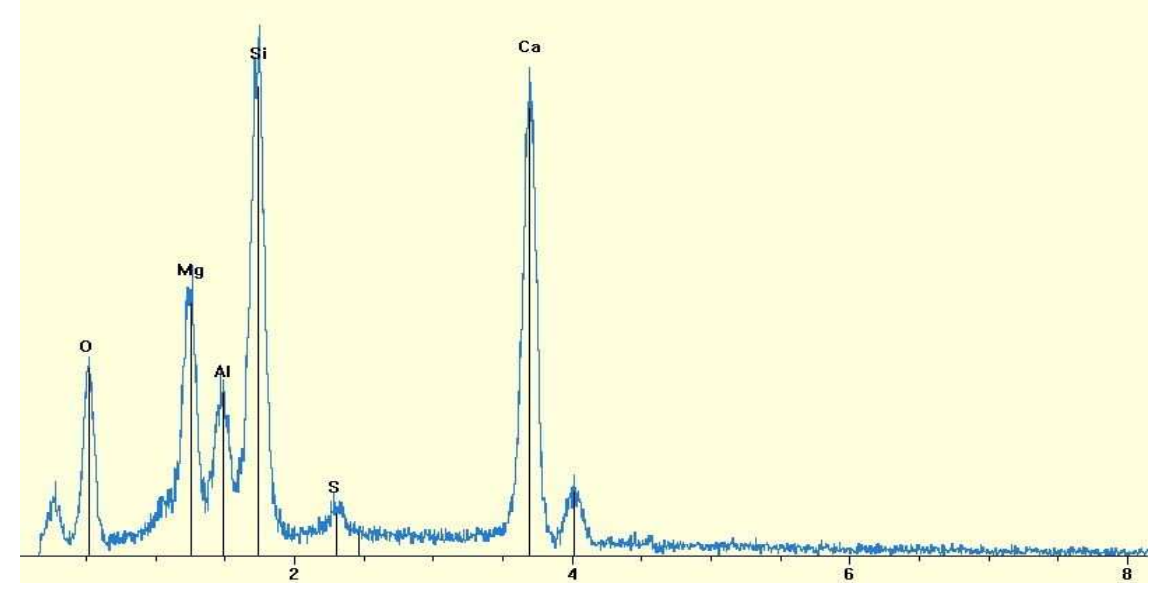

Figure A.9 - EDS measurement on anhydrous particle (slag) in figure A.8

Figure A.10 presents another zone of the sound saltstone. Cement agglomerates were not detected in this zone neither around it. Figure A.10, with its magnification x150, can be compared to Figure A.5: the saltstone microstructure is similar in both cases. 


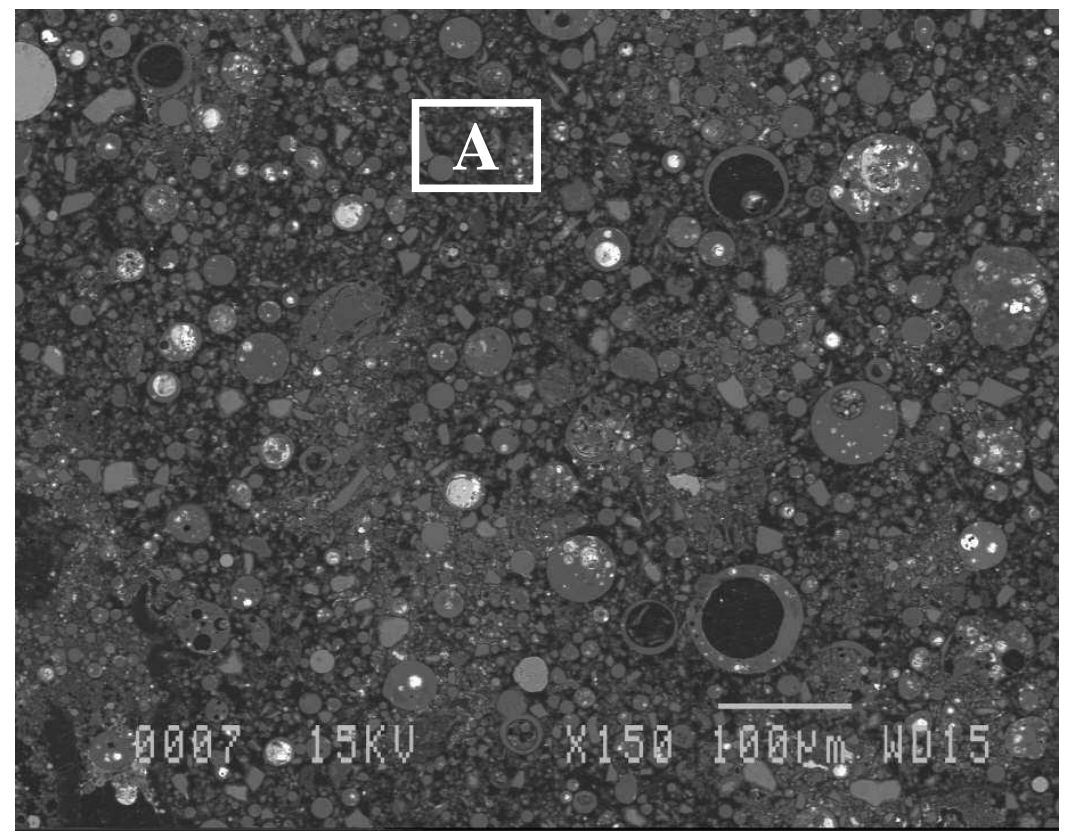

Figure A.10 - SEM micrograph of saltstone microstructure (x150)

Figure A.11 details the region A in Figure A.10 with a magnification x1000. Figures A.10 and A.11 confirm the large amount of voids. EDS is performed in Figure A.11 on different particles (Figures A.12 to A.14 respectively): fly ash (A), slag (B), and cement (C) are then characterized.

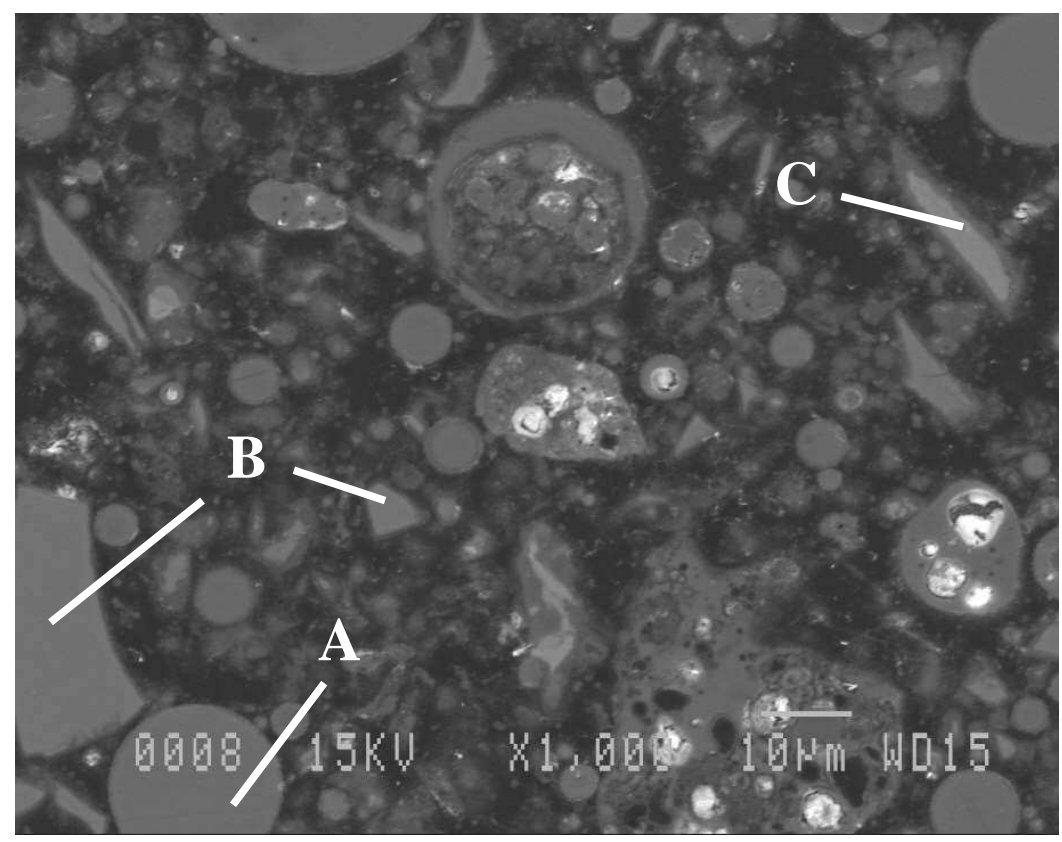

Figure A.11 - SEM micrograph of saltstone microstructure (x1000) 


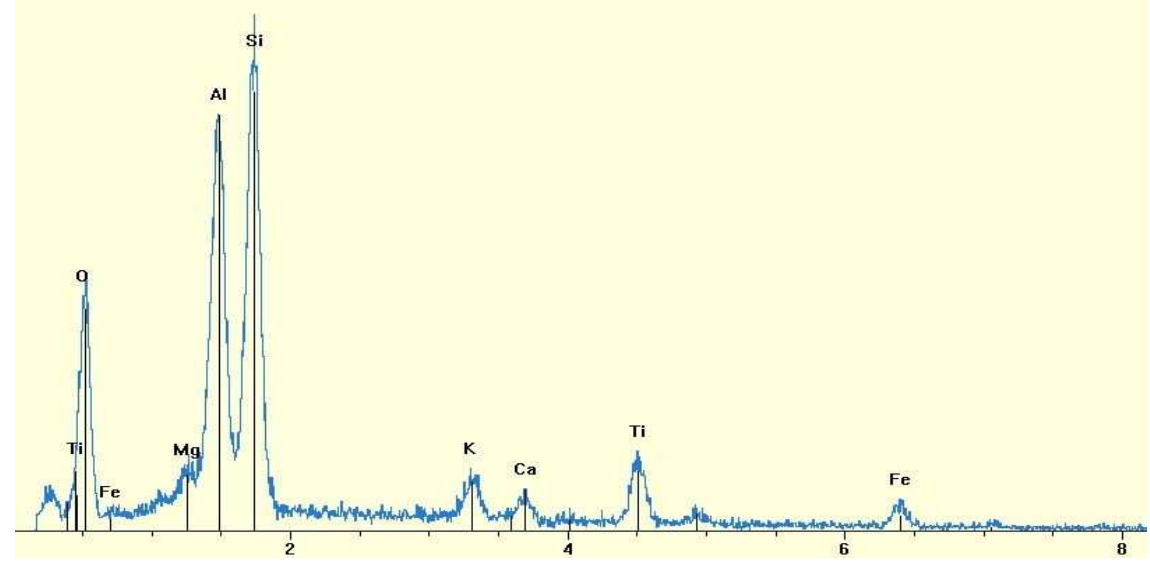

Figure A.12 - EDS measurement on unhydrated fly ash (A in Figure A.11)

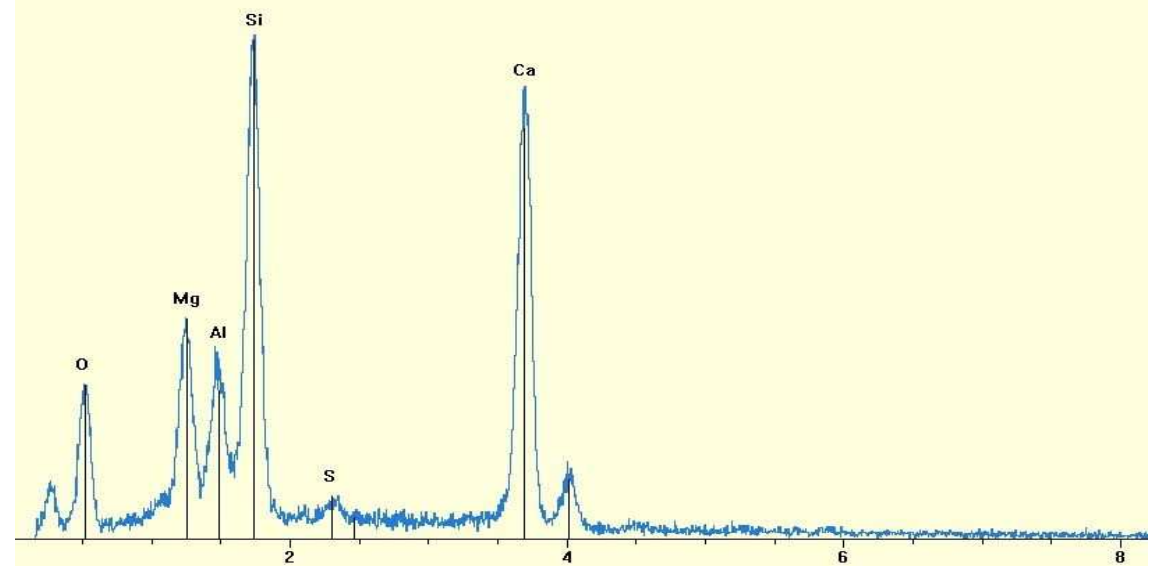

Figure A.13 - EDS measurement on unhydrated slag (B in Figure A.11) 


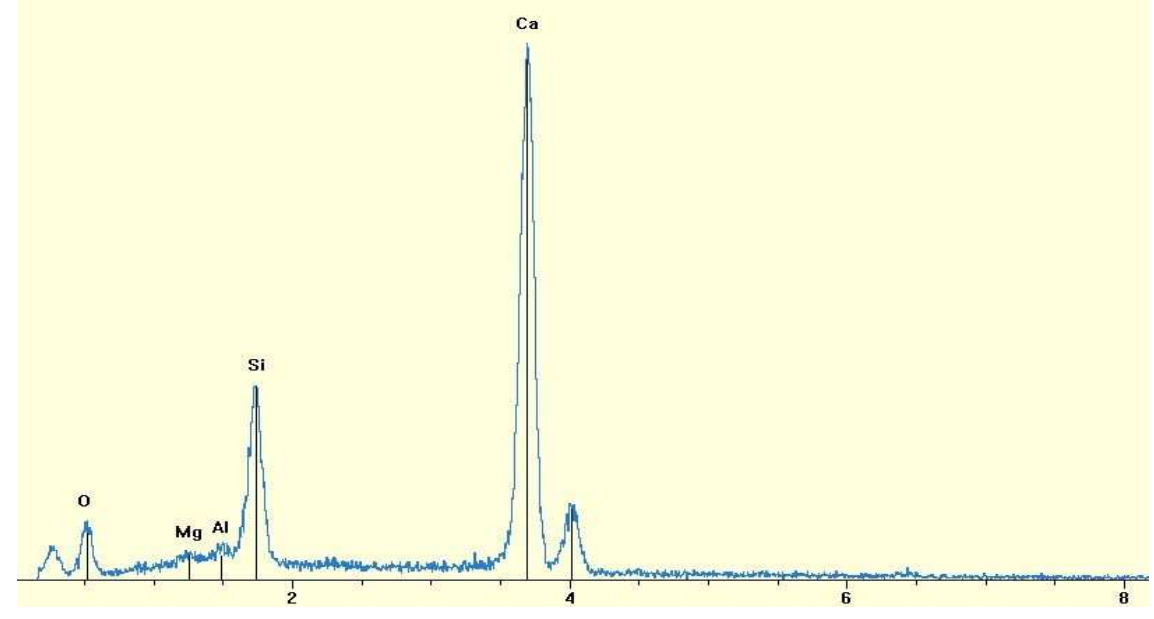

Figure A.14 - EDS measurement on unhydrated cement (C in Figure A.11)

An unpolished prism was taken from sound saltstone for SEM analysis. Figure A.15 shows a general view of the structure. Fly ash particles are embedded in amorphous hydrates. Calcium Silicate Hydrates (C-S-H) layered structure is clearly identified in Figures A.16 and A.17. Undefined particles were seen with C-S-H. Unfortunately, EDS analysis did not allow to precisely characterize these particles. The shape of the mineral suggest a well crystallized mineral such as calcite or gypsum but additional analysis are needed to get a precise answer. 


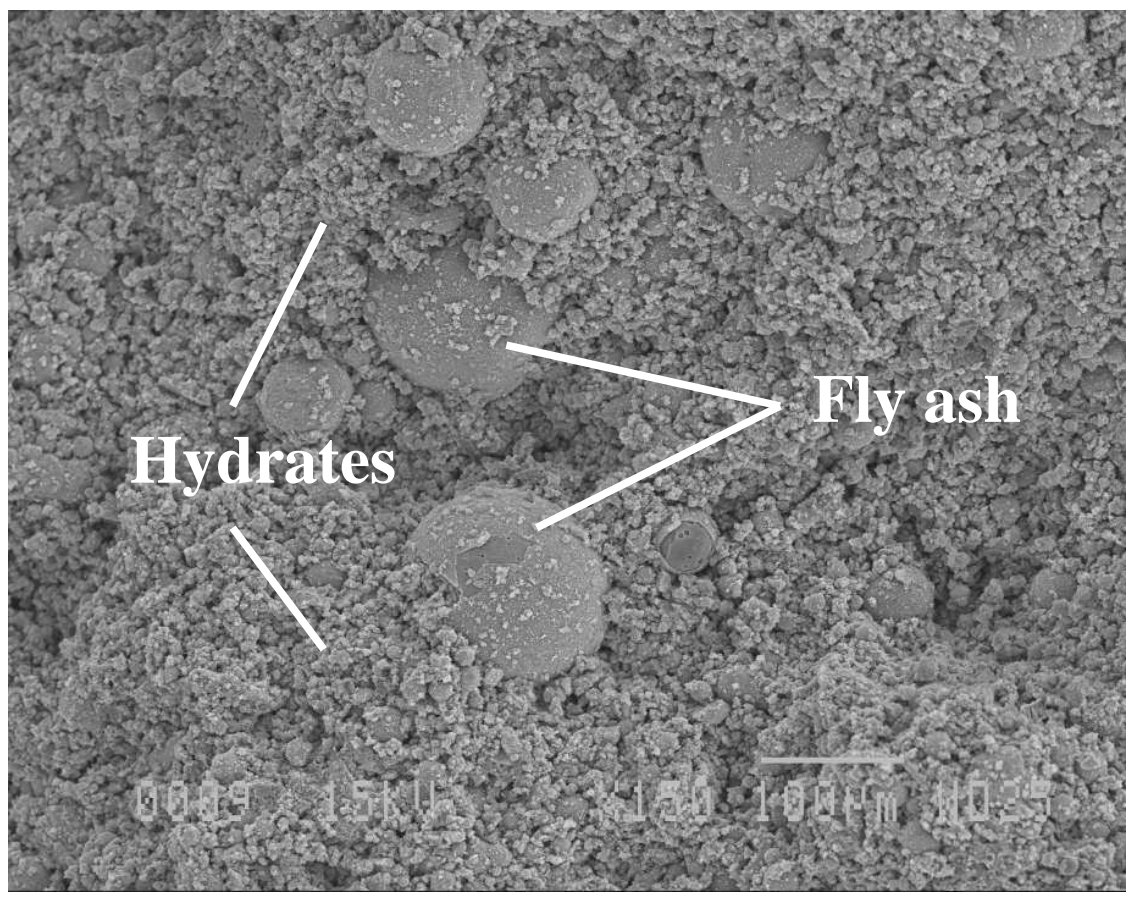

Figure A.15 - SEM micrography on sound saltstone (x150)

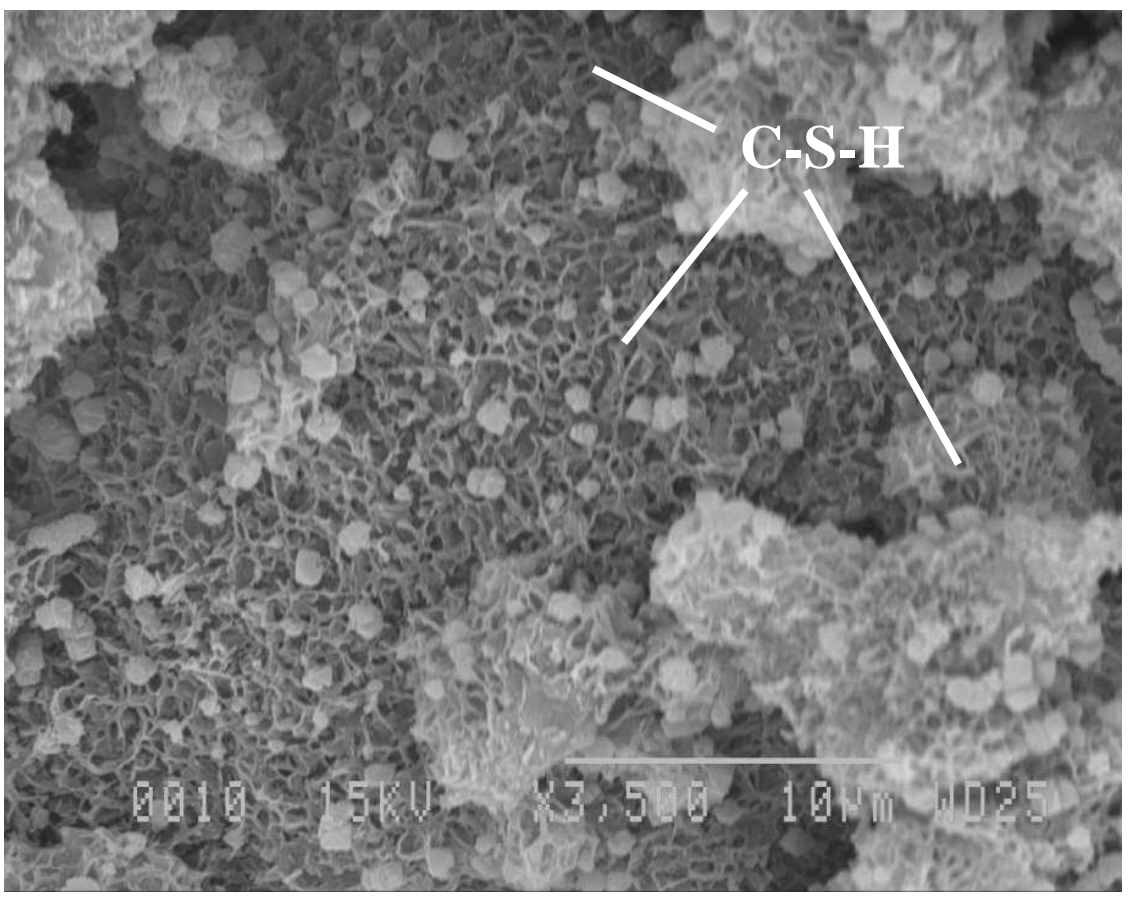

Figure A.16 - SEM micrography on sound saltstone - C-S-H structures (x3500) 


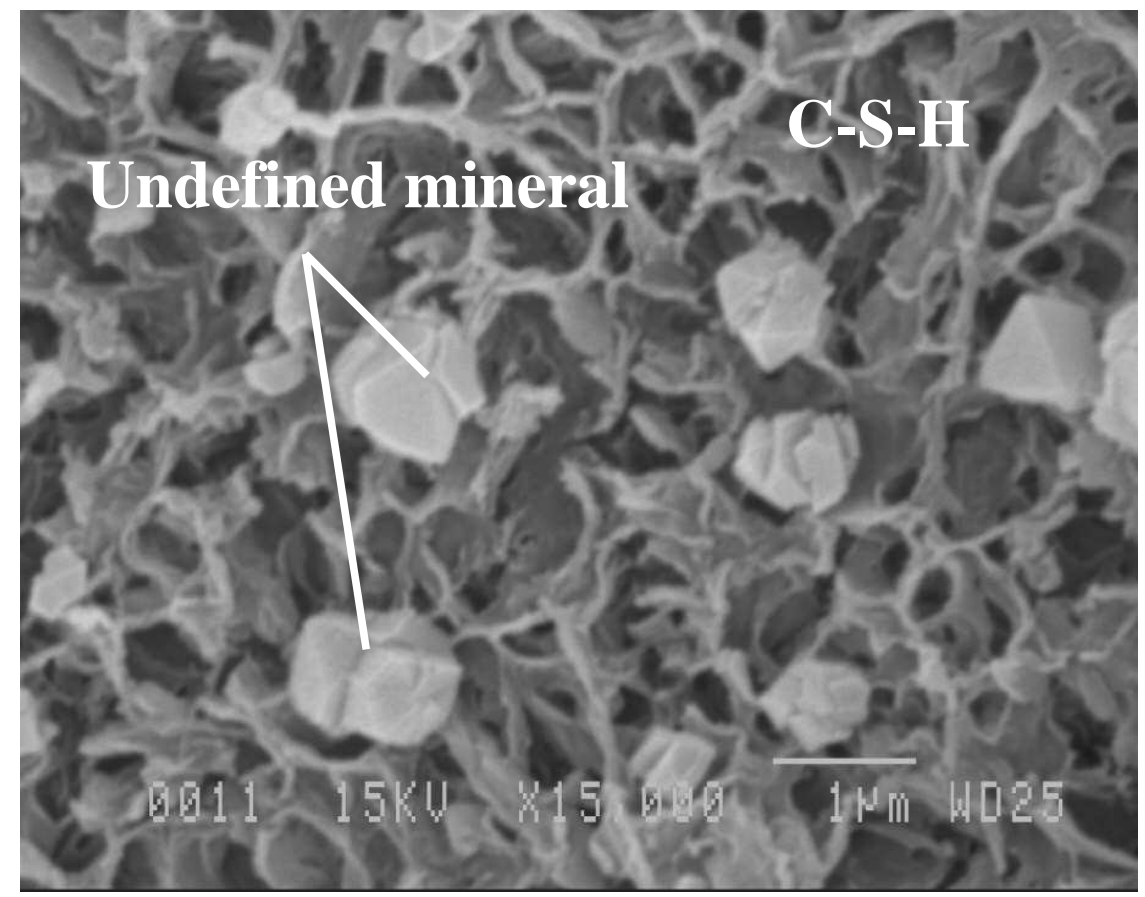

Figure A.17 - SEM micrography on sound saltstone - C-S-H structures (x15000)

\section{A.2 Leached saltstone}

The microprobe characterization of the polished specimens did not show any significant difference between the sound and leached material. An unpolished prism from the saltstone sample near the exposed surface is analyzed in this section.

Figure A.18 shows the analyzed surface relatively to the exposed surface. At this scale, no change due to leaching can be observed. The zone A, indicated in Figure A.18, is detailed in Figure A.19. No specific mineral phases are detected. However, the C-S-H structure, as seen in figures A.16 and A.17, is not observed, even with a magnification $\mathrm{x} 15000$. The layered structure has disappeared. C-S-H is still present but its structure has changed. This change of the microstructure is assumed to be characteristic of a decalcified C-S-H. 


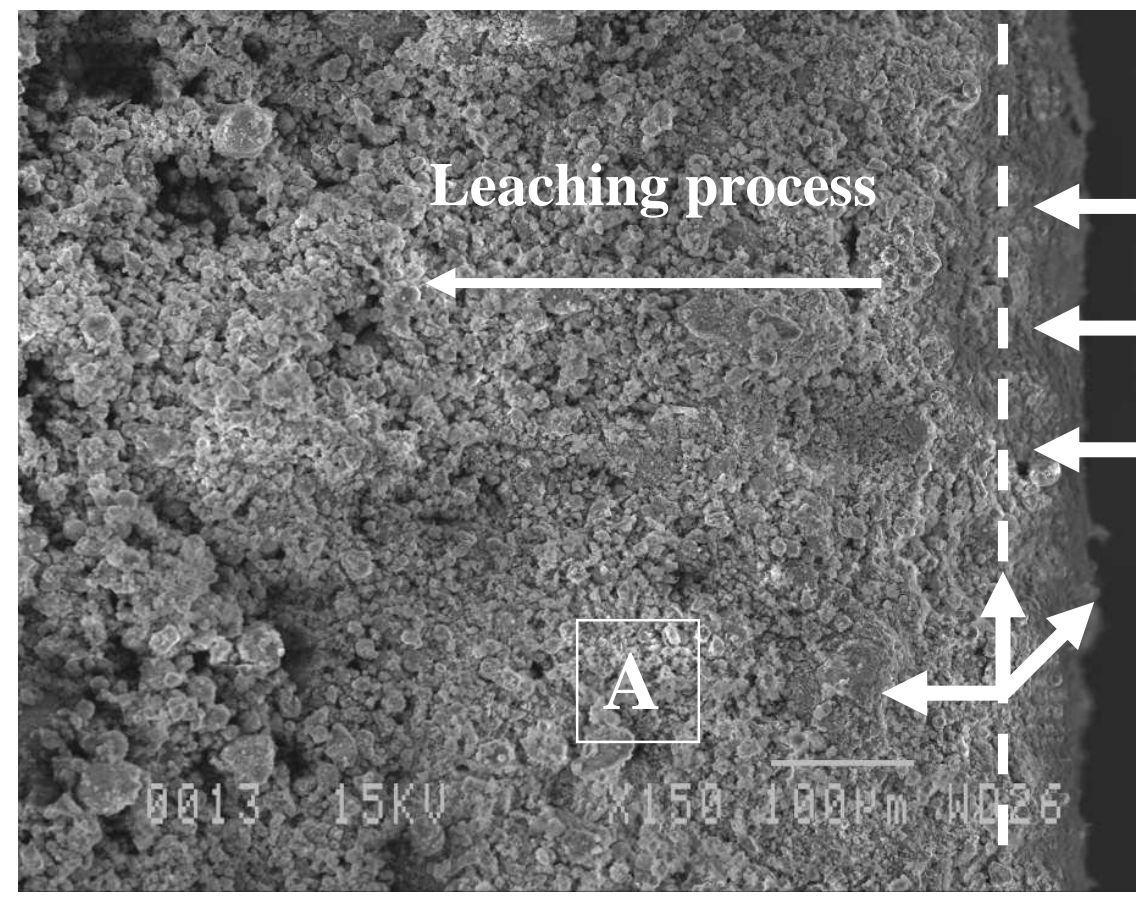

Surface exposed

to pure water

Figure A.18 - SEM micrography of leached saltstone at the vicinity of the exposed surface (x150)

With the same magnification (x15000), Figure A.20 shows a view of the material core (around $10 \mathrm{~mm}$ from the surface); this zone is assumed to be sound as the leaching process did not reached it. Indeed, the C-S-H layered structure is similar to Figures A.16 and A.17. That confirms that the core of the leached specimen is unaltered.

It was possible to detect the transition zone of C-S-H decalcification, i.e. the depth for which sound C-S-H were still present from SEM observation near the exposed surface on an unpolished sample (Figure A.21). Figure A.22 shows layered C-S-H in the transition zone. From these observations, the depth of the decalcified C-S-H layer, induced by the leaching after pure water exposure, is estimated at $2.1 \mathrm{~mm}$.

Remark: the leached zone in Figure A.21 seems to be physically degraded. However, this degradation cannot be directly associated to the chemical attack of the saltstone. This degradation might have been caused by the extraction of the prism from the saltstone sample. 


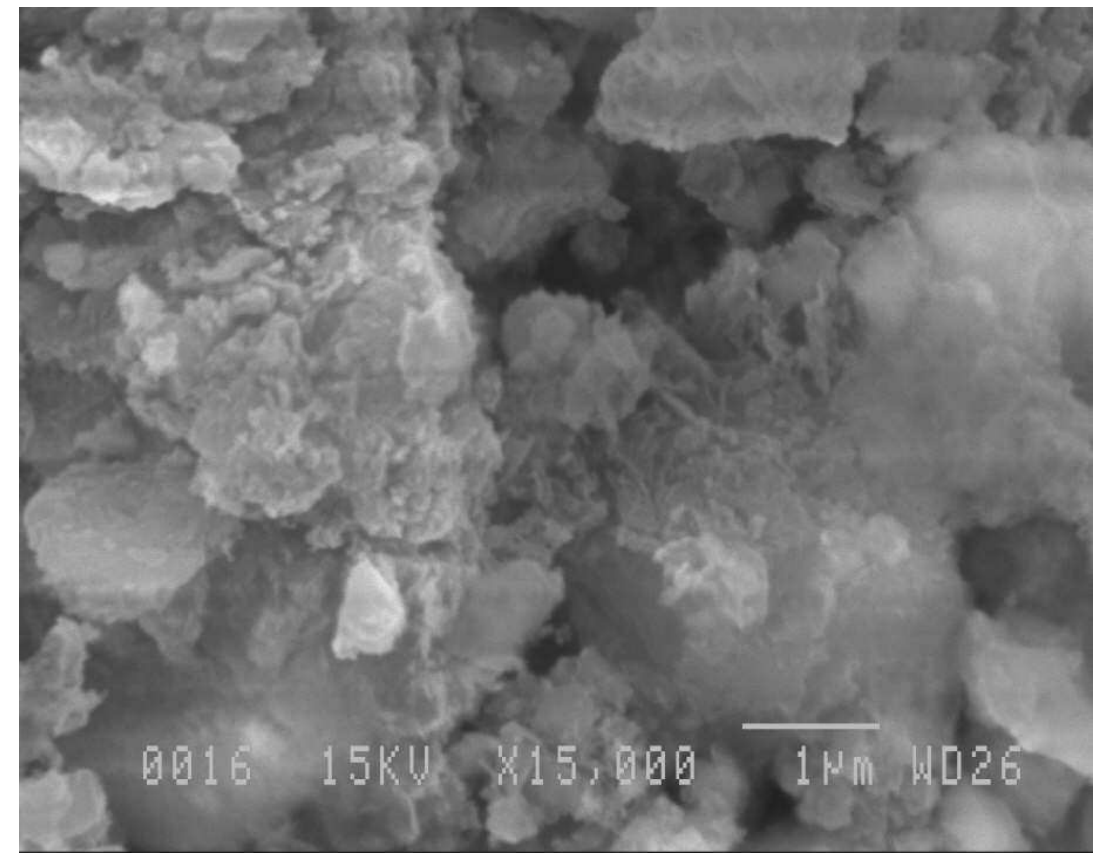

Figure A.19 - SEM micrography of leached saltstone at the vicinity of the exposed surface (x15000) - The layered C-S-H structure is absent

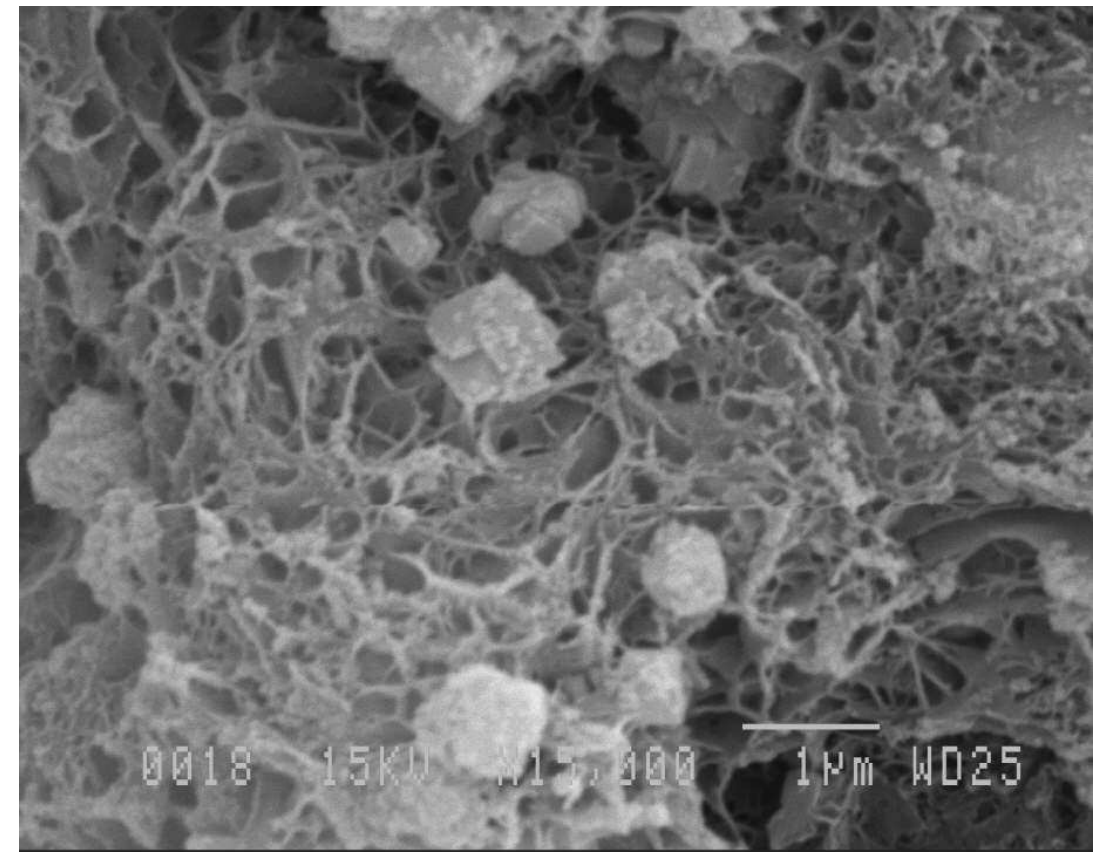

Figure A.20 - SEM micrography of leached saltstone in the sample core at $10 \mathbf{~ m m}$ from the exposed surface $(\mathbf{x 1 5 0 0 0})$ - The layered C-S-H structure is present 


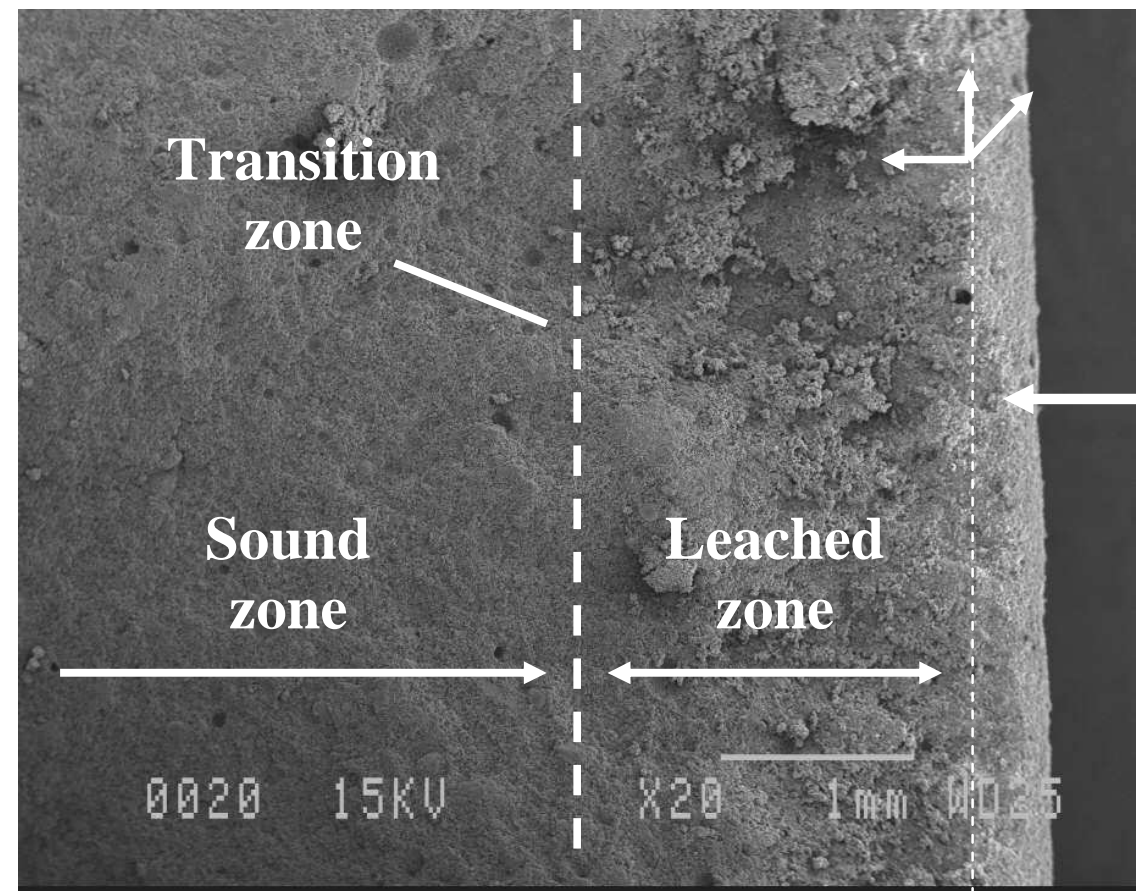

Surface exposed to pure water

Figure A.21 - SEM micrography of leached saltstone (x20) - estimation of the leached depth

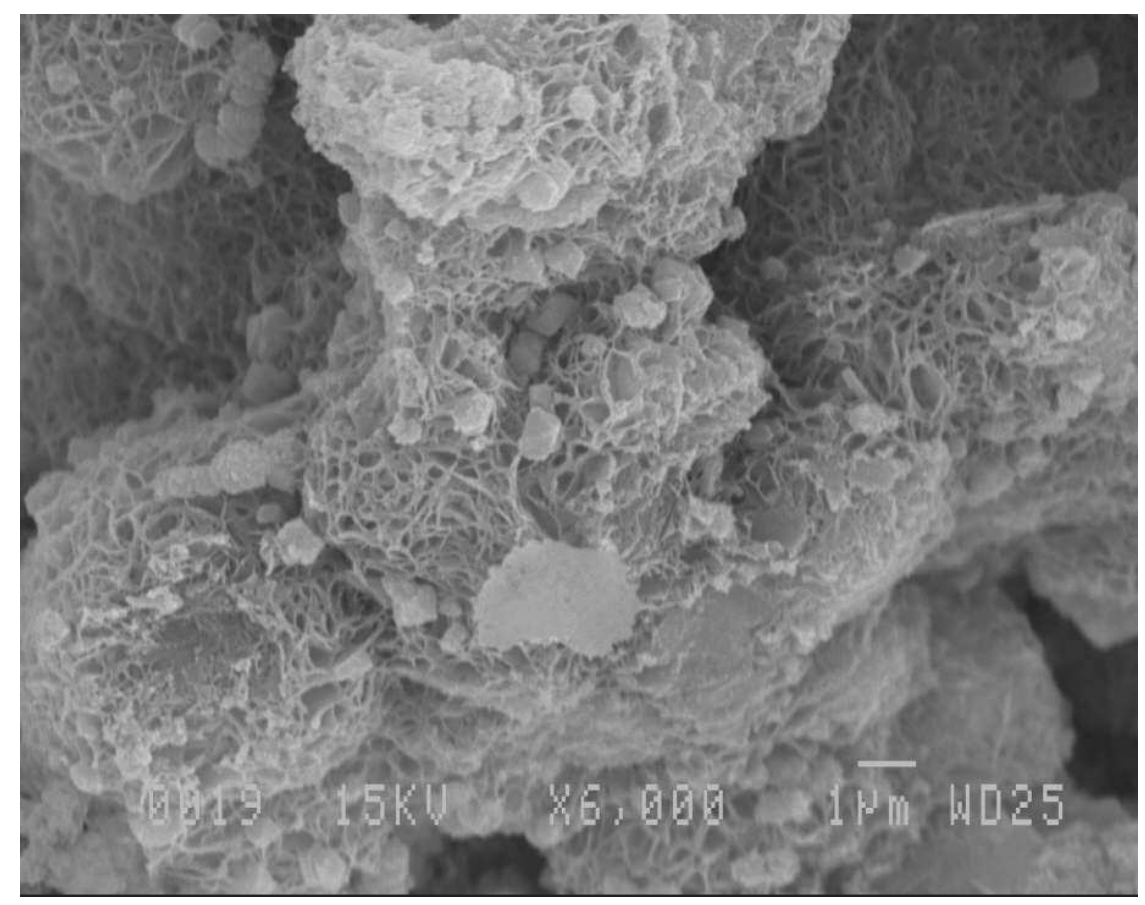

Figure A.22 - SEM micrography of leached saltstone at the transition zone as indicated in Figure A.20 (x6000) - Layered C-S-H structure is observed 
In Figure A.23, this C-S-H decalcification depth is compared to the simulated calcium profile given previously in the report (Figure 12). The numerical simulation of the calcium profile shows a slight decalcification zone. The depth of this zone is around 2.5 $\mathrm{mm}$ (Figure A.23). It is in accordance with the estimated C-S-H decalcification thickness. The decalcified layer was not seen by microprobe. The heterogeneous microstructure of saltstone did not allow determining small decalcified area. Particularly, the presence of voids and anhydrous fly ash particles induces a significant heterogeneous medium and limits reliable decalcification characterization by microprobe.

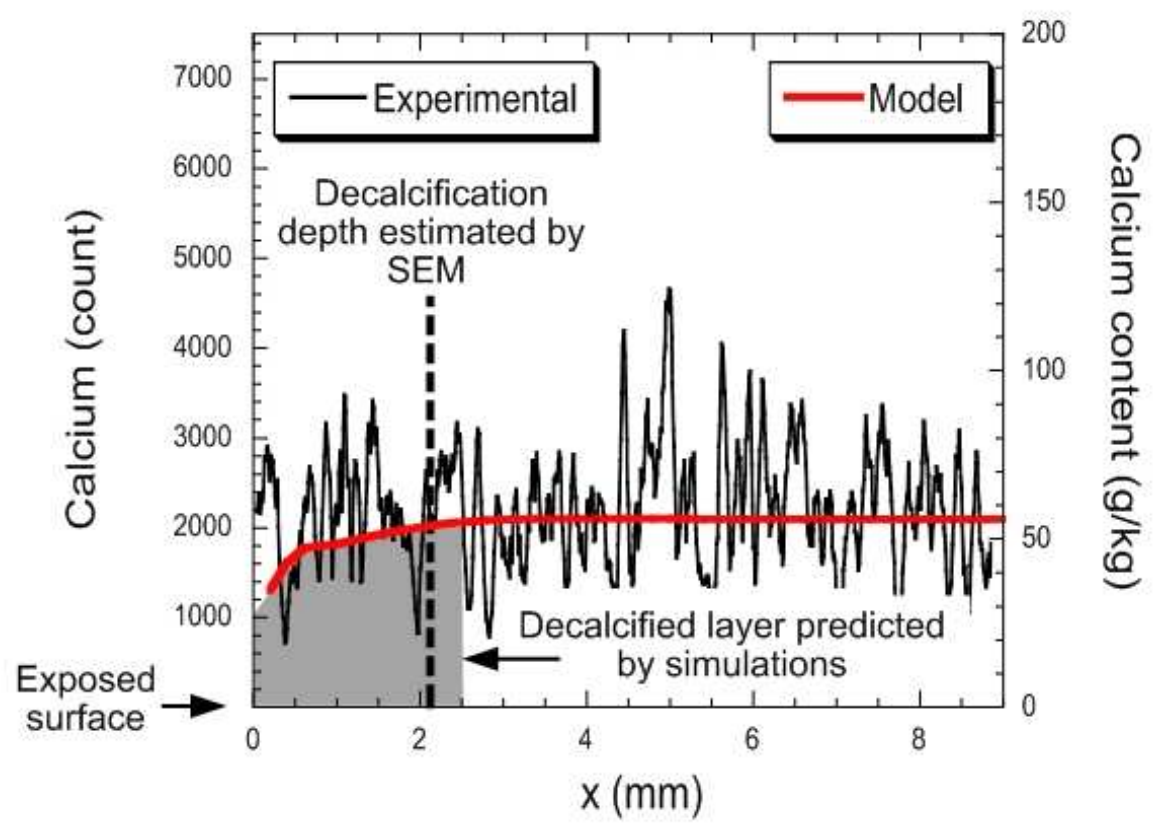

Figure A.23 - Estimated decalcification front by SEM micrography compared to simulated and experimental calcium content profiles (Figure 12) 


\section{DISTRIBUTION:}
A. B. Barnes, 999-W
H. H. Burns, 999-W
T. W. Coffield, 705-1C
A. D. Cozzi, 999-A
M. E. Dehnam, Jr., 773-42A
K. L. Dixon, 773-42A
G. P. Flach, 773-42A
J. C. Griffin, 773-A
E. K. Hansen, 999-W
J. R. Harbour, 999-W
C. C. Herman, 999-W
M. H. Layton, 705-1C
J. E. Marra, 773-A
S. L. Marra, 773-A
M. A. Phifer, 773-42A
T. C. Robinson, 705-1C
L. B. Romanowski, 705-1C
K. H. Rosenberger, 705-1C
R. R. Seitz, 773-43A
E. L. Wilhite, 773-43A 